\author{
Universidade de São Paulo \\ Instituto de Física
}

\title{
Caracterização estrutural de dispersões aquosas de vesículas lipídicas catiônicas com oligonucleotídeos
}

\author{
Cristofher Victor Vivas Palomares
}

Orientador: Profa. Dra. Maria Teresa Moura Lamy

Banca Examinadora:

Profa. Dra. Maria Teresa Moura Lamy (IFUSP)

Prof. Dr. Amando Siuiti Ito (FFCLRP-USP)

Prof. Dr. Tiago Ribeiro de Oliveira (UFABC) 


\section{FICHA CATALOGRÁFICA \\ Preparada pelo Serviço de Biblioteca e Informação do Instituto de Física da Universidade de São Paulo}

Vivas Palomares, Cristofher Victor

Caracterização estrutural de dispersões aquosas de vesículas de vesículas lipídicas catiônicas com oligonucleotídeos. São Paulo, 2018.

Dissertação (Mestrado) - Universidade de São Paulo. Instituto de Física. Depto de Física Geral

Orientador: Profa. Dra. Maria Teresa Moura Lamy.

Área de Concentração: Física Experimental - Biofísica.

Unitermos: 1. Biofísica; 2. Oligonucleotídeos; 3. Lipídios catiônicos; 4. Fluorescência; 5. Espectroscopia. 


\title{
University of São Paulo \\ Physics Institute
}

\section{Structural characterization of aqueous dispersions of cationic lipid vesicles whit oligonucleotides}

\author{
Cristofher Victor Vivas Palomares
}

Supervisor: Profa. Dra. Maria Teresa Moura Lamy

Dissertation submitted to the Physics Institute of the University of São Paulo in partial fulfillment of the requirement for the degree of Master of Science

Examining Committee:

Profa. Dra. Maria Teresa Moura Lamy (IFUSP)

Prof. Dr. Amando Siuiti Ito (FFCLRP-USP)

Prof. Dr. Tiago Ribeiro de Oliveira (UFABC) 
"Dedicado aos meus pais Victor Vivas, Julia Palomares e irmãos por todo apoio, dedicação e companherismo." 


\section{AGRADECIMENTO}

Aos meus pais, pelo incentivo e apoio incondicionais.

À Teresa, pela orientação e por tudo que me ensinou e vem ensinando durante nossos anos de convivência.

Ao amigo Evandro Duarte, pela co-orientação e auxílio durante todo este trabalho.

Ao amigo Marco Mussakawa, pelas discussões sempre esclarecedoras.

Aos colegas do Grupo Vinicuis, Fernanda, Juliana e Daniela.

À Flora, pelas discussões sobre a redação de meu trabalho e sua disposição para ajudar.

À meus queridos irmãos Darwin, Erika, Belen e Nelson, e aos meus familiares, pelo incentivo e entenderem a minha ausência nos ultimos anos.

Aos amigos Luis, Erick, Rodrigo, Rodrigo Souza, Parra, Giussepe, Antonio, Mateus, .., pela paciência, apoio e compreensão nestes anos de mestrado e que souberam entender a minha ausência e as minhas loucuras.

A todos que de alguma forma contribuíram para o término deste trabalho.

Ao $\mathrm{CNPq}$ pelo apoio financeiro. 


\section{RESUMO}

Neste trabalho foi investigado o efeito do oligonucleotídeo-modelo $5^{\prime}-A A A A A A A A A A-$ $3^{\prime}(O D N)$ sobre a estabilidade e estrutura de vesículas catiônicas de brometo de dioctadecildimetilamônio (DODAB), extrusadas através filtros de $100 \mathrm{~nm}$, em dispersão aquosa, com as técnicas de espalhamento de luz dinâmico (DLS), medidas de potencial de superfície (potencial zeta), calorimetria diferencial de varredura (DSC), espalhamento de raios-X a baixos ângulos (SAXS), espectroscopias de absorção óptica e de fluorescência do estado estacionário da sonda Laurdan incorporada a vesículas de DODAB-ODN. Este fluoróforo monitora a polaridade e estrutura da superfície da membrana de DODAB.

Variando a concentração de ODN, três diferentes regimes foram observados. Para baixas concentrações de ODN, $([\mathrm{ODN}] /[\mathrm{DODAB}]) \leq 0.025 \mathrm{mM}$, a dispersão é estável, límpida, apesar do diâmetro médio das vesículas aumentar, um aumento de turbidez ser observado por medidas de Absorbância, e o SAXS já acusar a presença de algumas poucas multilamelas. As vesículas mistas apresentam potencial de superfície positivo, semelhante ao potencial medido para vesículas de puro DODAB. A calorimetria mostra a coexistência de regiões da bicamada de puro DODAB, e regiões mistas, com DODAB-ODN, sendo estas últimas mais estáveis, apresentando maior temperatura de transição gel-fluido. A forma e posição da banda de fluorescência do Laurdan incorporado às vesículas não são alteradas pela presença do oligonucleotídeo, indicando pouca variação na polaridade e estrutura da superfície da membrana mista monitorada pela sonda. Um segundo regime é observado para $([\mathrm{ODN}] /[\mathrm{DODAB}]) \approx 0.05 \mathrm{mM}$, onde não é mais observado por calorimetria a presença significativa de domínios de puro DODAB, e a dispersão mostra-se instável, turva, com agregação/fusão das vesículas. Finalmente, o terceiro regime, para altas concentrações de ODN, $([\mathrm{ODN}] /[\mathrm{DODAB}]) \geq 0.075 \mathrm{mM}$, onde é observado um potencial de superfície negativo, portanto, com predominância da carga do oligonucleotídeo, e a dispersão volta a ser estável, apresentando baixa turbidez. Neste regime, a calorimetria indica uma grande estabilidade da fase gel, medidas de SAXS mostram a formação de estruturas multilamelares, porém DLS indica a presença de vesículas pequenas, com dimensões às observadas para DODAB puro. Neste regime, a sonda Laurdan monitora variações na superfície da membrana, possivelmente indicando a diminuição da quantidade de moléculas de água na superfície e/ou um enrijecimento da bicamada.

Palavras-chave: DODAB, oligonucleotídeo, DSC, DLS, Fluorescência Laurdan. 


\begin{abstract}
In the present work the effect of $5^{\prime}-A A A A A A A A A A-3$ 'oligonucleotide model (ODN) was investigated on the stability and structure of dioctadecyldimethylammonium bromide (DODAB) cationic vesicles, extruded through $100 \mathrm{~nm}$ filters in aqueous dispersion, with dynamic scattering techniques (DLS), surface potential measurements (zeta potential), differential scanning calorimetry (DSC), small angle X-ray scattering (SAXS), optical absorption spectrometry and stationary-state fluorescence spectroscopy of Laurdan incorporated into DODAB-ODN vesicles. This fluorophore monitors the polarity and surface structure of the DODAB membrane.

Varying the ODN concentration, three different behaviors were observed. For low concentrations of ODN, $([\mathrm{ODN}] /[\mathrm{DODAB}]) \leq 0.025 \mathrm{mM}$, the dispersion is stable, clear, although the mean diameter of the vesicles increases, an increase in turbidity is observed by Absorbance measurements, and SAXS already shows the presence of a few multilamellar structure. The mixed vesicles present positive surface potential, similar to the potential measured for pure DODAB vesicles. Calorimetry shows the coexistence of regions of the pure DODAB bilayer, and mixed regions, with DODAB-ODN, the latter being more stable, presenting a higher gel-fluid transition temperature. The shape and position of the Laurdan fluorescence band incorporated into the vesicles are not altered by the presence of the oligonucleotide, indicating minor variation in the polarity and surface structure of the mixed membrane monitored by the probe. A second behavior is observed for $([\mathrm{ODN}] /[\mathrm{DODAB}]) \approx 0.05 \mathrm{mM}$, where the presence of pure DODAB domains is no longer detected by calorimetry, and the dispersion is unstable, cloudy, displaying vesicle aggregation/fusion. Finally, the third behavior is detected at high concentrations of ODN, $([\mathrm{ODN}] /[\mathrm{DODAB}]) \geq 0.075 \mathrm{mM}$, where a negative surface potential is observed, therefore, with predominance of the charge of the oligonucleotide, and the dispersion is stable, exibiting low turbidity. In this regime, the calorimetry indicates a great stability of the gel phase, SAXS measurements show the formation of multilamellar structures, however DLS indicates the presence of small vesicles, with dimensions to those observed for pure DODAB. In this region, the Laurdan probe monitors variations at the surface of the membrane, possibly indicating the decrease in the amount of water molecules on the surface and/or a stiffening of the bilayer.
\end{abstract}

Keywords: DODAB, oligonucleotide, DSC, DLS, Laurdan fluorescence. 


\section{LISTA DE FIGURAS}

Figura 1 Estrutura do oligonucleotídeo. Adaptado de (Nelson e Cox, 2002). ....... 17

Figura 2 Estrutura do lipídio DODAB. ............................... 20

Figura 3 Bicamadas fechadas de DODAB (Figura da esquerda). Fragmentos de bicamdas de DODAB (Figura da direita). Adaptado de (Carmona-Ribeiro, 1992).

Figura 4 Estruturas da sonda fluorescente Laurdan. $\ldots \ldots \ldots \ldots \ldots \ldots \ldots \ldots \ldots \ldots \ldots \ldots$

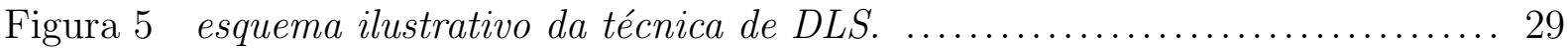

Figura 6 Esquema para o cálculo da função de autocorrelação temporal do campo elétrico.

Figura 7 Representação esquemática do espalhamento de luz eletroforética para uma amostra de partículas. Adaptada de (Ware e Flygare, 1971).

Figura 8 Espectro de frequência da intensidade da luz espalhada com o campo elétrico desligado e ligado. Adaptada de (Ware e Flygare, 1971).

Figura 9 Relação do vetor de espalhamento, $\vec{q}$, e a velocidade de desplasamento, $\vec{v}_{d}$. 34

Figura 10 Esquema da distribuição de cargas na vizinhança de uma partícula carregada (adaptado de Jafelicci e Laudemir , 1999).

Figura 11 Distorção do campo elétrico aplicado sobre uma partícula esférica de raio a. As linhas tracejadas representam a espessura da camada dupla, $1 / k$. (Hiemenz, 1986).

Figura 12 Esquema ilustrativo da medida de SAXS 38

Figura 13 Representação ilustrativa da transição gel-fluido em sistemas lipídicos. O sistema organizado caracteriza a fase gel, enquanto o sistema desorganizado caracteriza fase fluida. Cabe ressaltar que após a transição a área ocupada por cada lipídio da bicamada aumenta e sua espessura, $d_{2}$, diminui.

Figura 14 Representação esquemática de um calorímetro diferencial de varredura. Sendo $R$, a cela de refêrencia e $A$ a cela da amostra. Figura extraída de (Barroso, 2010). 
Figura 15 Níveis de energia de uma molécula diatômica, A-B, simples. Figura baseada do texto Takara, 2006.

Figura 16 Ilustração da atenuação da luz incidente no recipiente de caminho ótico $d$.

Figura 17 Diagrama de Perrin-Jablonski e a ilustração da posição relativa dos espectros de absorção, fluorescência e fosforescência, onde IC (Internal Conversion) significa conversão interna e ISC (InerSystem Crossing) significa cruzamento de sistemas. Figura baseada no texto Moreira, 2009 (original de Valeur, 2001).

Figura 18 Ilustração do modelo de Lippert, de campos elétricos de reação em interação com dipolos da molécula no estado fundamental, $\mu_{G}$, e no estado exitado, $\mu_{E}$. Figura extraída de Lakowicz, 2006 (modificada).

Figura 19 Diagrama esquemático para a medida de anisotropia de fluorescência. Adaptada de (Valeur, 2001).

Figura 20 Moléculas utilizadas neste trabalho. (a) oligonucleotídeo, (b) sonda fluorescente Laurdan, e (c) lipídio DODAB

Figura 21 Tratamento dos dados de um experimento de DSC para $1 \mathrm{mM}$ de vesículas extrusadas de DODAB em presença de ODN. (a) Normalização a uma taxa de aquecimento/resfriamento de $20^{\circ} \mathrm{C} / \mathrm{h}$. e subtração da linha de base do tampão. (b) Normalização pela concentração do lípido. (c) Criação da linha de base. (d) Curva de DSC final após a subtração da linha de base da curva.

Figura 22 Demostração da análise do espectro de absorção do Laurdan inserido no complexo DODAB/ODN. (a) Espectros medidos para o tampão puro (linha preta) e para Laurdan inserido no DODAB/ODN (linha vermelha). (b) Espectro do Laurdan inserido no DODAB/ODN já subtraído do tampão, espectro final.

Figura 23 Espectro de absorção do Laurdan incorporado en vesículas de DODAB em presença e ausencia de ODN. As setas apontam a excitação (1) e a região de emissão do Laurdan (2).

Figura 24 Avaliação da turbidez para $1 \mathrm{mM}$ de vesículas extrusadas de DODAB em presença de $O D N$, após 30 minutos de incubação a T: $20^{\circ} \mathrm{C}$. 
Figura 25 Avaliação da turbidez para $1 \mathrm{mM}$ de vesículas extrusadas de DODAB em presença de ODN, após 7 dias de incubação.

Figura 26 Efeito da concentração de ODN sobre os diâmetro médios (a) e os potenciaiszeta (b) de DODAB, após 30 e 70 minutos de incubação respectivamente, para cada técnica.

Figura 27 Efeito da concentração de ODN sobre os diâmetros médios (nm) após 30 minutos e 7 dias da incubação do complexo DODAB/ODN.

Figura 28 Curvas de SAXS para vesículas extrusadas de DODAB em tampão, medidas nas temperaturas de $30^{\circ} \mathrm{C}$ e $60^{\circ} \mathrm{C}$.

Figura 29 Curvas de SAXS para vesículas extrusadas de DODAB em presença de $0.0125 \mathrm{mM}$ de $\mathrm{ODN}$, medidas nas temperaturas de $30^{\circ} \mathrm{C}$ e $60^{\circ} \mathrm{C}$

Figura 30 Curvas de SAXS para vesículas extrusadas de DODAB em presença de $0.1 \mathrm{mM}$ de $O D N$, medidas nas temperaturas de $30^{\circ} \mathrm{C}$ e $60^{\circ} \mathrm{C}$. 76

Figura 31 Diminuição do valor da distância de repetição, d, na conversão da fase fluida para gel e por último a coagel. Figura extraída de Fu-Gen Wu, 2009. 77

Figura 32 Termogramas de $1 \mathrm{mM}$ de vesículas extrusadas de DODAB em tampão. As linhas tracejadas marcam os máximos dos picos para os dois processos, de aquecimento e resfriamento.

Figura 33 Termogramas de $1 \mathrm{mM}$ de vesículas extrusadas de DODAB em presença de $0.00625 \mathrm{mM}$; $0.0125 \mathrm{mM}$; $0.025 \mathrm{mM}$ e $0.05 \mathrm{mM}$ ODN. As linhas tracejadas são as mesmas mostradas na Figura 32, para comparação.

Figura 34 Comparação dos termogramas no processo endotérmico (a) e exotérmico (b) de $1 \mathrm{mM}$ de vesículas extrusadas de DODAB em presença de altas concentrações de ODN. O perfil obtido para $[O D N]=0.075 \mathrm{mM}$ está também mostrado para comparação.

Figura 35 Termogramas de $1 \mathrm{mM}$ de vesículas extrusadas de DODAB em presença de $0.075 \mathrm{mM} ; 0.1 \mathrm{mM} ; 0.15 \mathrm{mM}$ e $0.2 \mathrm{mM}$ ODN. As linhas tracejadas são as mesmas mostradas nas Figuras anteriores, para comparação.

Figura 36 Comparação dos termogramas no processo endotérmico (a) e exotérmico (b) de $1 \mathrm{mM}$ de vesículas extrusadas de DODAB em presença de altas concentrações de $O D N$. 
Figura 37 Efeito da concentração de ODN sobre o parâmetro termodinâmico da entalpia em $1 \mathrm{mM}$ de vesículas extrusadas de DODAB.

Figura 38 (a) espectros de absorção na fase gel e fluida do DODAB em Hepes. (b) espectros de absorção de $0.025 \mathrm{mM}$ de ODN disperso em Hepes.

Figura 39 espectros de absorção do Laurdan inserido nas vesículas de DODAB em ausência e presença de baixas concentrações de ODN (a) na fase gel e (b) fluida do DODAB. Espectros reproduzidos para três ou mais amostras diferentes.

Figura 40 Avaliação da turbidez para $1 \mathrm{mM}$ de vesículas extrusadas de DODAB em presença de baixas concentrações de ODN, após 4 horas de incubação a T: $30^{\circ} \mathrm{C}$.

Figura 41 espectros de absorção do Laurdan inserido nas vesículas de DODAB em ausência e presença de altas concentrações de ODN (a) na fase gel e (b) fluida do DODAB. Espectros reproduzidos para três ou mais amostras diferentes.

Figura 42 Avaliação da turbidez para $1 \mathrm{mM}$ de vesículas extrusadas de DODAB em presença de altas concentrações de ODN, após 4 horas de incubação a T: $30^{\circ} \mathrm{C}$.

Figura 43 Espectros de emissão da sonda Laurdan inserido em $1 \mathrm{mM}$ de vesículas extrusadas de DODAB em Hepes. As linhas tracejadas marcam os máximos das intensidades para as duas fases dos lipídios, em $30{ }^{\circ} \mathrm{C}$ e $60^{\circ} \mathrm{C}$.

Figura 44 Espectros de emissão do Laurdan inserido em $1 \mathrm{mM}$ de vesículas extrusadas de DODAB, em presença de baixas concentrações de ODN, para 30 ${ }^{\circ} \mathrm{C}$ (a) e $60{ }^{\circ} \mathrm{C}(\mathrm{b})$. Os gráficos inseridos nos paneis à direita mostram os espectros do Laurdan normalizados. As linhas tracejadas são as mesmas mostradas na Figura 43, para comparação.

Figura 45 Espectros de emissão do Laurdan inserido em $1 \mathrm{mM}$ de vesículas extrusadas de DODAB, em presença de baixas concentrações de ODN, para 30 ${ }^{\circ} \mathrm{C}$ (a) e $60{ }^{\circ} \mathrm{C}(\mathrm{b})$. Os gráficos inseridos nos paneis à direita mostram os espectros do Laurdan normalizados. As linhas tracejadas são as mesmas mostradas na Figura 43, para comparação... 
Figura 46 Espectros de emissão do Laurdan inserido em $1 \mathrm{mM}$ de vesículas extrusadas de DODAB, em presença de baixas concentrações de ODN, para 30 ${ }^{\circ} \mathrm{C}$ (a) e $60{ }^{\circ} \mathrm{C}($ b). Os gráficos inseridos nos paneis à direita mostram os espectros do Laurdan normalizados. As linhas tracejadas são as mesmas mostradas na Figura 43, para comparação.

Figura 47 Espectros de emissão do Laurdan inserido em $1 \mathrm{mM}$ de vesículas extrusadas de DODAB em presença de altas concentrações de ODN, para 30 ${ }^{\circ} \mathrm{C}$ (a) e $60^{\circ} \mathrm{C}$ (b). Os gráficos inseridos nos paneis à direita mostram os espectros do Laurdan normalizados. As linhas tracejadas são as mesmas mostradas na Figura 43, para comparação...

Figura 48 Espectros de emissão do Laurdan inserido em $1 \mathrm{mM}$ de vesículas extrusadas de DODAB em presença de altas concentrações de ODN, para 30 ${ }^{\circ} \mathrm{C}$ (a) e $60{ }^{\circ} \mathrm{C}(\mathrm{b})$. Os gráficos inseridos nos paneis à direita mostram os espectros do Laurdan normalizados. As linhas tracejadas são as mesmas mostradas na Figura 43, para comparação.

Figura 49 Espectros de emissão do Laurdan inserido em $1 \mathrm{mM}$ de vesículas extrusadas de DODAB em presença de altas concentrações de ODN, para 30 ${ }^{\circ} \mathrm{C}$ (a) e $60^{\circ} \mathrm{C}$ (b). Os gráficos inseridos nos paneis à direita mostram os espectros do Laurdan normalizados. As linhas tracejadas são as mesmas mostradas na Figura 43, para comparação...

Figura 50 Anisotropia de fluorescência do Laurdan inserido em vesiculas extrusadas de DODAB com o aumento da concentração de ODN, para as temperaturas $T=30,40,50,60^{\circ} \mathrm{C}$. As medidas da anisotropia foram realizadas utilizando $\lambda_{\text {exc }}=350 \mathrm{~nm}$ e $\lambda_{\text {em }}=470 \mathrm{~nm}$.

Figura 51 Caracterização dos três regimes observados em dispersões aquosas DODAB$O D N$. 106

Figura 52 Esquema subtraído de (Rosenfeld et al., 2013). 108 


\section{LISTA DE TABELAS}

Tabela 1 Valores de diâmetro médio e potencial-zeta de dispersão, em diferentes concentrações a, $20^{\circ} \mathrm{C}$, para três ou mais amostras diferentes.

Tabela 2 Valores de diâmetro médio (nm) após 30 min e 7 dias da incubação, do complexo DODAB/ODN a $20^{\circ} \mathrm{C}$.

Tabela 3 Valores de SAXS, das propriedades físicas de dispersão, em diferentes temperaturas e concentração.

Tabela 4 Valores dos parâmetros termodinâmicos de transição de fase, para o processo de aquecimento de $1 \mathrm{mM}$ de vesículas de DODAB em presença e ausência de $O D N$.

Tabela 5 Valores dos parâmetros termodinâmicos de transição de fase, para o processo de resriamento de $1 \mathrm{mM}$ de vesículas de DODAB em presença e ausência de ODN.

Tabela 6 Valores máximos de emissão, $\lambda_{m}(\mathrm{~nm})$, em diferentes solventes, para o Laurdan. Dados extraídos da literatura (Vequi-Suplicy et al., 2015).

Tabela 7 Magnitude da carga relativa total ODN/DODAB na dispersão, considerando que tanto ODN como o DODAB estão totalmente ionizados, e potencial zeta medido para as vesículas. 


\section{SUMÁRIO}

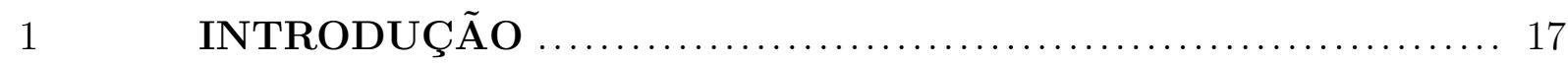

1.1 Oligonucleotídeo: características e suas aplicações ............... 17

1.2 Bicamadas lipídicas catiônicas: características ................... 18

1.2.1 Brometo de dioctadecildimetilamônio e suas aplicações .................... 19

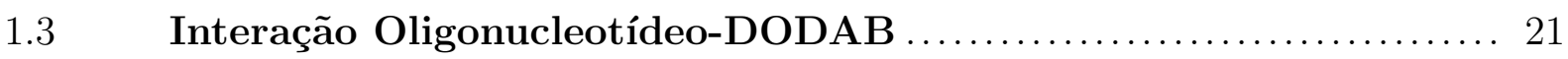

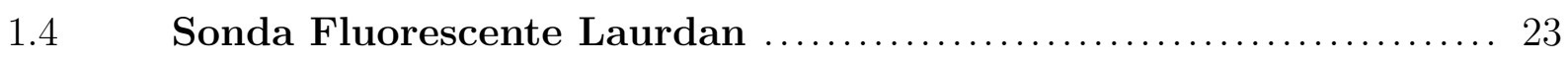

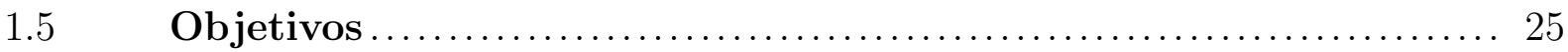

1.6 Sumario dos Próximos Capítulos ............................. 25

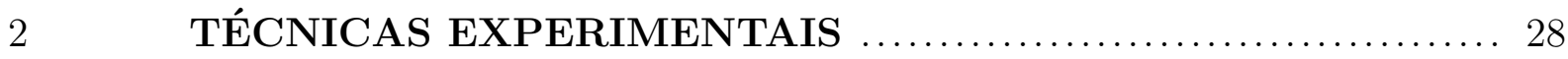

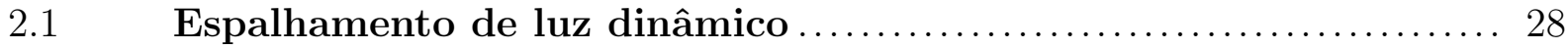

2.1.1 Movimento Browniano........................................ 28

2.1.2 Espalhamento de Luz ......................................... 29

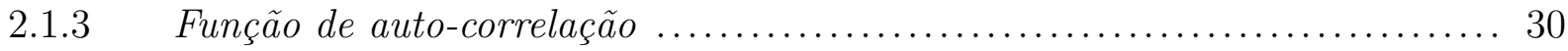

2.1.4 Análise da função de correlação do campo elétrico ......................... 30

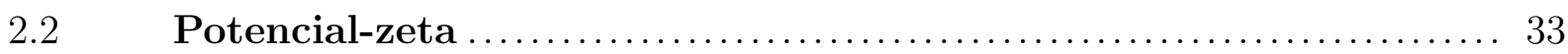

2.2.1 Medição da mobilidade eletroforética ............................... 33

2.2.2 Mobilidade eletroforética relacionada ao potencial -zeta .................. 35

2.3 Espalhamento de raios- $\mathrm{X}$ a baixo ângulo ..................... 37

2.4 Calorimetria diferencial de varredura ......................... 40

2.4.1 Transição gel-fluido .............................................. 40

2.4.2 Cálculo do calor específico......................................... 41

2.5 Absorção Óptica da Luz .................................... 43

2.5.1 Lei de Lambert-Beer ............................................ 45

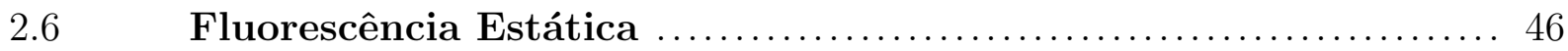

2.6.1 Deslocamento de Stokes .......................................... 47

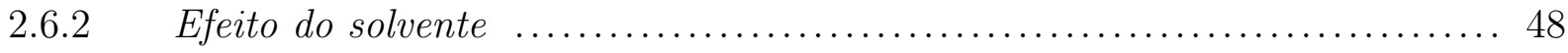

2.6.3 Correção dos espectros de fluorescência $\quad$............................... 49

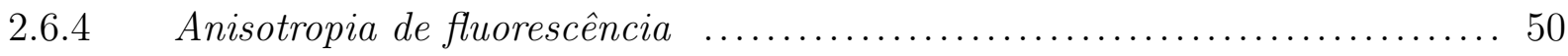


MATERIAIS E MÉTODOS ................................ 54

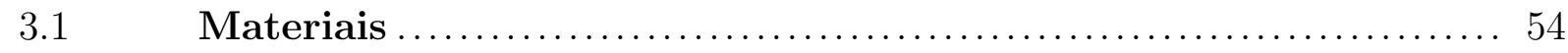

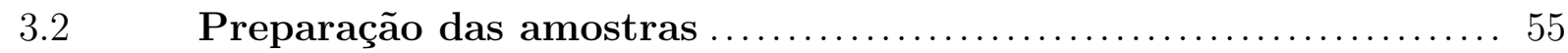

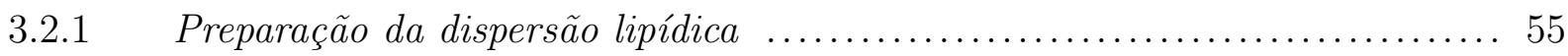

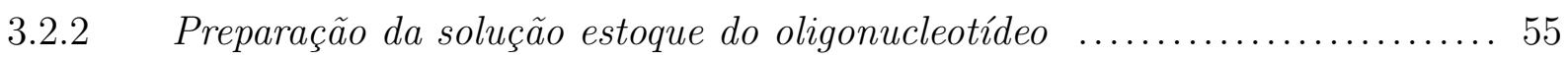

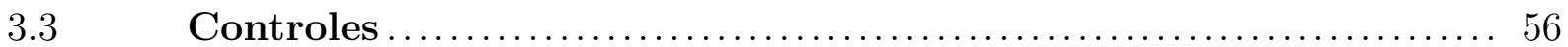

3.3.1 Vesículas extrusadas .............................................. 56

3.3.2 Protocolo de Incubação vs Sequências de técnicas $\ldots . \ldots \ldots \ldots \ldots \ldots \ldots \ldots . . . \ldots . \ldots 7$

$3.4 \quad$ Métodos Experimentais ................................... 58

3.4.1 Espalhamento de Luz Dinâmico ................................. 58

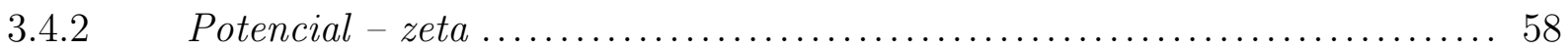

3.4.3 Espalhamento de raios- $X$ a baixo ângulo .......................... 59

3.4.4 Calorimetria diferencial de varredura $\ldots \ldots \ldots \ldots \ldots \ldots \ldots \ldots \ldots \ldots \ldots \ldots \ldots$

3.4.5 Absorção óptica do Laurdan ..................................... 61

3.4.6 Fluorescência estática e Anisotropia de Laurdan ...................... 62

3.4.7 Reprodutibilidade dos experimentos .............................. 64

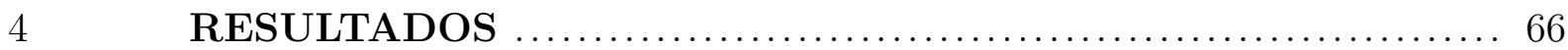

4.1 Efeito do ODN sobre as vesículas de DODAB $\ldots \ldots \ldots \ldots \ldots \ldots \ldots$

4.1.1 Estabilidade coloidal .......................................... 66

4.1.2 Caracterizações das vesículas de DODAB ........................ 69

4.1.2.1 Espalhamento de luz Dinâmico e Potencial- zeta ...................... 69

4.1.2.2 Espalhamento de raios-X a baixos ângulos $(S A X S) \ldots \ldots \ldots \ldots \ldots \ldots \ldots \ldots$

4.2 Efeito do ODN sobre a transição de fase das bicamadas de DODAB 78

4.3 Sensibilidade da sonda Laurdan em monitorar alterações nas vesículas de DODAB causadas pelo ODN $\ldots \ldots \ldots \ldots \ldots \ldots \ldots \ldots \ldots$

4.3.1 Espectros de absorção óptica do Laurdan inserido em DODAB em presença

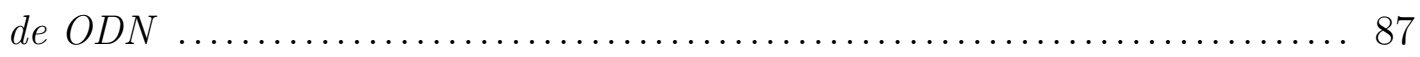

4.3.2 Espectros de emissão do Laurdan inserido em DODAB em presença de

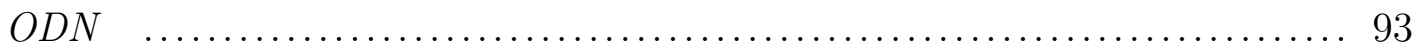

4.3.3 Anisotropia do Laurdan .......................................... 102

5 CONCLUSÕES E PERSPECTIVAS ......................... 105 
REFERÊNCIAS 


\section{CAPÍTULO 1}

"El cambio es la ley de la vida. Y aquellos que miran solo al pasado se perderan seguro el futuro"

John F. Kennedy 


\section{INTRODUÇÃO}

\subsection{Oligonucleotídeo: características e suas aplicações}

A estrutura primária de oligonucleotídeos (ODN) são os nucleotídeos (18-20 nucleotídeos ) (Nelson e Cox, 2002). A união entre nucleotídeos é dada por ligações de fosfodiésteres, as quais se estabelecem entre o -OH do carbono 5' da pentose de um nucleotídeo e o - $\mathrm{OH}$ do carbono 3' da pentose do nucleotídeo seguinte (veja-se a Figura 1).

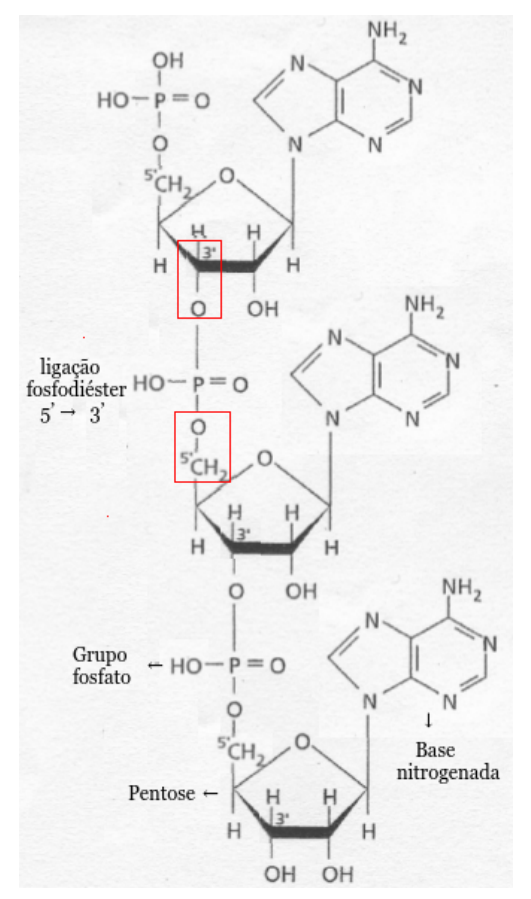

Figura 1: Estrutura do oligonucleotídeo. Adaptado de (Nelson e Cox, 2002).

Os oligonucleotídeos apresentam uma série de características, como, por exemplo, são de natureza hidrofílica devido ao fato dos grupos fosfatos e - $\mathrm{OH}$ da pentose poderem formar pontes de hidrogênio com a água (Koolman e Rohm, 2005). Além disso, apresentam carga negativa significativa em $p H$ fisiológico (Devlin, 2004), devido aos grupos fosfatos terem uma constante de equilíbrio baixa. Neste mesmo $p H$, todos os oligonucleotídeos comuns absorvem luz em um comprimento de onda próximo a $260 \mathrm{~nm}$, isso devido às ligações duplas conjugadas das bases nitrogenadas (purina e pirimidina) (Rodwell, et al, 2015 ). 
O ODN apresenta uma série de aplicações, desde o uso em ferramentas biológicas moleculares ( Goodchild, et al., 1988), até em terapia gênica, promovendo o silenciamento de genes específicos (Fichou e Férec, 2006). Alguns ODNs são projetados para se ligar ao RNA mensageiro dentro da célula, e assim, bloquear o processamento do RNA mensageiro (Juliano, et al., 2008). Esta hibridização do RNA mensageiro pode regular, por exemplo, a proliferação celular, programando assim, a morte das células (apoptose), ou outras atividades biológicas. Este método é muito utilizada como agente terapêutico e para o tratamento de câncer de próstata (Marvin, et al, 1996; Crooke ST, 2004;Gleave e Monina,2005).

Apesar das potencialidades amplamente demostradas em várias experiências, os oligonucleotídeos possuem limitações a serem vencidas. Por exemplo, sendo moléculas com uma carga elevada (proveniente dos grupos fosfatos), têm pouca probabilidade de penetrarem na célula rapidamente, atravessando a membrana (Monkkonen e Utrtti, 1998). Esta limitação levou vários laboratórios a desenvolver métodos para melhorar o transporte dos oligonucleotídeos para dentro das células. A abordagem mais utilizada recorre a lipídios e polímeros catiônicos (Shea et al., 1990). Desde o primeiro uso de um lipídio catiônico para entrega de ODN (Bennet et al., 1992), mais de vinte lipídios catiônicos diferentes foram desenvolvidos em forma de fragmentos de bicamadas, vesículas e lipossomos com a finalidade de entregar ODN (Petri e Carmona-Ribeiro, 2007 ;Yang e Machato, 2010).

No entanto, os lipídios catiônicos sintéticos ainda precisam da determinação sistemática e detalhada de seus efeitos in vivo referentes à biocompatibilidade e biodegradabilidade (Mastrobattista et al., 2006), para apresentarem segurança e eficiência com baixa toxicidade na entrega de ODN. Portanto, na seguinte seção estudaremos as características deste tipo de lipídios catiônicos.

\subsection{Bicamadas lipídicas catiônicas: características}

Na área de Biofísica, o estudo de agregados anfifílicos é de extrema importância por mimetizar a membrana celular, elemento essencial para a vida da célula. As membranas biológicas que envolvem a célula possuem uma estrutura formada principalmente de moléculas de lipídios e proteínas, com uma menor proporção de carboidratos, unida por interações não covalentes. Em particular, estaremos interessados apenas nos lipídios de membrana, por atuarem como uma barreira relativamente impermeável à passagem de 
muitas moléculas hidrossolúveis (Alberts et al., 1997).

Em geral, lipídios da membrana celular são moléculas que têm uma estrutura anfifílica, possuindo: uma região hidrofóbica devido às cadeias hidrocarbônicas que podem possuir ligações simples (saturados), duplas ou triplas (insaturados) entre os carbonos. A outra região é chamada de hidrofílica devido a grupos moleculares polares, podendo-se assim, classificar os lipídios quanto à sua carga, em $p H$ neutro, como aniônicos (carga negativa), catiônicos (carga positiva) ou zwiteriônicos (carga neutra)(Lehninger, 1984).

Em sistemas aquosos os lipídios anfifílicos se dispersam formando diversos tipos de estruturas, na qual a região hidrofílica interage com a água através de pontes de hidrogênio ou interações eletrostáticas (Israelachvili, 1992), e a região hidrofóbica minimiza seu contato com as moléculas de água.

De um ponto de vista termodinâmico, a principal interação que dirige a formação e estabilização de agregados de anfifílicos hidratados é o efeito hidrofóbico (Evans e Wennerström, 1994). Portanto, qualquer tipo de estrutura formada por lipídios que se auto associam depende da geometria das moléculas (Gennis, 1989). Por exemplo, lipídios com grande cabeça polar e pequena seç̧ão transversal das cadeias alquil têm uma geometria semelhante a um cone, e se auto associam em micelas. Lipídios que apresentam cabeças pequenas exibem curvatura de membrana negativa e adotam fases invertidas, como a micela invertida (Ilarduya et al., 2010). Já lipídios que apresentam áreas ocupadas pela cabeça e pela secção transversal semelhante têm forma cilíndrica, e se auto associam em bicamadas (New, 1990).

As estruturas que se organizam em forma de bicamadas fechadas (vesículas) são consideradas como sistemas que mais se aproximam das membranas celulares. Esta semelhança iniciou uma nova área de pesquisa com vesículas catiônicas, as quais podem ser utilizadas como carregadores de drogas (Cuccovia et al., 1989). De fato, o lipídio catiônico utilizado nesta dissertação se organiza em forma de bicamadas fechadas no meio aquoso. A seguir, será dada uma maior ênfase a esta molécula.

\subsubsection{Brometo de dioctadecildimetilamônio e suas aplicações}

Brometo de dioctadecildimetilamônio (DODAB) é um lipídio anfifílico saturado, formado por 18 carbonos em suas duas cadeias hidrocarbônicas (região hidrofóbica) e por um grupo amônio quaternário na cabeça polar (região hidrofílica com carga positiva), 
como mostrada na Figura 2.

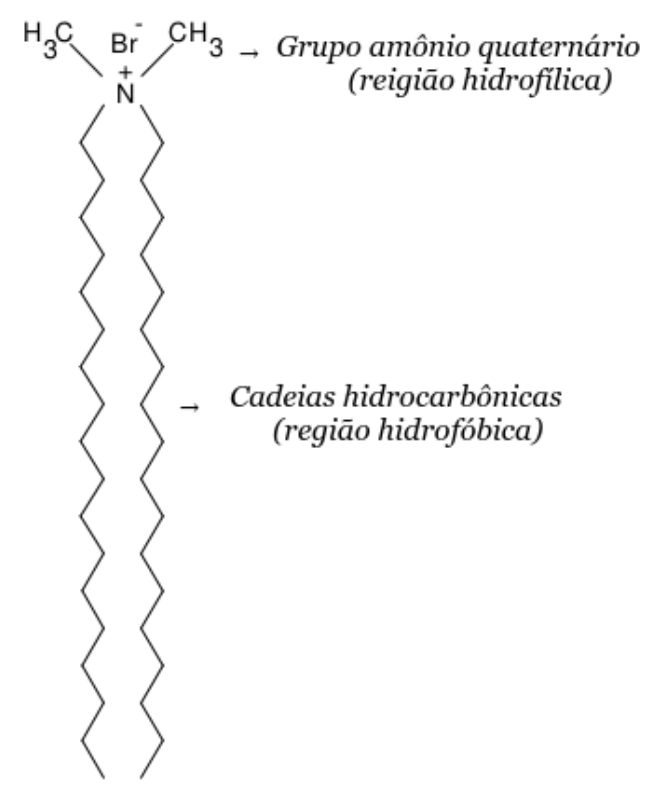

DODAB

Figura 2: Estrutura do lipídio DODAB.

A molécula de DODAB devido a sua geometria molecular aproximadamente cilíndrica, é capaz de se auto associar em dispersão aquosa em bicamadas fechadas ou em fragmentos de bicamada (Carmona-Ribeiro, 1992). É importante notar que a obtenção de qualquer desses agregados vai depender do método de preparação do DODAB em solução ( New, 1990). Por exemplo, o método de preparação usando ultrassom de ponta gera fragmentos de bicamadas. Por outro lado, o método de preparação por vaporização clorofórmica (Carmona Ribeiro e Chaimovich, 1986), gera bicamadas fechadas grandes (vesículas), ver Figura 3.

Em muitos casos, estas dispersões de vesículas grandes são extrusadas para à obtenção de vesículas pequenas de DODAB (Feitosa et al., 2000). Isto devido ao fato de ser o tamanho da vesícula um parâmetro muito importante na determinação da penetração e da meia-vida destes sistemas nos organismos, e no encapsulamento da droga a ser veiculada (Behar-Cohen, 2002).

As vesículas de DODAB possuem algumas propriedades que as caracterizam. Uma dessas propriedades é o fenômeno de histerese do comportamento termotrópico. Este fenômeno consiste na variação da temperatura de transição da fase gel para líquida cristalina, $T_{m}$, quando a amostra é aquecida ou resfriada. 


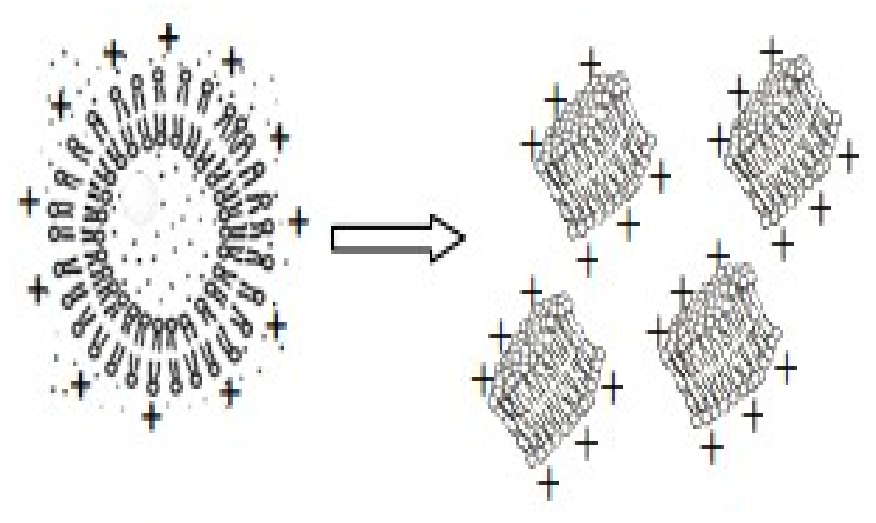

Figura 3: Bicamadas fechadas de DODAB (Figura da esquerda). Fragmentos de bicamdas de DODAB (Figura da direita). Adaptado de (Carmona-Ribeiro, 1992).

No entanto, esta $T_{m}$ não é uma característica das vesículas de DODAB, pois depende do método de preparação (Feitosa et al., 2006) e da concentração do DODAB em dispersão aquosa. Por exemplo, resultados apresentados por Fu-Gen Wu e colaboradores (2011), mostram que $T_{m}$ diminui em baixas concentrações de DODAB e aumenta para altas concentrações de DODAB.

As características de tamanho e tipos de estrutura foram amplamente estudadas para vesículas de DODAB em várias condições experimentais, tais como, a presença de diferentes forças iônicas e contra-íons (Bennati et al., 2001; Feitossa et al., 2006). No entanto, a interação entre lipídios catiônicos e material genético ainda é pouco compreendida. Portanto, na seguinte seção, estudaremos a interação entre vesículas catiônicas de DODAB e oligonucleotídeos.

\subsection{Interação Oligonucleotídeo-DODAB}

De um ponto de vista físico-químico, a interação entre os grupos fosfato dos oligonucleotídeos e as cabeças do DODAB pode ser vista como uma interação eletrostática entre dois polieletrólitos de cargas opostas, levando à formação de um complexo conhecido como lipoplexe (Lonez et al., 2008).

Os lipoplexes formados possuem algumas propriedades que os caracterizam. Uma dessas é a heterogeneidade em sua topologia devido aos diferentes tipos de modificações estruturais que sofrem, tanto as bicamadas catiônicas, como o material genético, quando 
estas se mesclam entre si.

Por exemplo, está determinado que a interação de sequências largas de dupla fita de DNA com vesículas catiônicas de DODAB podem levar a formação de um complexo globular, levando consigo modificações estruturais como a perda da integridade da vesícula catiônica (detectada por efeitos de temperatura) e a separação da dupla fita de DNA por efeito hidrofóbico (Kikuchi e Carmona-Ribeiro, 2000). O efeito hidrofóbico parece ter um papel muito importante na encapsulação de material genético e no transporte para as células (Wang et al., 2006 ).

No entanto, de acordo com Mitrakos e Macdonal (2000) quanto maior é a cadeia de nucleotídeos, maior é a dificuldade de pareamento com anfifílicos catiônicos, e, portanto, menor a eficiência de sua incorporação em vesículas. Diferente das cadeias grandes de nucleotídeos, os oligonucleotídeos (cadeias curtas) parecem ser melhores para prover uma liberação intracelular. Além disso, a sua formação supramolecular com diferentes tipos de anfifílicos catiônicos parece ser melhor (Romero et al., 2000).

Resultados da interação de fragmentos de bicamada de DODAB com oligodeoxinucleotídeo-poli(dA) (Rozenfeld et al, 2011), mostraram que o poli(dA) induziu a fusão dos fragmentos de bicamada de DODAB, atingindo assim, complexos de tamanhos grandes. Além disso, espectros de dicroísmo circular mostraram que o poli(dA) manteve sua estrutura helicoidal. Este importante efeito acompanhado com outras caraterísticas do lipoplexe, levou Rozenfeld e seus colaboradores, (2015) a dar continuidade a esta linha de pesquisa, com a utilização de altas concentrações de oligonucleotídeo (ODN) interagindo com vesículas grandes de DODAB. Nesse trabalho, usando EPR com marcadores de spin e SAXS (Small Angle X-ray scattering), mostraram que os oligonucleotídeos induzem a formação de estruturas multilamelares em dispersões aquosas de DODAB. Além disso, obtiveram forte indicação de que os oligonucleotídeos desidratam a superfície das membranas de DODAB.

A caraterística multilamelar deste complexo é importante para a condensação e encapsulação do oligonucleotídeo (Oberle et al., 2000), e para o transporte para as células.

Como visto anteriormente, tanto o método de preparação do lipídio em solução aquosa (seção 1.2.1), como a complexação com o oligonucleotídeo são importantes para a formação do arranjo supramolecular. Neste contexto, nesta dissertação propomos um método mais rigoroso para o preparo deste complexo, como a extrusão das vesículas de 
DODAB e a estabilidade do complexo através de controles de tempo. Além disso, as modificações estruturais da superfície de DODAB causadas pelo ODN serão monitoradas através de espectros de fluorescência, com a utilização da sonda Laurdan. Na próxima seção, será enfatizada a razão da escolha desta sonda para o estudo dos sistemas DO$\mathrm{DAB} / \mathrm{ODN}$.

\subsection{Sonda Fluorescente Laurdan}

Devido às vantagens que a técnica de fluorescência apresenta, nos últimos anos cada vez mais moléculas fluorescentes são utilizadas para monitorar sistemas biológicos, tanto em medidas espectroscópicas como em medidas de microscopia de fluorescência (Valeur, 2000; Lakowicz, 1991).

A característica de separação de carga que apresenta a sonda Laurdan, a qual é constituída por um naftaleno e esse por sua vez é ligado na posição 2 com o grupo dimetilamino e na posição 6 com o grupo dodecanoil (Figura 4), é aproveitada como sensor de polaridade do ambiente que a rodeia. Quanto maior for a polaridade do ambiente, maior será o deslocamento espectral que a sonda Laurdan sofrerá ( Vequi-Suplicy et al,2006). Foi também mostrado que a sonda é sensível à viscosidade do microambiente que a rodeia.

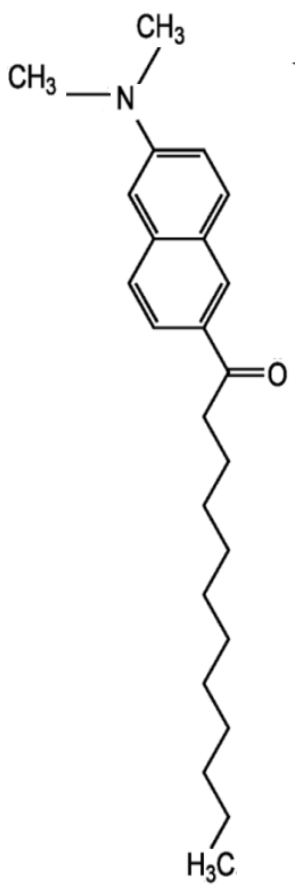

Figura 4: Estruturas da sonda fluorescente Laurdan. 
Outra caraterística apresentada pelo Laurdan é a presença de cadeia hidrocarbônica (12 carbonos). Portanto, em solução aquosa a molécula torna-se hidrofóbica. Essa caraterística pode ser utilizada para determinar sua localização e suas propriedades, mediante mudanças ou efeitos causados dentro do ambiente que a rodeia. Por exemplo, o comportamento da sonda Laurdan inserida em bicamadas lipídicas foi amplamente estudado, mostrando que a forma do espectro de fluorescência pode mudar com a transição de fase da bicamada lipídica (Parasassi et al., 1998; Vequi-Suplicy, 2015). Trabalhos foram feitos com a sonda fluorescente Laurdan inserida em vesículas lipídicas de DMPG, DLPC e DPPG ( Enoki, 2016; Lucio et al., 2009; Vequi-Suplicy et al, 2006), mostrando assim que o Laurdan é um bom indicador para monitorar transições de fase dos lipídios.

Por outro lado, mais recentemente, o nosso grupo de Biofísica ( Musukawa et al, 2016, em preparação), descreveu um comportamento diferente para o Laurdan inserido em vesículas de DODAB, mostrando que os espetros de fluorescência não sofrem uma grande mudança com a maior mobilidade dos lipídios catiônicos. Este resultado levou o DODAB a ser o primeiro lipídio em que o Laurdan se mostra insensível à transição de fase gel-fluido, podendo-se dizer, que aparentemente, o Laurdan encontra-se quase totalmente na parte aquosa da interface água membrana (superfície do DODAB).

Dando prosseguimento a este estudo, nesta dissertação de Mestrado, aproveitando a localização da sonda Laurdan na superfície da bicamada de DODAB e os controles anteriormente citados (seção 1.3) para a formação do arranjo supramolecular ODN/ DODAB, pretendemos monitorar a superfície das vesículas de DODAB com o marcador fluorescente Laurdan, para a melhor compreensão, a nível molecular, desta possível "desidratação" causada por oligonucleotídeos em DODAB. O resultado obtido deverá ser levado em consideração, por exemplo, na elaboração de vacinas com DODAB para a entrega de ODN. 


\subsection{Objetivos}

O sistema em estudo nesta dissertação de mestrado consiste em vesículas extrusadas catiônicas de DODAB, oligonucleotídeo (ODN) e a sonda fluorescente Laurdan.

Este trabalho tem como objetivos:

- Obter arranjos supramoleculares de vesículas de DODAB com ODN.

- Caracterizar as propriedades estruturais dos arranjos obtidos, e analisar o efeito da blindagem eletrostática causada pelo ODN na superfície do DODAB (estabilidade coloidal, tamanho, potencial-zeta, comportamento térmico da bicamada lipídica).

- O estudo das modificações estruturais causadas pelo oligonucleotídeo na superfície da vesícula de DODAB, usando a sonda fluorescente Laurdan incorporada na vesícula

lipídica. Em especial, pretendemos estudar a sensibilidade da sonda Laurdan em monitorar alterações na superfície de membranas de DODAB.

Para isto, foram utilizadas técnicas como espalhamento de luz dinâmico (DLS), potencial-zeta, espalhamento de Raios-X a baixos ângulos (SAXS), calorimetria diferencial de varredura (DSC), imagens de turbidez. As respostas do Laurdan em presença de DODAB e ODN foram testadas através das técnicas de absorção ótica, fluorescência estática e anisotropia de fluorescência.

\subsection{Sumario dos Próximos Capítulos}

No capítulo 2, apresentamos brevemente os princípios básicos das principais técnicas experimentais aplicadas para estudarmos tanto o efeito da blindagem eletrostática causada pelo ODN na superfície do DODAB, como a sensibilidade da sonda Laurdan em monitorar alterações na superfície de membranas de DODAB. Devido ao grande volume de técnicas experimentais, nesta dissertação, optamos por uma descrição resumida, apenas colocando as equações quando fosse extremamente necessário. Na seção 2.1, 2.2 e 2.3, foram descritas as técnicas que serão utilizadas para caracterizar o complexo ODN /DODAB. Na seção 2.4, descrevemos a técnica que vai monitorar a transição de fase do DODAB com adição de ODN. Finalmente na última seção 2.5 e 2.6, foram descritas as 
duas técnicas espectroscópicas utilizadas, absorção óptica de luz e a fluorescência estática para monitorar a superfície da vesícula de DODAB.

No capítulo 3, apresentamos a descrição dos materiais e métodos utilizados, a qual foi separada em quatro partes: na primeira, detalhamos os materiais utilizados (seção 3.1); na segunda parte, são descritos os protocolos de preparação das amostras (seção 3.2); na terceira parte descrevemos os detalhes dos controles experimentais para a formação do complexo supramolecular (seção 3.3); e na quarta parte, são descritos os métodos experimentais utilizados, bem como os equipamentos (seção 3.4).

Capítulo 4 foi divido em três partes: na primeira, analisamos o efeito do oligonucleotídeo (ODN) sobre a estabilidade coloidal das vesículas de DODAB e em seguida caracterização de esta (seção 4.1); na segunda parte analisamos o efeito do ODN sobre a transição de fase das bicamadas de DODAB (seção 4.2). Na terceira e última parte, verificamos a sensibilidade da sonda Laurdan em monitorar alterações na superfície das vesículas de DODAB causadas pelo ODN (seção 4.3).

Por último, no capítulo 5 , colocamos as conclusões e perspectivas. 


\section{CAPÍTULO 2}

"El destino no es cuestion de suerte, es cuestion de elección. No es algo a esperar, es algo a ser conseguido"

Willian Jennings Bryan 


\section{TÉCNICAS EXPERIMENTAIS}

Este capítulo apresenta os princípios básicos das técnicas experimentais utilizadas ao longo do trabalho desta dissertação. Devido à variedade de técnicas experimentais estudadas, estas serão aqui apresentadas de forma sucinta e dirigidas para nossos estudos.

\subsection{Espalhamento de luz dinâmico}

A técnica de espalhamento Dinâmico de Luz (Dynamic Light Scaterring, DLS) está baseada no movimento browniano e no espalhamento de luz por partículas, permitindo assim a avaliação das dimensões de partículas em suspensão, tanto na pesquisa como na indústria (Pecora, 2000; Nomura,et al., 2016).

\subsubsection{Movimento Browniano}

O movimento browniano de uma partícula em suspensão resulta no fato dela estar continuamente sendo bombardeada pelas moléculas do meio solvente, as quais estão em constante agitação térmica (Mörters et al, 2008).

A teoria para descrever o movimento browniano foi proposta por Albert Einstein em 1905, e está baseada na hipótese de que o movimento errático de uma partícula em um meio composto por moléculas colidindo com ela é melhor descrito em termos probabilísticos. O modelo probabilístico mais simples, que permite explicar o movimento browniano das partículas em termos das leis macroscópicas de difusão é o modelo do passeio aleatório (Pearson, 1905). Neste modelo, o coeficiente de difusão, D (variável macroscópica), está relacionado às variáveis microscópicas: distância, $\Delta l$, percorrida por uma partícula entre duas colisões e, o intervalo de tempo, $t$, entre duas colisões, que descrevem o movimento aleatório das partículas. Desta forma, podemos escrever a equação 2.1 .

$$
D=\frac{\Delta l^{2}}{2 t}
$$


Com este modelo, o deslocamento através do espaço e tempo da partícula em difusão poderá ser estudado a partir de um experimento de distribuição binomial. Logo, a partir dessa descrição microscópica do deslocamento da partícula, é possível fazer uma descrição macroscópica do seu deslocamento em termos de escalas macroscópicas de espaço, $\Delta r$, e tempo, $\tau$. Para isso, as referências da literatura (Roque, 2016; Donsker, 1952) demostram que a distribuição binomial pode convergir para uma distribuição normal gaussiana. Com isso, temos como resultado uma função de probabilidade gaussiana do deslocamento da partícula que relaciona os parâmetros de posição $(\Delta r)$, tempo $(\tau)$ e difusão $(D)$ :

$$
p(\Delta r, \tau)=\left(\frac{1}{4 \pi D \cdot \tau}\right)^{3 / 2} \cdot e^{-\Delta r^{2} / 4 D \cdot \tau}
$$

A expressão para o parâmetro de difusão, $D$, da equação 2.2, para partículas esféricas de diâmetro, $d_{Z}$, em movimento browniano, pode ser encontrada a partir da equação de Stokes-Einstein (Kubo, 1966;Carter, 2001 ),

$$
D=\frac{K_{B} T}{3 \pi \eta d_{Z}}
$$

sendo $K_{B}$ a constante de Boltzmann, T, a temperatura e $\eta$ a viscosidade do meio.

\subsubsection{Espalhamento de Luz}

A técnica de DLS consiste na iluminação com um feixe de luz visível incidente de comprimento de onda, $\lambda_{0}$, e vetor de onda, $\vec{k}_{0}$, sobre uma amostra composta por partículas espalhadoras em movimento Browniano, que irão espalhar o feixe de luz (campo elétrico) com vetor de onda, $\vec{k}_{S}$, em um determinado ângulo, $\theta$, Figura 5.

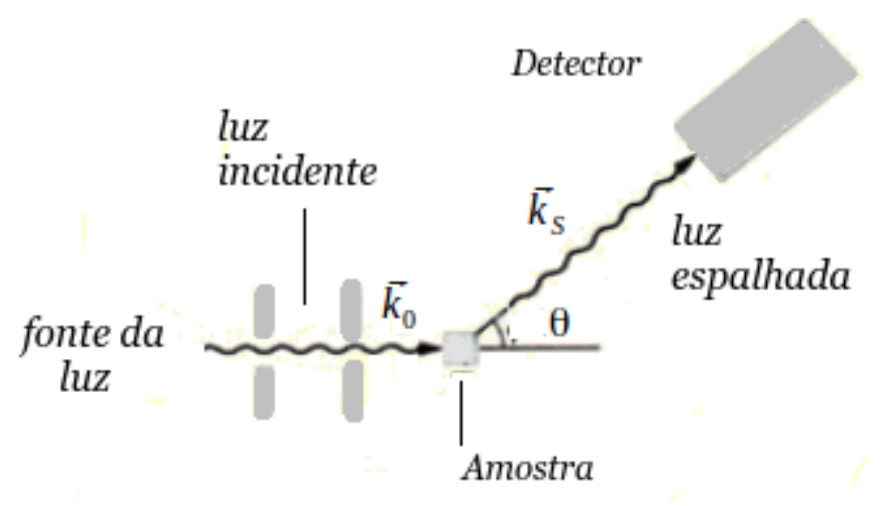

Figura 5: esquema ilustrativo da técnica de DLS. 
Em 1964, Pecora mostrou (Pecora, 1964) que o constante deslocamento das partículas em sua posição, através do tempo, geraria mudanças no campo elétrico espalhado (efeito Doppler). Com isso, a intensidade da luz sofrerá variações no tempo. A correlação da variação na intensidade de luz espalhada nos proporcionará informações do coeficiente de difusão, $D$, e do tamanho da partícula, utilizando a relação de Stokes-Einstein (equação $2.3)$.

\subsubsection{Função de auto-correlação}

Essa análise é feita com um correlator, que mede o grau de semelhança entre dois sinais, tomando os valores de intensidade, $I(t)$, da luz espalhada em um instante de tempo, $t$, e a correspondente quantidade, $\mathrm{I}(\mathrm{t}+\tau)$, em um instante posterior, $\mathrm{t}+\tau$, para todo $\mathrm{t}$ dentro do intervalo do tempo total, $T_{\text {total }}$, em que o sinal é observado.

O correlator calcula a função de autocorrelação da intensidade de luz espalhada, $G^{(2)}(\tau)$, através da média do produto da segunda igualdade da equação 2.4:

$$
G^{(2)}(\tau)=\langle I(t) \cdot I(t+\tau)\rangle_{t}=\lim _{N \rightarrow \infty} \frac{1}{N} \sum_{j}^{N} I_{j} \cdot I_{j+n}
$$

onde, na prática, a média é calculada tomando-se medidas da intensidade em intervalos discretos de tempo $\Delta$ t. Na qual $I_{j}$ é a medida da intensidade de luz no instante $t_{j}$, e $I_{j+n}$ é a medida de intensidade no instantete, $t_{j+n}$, sendo $n \Delta t=t_{j+n}-t_{j},=\tau$.

O aparelho fixa uma janela de tempo $\tau$, e calcula a segunda igualdade da equação (2.4), para cada j. No final toma a média fazendo a divisão por $\mathrm{N}$, sendo que, $N . \Delta \mathrm{t}$, coincide com o tempo total, $T_{\text {total }}$, em que o sinal é observado no limite para o qual $N \rightarrow \infty$ e $\Delta t \rightarrow 0(\tau \rightarrow \infty$ e $\tau \rightarrow 0)$.

Os resultados são apresentados num gráfico, mostrando a função de autocorrelação $G^{(2)}$ em função de $(\tau)$, nos limites $G^{(2)}(\tau \rightarrow \infty)=\langle I\rangle^{2}$ e $G^{(2)}(\tau \rightarrow 0)=\left\langle I^{2}\right\rangle$. A função de autocorrelação normalizada é dada por,

$$
g^{(2)}(\tau)=\frac{G^{(2)}(\tau)}{\langle I\rangle^{2}}
$$

2.1.4 Análise da função de correlação do campo elétrico 
A soma de todos os campo elétricos espalhados na direção, $\vec{k}_{S}$, pela movimentação das partículas pode ser escrita como,

$$
\vec{E}_{S, t o t a l}=\sum_{j=1}^{N} \vec{E}_{S, j}=\sum_{j=1}^{N} \vec{E}_{0} \cdot e^{-i\left(\vec{k}_{S} \cdot \vec{R}-\omega t\right)} \cdot e^{i \Delta \phi_{j}}
$$

onde a diferença de caminho ótico (ver Figura 6) é escrita como,

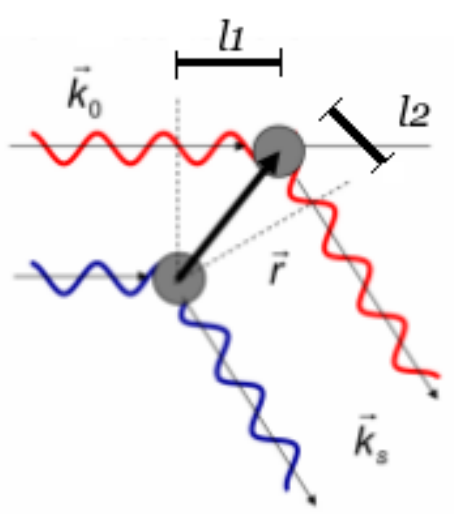

Figura 6: Esquema para o cálculo da função

$$
l_{1}-l_{2}=\hat{k}_{S} \cdot(-\vec{r})+\hat{k}_{0} \cdot \vec{r}=\frac{\lambda_{0}}{2 \pi} \cdot\left(\vec{k}_{0}-\vec{k}_{S} \cdot\right)(\vec{r})
$$
de autocorrelação temporal do campo elétrico.

sendo $\lambda_{0}$, o comprimento de onda da luz. Portanto a diferença de fase é escrita como $\Delta \phi=\frac{\lambda_{0}}{2 \pi} \cdot\left(l_{1}-l_{2}\right)=\left(\vec{k}_{s}-\vec{k}_{0}\right) \cdot \vec{r}=\vec{q} \cdot \vec{r}$. Na qual, $\vec{q}$, é chamado vetor de espalhamento com módulo, $q=\frac{4 \pi n_{0}}{\lambda_{0}} \sin \left(\frac{\theta}{2}\right)$, sendo $n_{0}$ o índice de refração do meio, e, $\theta$, o ângulo de espalhamento.

O campo elétrico total, $\vec{E}_{S, \text { total }}$, da equação 2.6, pode ser reescrito somando todos os campos e substituíndo à diferença de fase, resultando:

$$
\vec{E}_{s, t o t a l}=\vec{b} \sum_{j=1}^{N} e^{i \vec{q} \cdot \vec{r}_{j}}
$$

O cálculo da função de autocorrelação temporal do campo elétrico, $G^{(1)}(\tau)$, é feita através da média do produto de campo elétrico espalhado para dois instantes de tempo diferente $\left(\vec{E}_{s, t o t a l}(0)\right.$ e $\left.\vec{E}_{s, t o t a l}(\tau)\right)$, segundo a equação 2.9 .

$$
G^{(1)}(\tau)=\left\langle\vec{E}_{s, \text { total }}(\tau) \cdot \vec{E}_{s, \text { total }}(0)\right\rangle=\left\langle\vec{b} \sum_{j=1}^{N} e^{i \vec{q} \cdot \vec{r}_{j}(\tau)} \cdot \vec{b} \sum_{i=1}^{N} e^{i \vec{q} \cdot \vec{r}_{i}(0)}\right\rangle
$$

Se as posições das partículas i e j são independentes, os termos com i $\neq$ j serão zero, portanto, $G^{(1)}(\tau)$ assume a forma da equação 2.10 .

$$
G^{(1)}(\tau)=\left\langle e^{i \vec{q} \cdot \vec{r}_{j}(\tau)} \cdot e^{i \vec{q} \cdot \vec{r}_{i}(0)}\right\rangle=\left\langle e^{i \vec{q} \cdot \overrightarrow{\Delta r}(\tau)}\right\rangle
$$

O cálculo de, $G^{(1)}$, é obtido integrando-se, o produto da função de campo elétrico 
espalhado pela densidade de probabilidade de deslocamento da partícula (equação 2.2). Segundo a equação 2.11 .

$$
G^{(1)}(\tau)=\left\langle e^{i \vec{q} \cdot \overrightarrow{\Delta r}(\tau)}\right\rangle=\int p(\Delta \vec{r}, \tau) \cdot e^{i \vec{q} \cdot \overrightarrow{\Delta r}(\tau)} d \Delta \vec{r}(\tau)
$$

- Para partículas monodispersas não interagentes, a função de autocorrelção de campo elétrico (equação 2.11) toma a forma da equação (2.12) (para maiores detalhes do calculo da integral, revisar os autores Teixeira e Geissler, 2007)

$$
\begin{gathered}
G^{(1)}(\tau)=\langle I\rangle \cdot e^{-D q^{2} \tau} \\
g^{(1)}(\tau)=e^{-D q^{2} \tau}
\end{gathered}
$$

A função de autocorrelação normalizada do campo elétrico, $g^{(1)}(\tau)$, pode ser relacionada a autocorrelação de intensidades normalizada, $g^{(2)}(\tau)$, a partir da relação de Siegert, em sistemas diluídos,

$$
g^{(2)}(\tau)=1+\gamma\left|g^{(1)}(\tau)\right|^{2}=1+\gamma e^{-2 D q^{2} \tau}
$$

onde $\gamma$ depende de condições instrumentais.

Da equação (2.14) podemos ver que a função de autocorrelação normalizada em função do tempo, $g^{(2)}(\tau)$, decai exponencialmente com uma taxa, $\Gamma=D q^{2}$.

- Para partículas polidispersas não interagentes, a função de autocorrelação normalizada de campo elétrico, $g^{(1)}(\tau)$, contém a informação de diversos decaimentos, ou de forma equivalente diferentes coeficientes de difusão, correspondendo a diferentes $\operatorname{taxas} \Gamma=D q^{2}$.

Em geral, supõe-se que as diversas taxas presentes na amostra são distribuídas segundo uma função $\mathrm{P}(\Gamma)$ caraterística do sistema, e portanto, o resultado mostrado na equação (2.11) pode ser generalizado tomando a média,

$$
\left\langle g^{(1)}(\tau)\right\rangle=\int p(\Gamma) \cdot e^{-\Gamma \tau} d \Gamma
$$

sendo $P(\Gamma) d \Gamma$ o número de partículas com valores de gama entre $\Gamma$ e $\Gamma+d \Gamma$. 
Vários métodos são usados para estimar a forma da distribuição $\left\langle g^{(1)}(\tau)\right\rangle$. Nos resultados experimentais apresentados na seção 4.1, utilizamos o método dos cumulantes(Koppel, 1975), segundo o qual

$$
\left\langle g^{(1)}(\tau)\right\rangle=B e^{\left(-\langle\Gamma\rangle \tau+\frac{\rho_{2}}{2} \tau^{2}+\frac{\rho_{3}}{6} \tau^{3}+\ldots\right)}
$$

onde, $\rho_{n}$, corresponde aos momentos, ou cumulantes, da expansão.

Deste modo, foi obtida a taxa de relaxação média dos centros espalhadores, $\langle\Gamma\rangle$, que, por sua vez, pode ser relacionado ao coeficiente de difusão, $D$ e ao vetor de espalhamento $q$. Uma vez obtido o coeficiente de difusão dos centros espalhadores, livre de interações com relação aos demais centros é possível determinar o diâmetro, $d_{Z}$, assumidas esferas, de acordo com a equação de Stokes-Einstein (equação 2.3).

É importante ressaltar que as medidas de DLS podem ser influenciadas por interações entre partículas e a anisotropia dos centros espalhadores. Para vesículas na ausência de ODN, podemos assegurar a medida de um coeficiente de difusão puramente translacional, para medidas dos raios efetivos em presença de ODN, a medida pode conter contribuições das interações causadas pelo ODN.

\subsection{Potencial-zeta}

A técnica do potencial - zeta $(\zeta)$ tem sido amplamente utilizada como um bom indicador de carga superficial, permitindo fornecer informações como a estabilidade de suspensões coloidais (Lytle et al., 1999). Nos experimentos, o potencial-zeta é obtido a partir da mobilidade eletroforética, $\mu$, (Wilson et al., 2000) (Kirby, 2010), conceito que se resume a seguir para orientar o leitor para as aplicações práticas do nosso trabalho.

\subsubsection{Medição da mobilidade eletroforética}

O espalhamento de luz eletroforético é uma técnica utilizada para medir a mobilidade eletroforética das partículas em dispersão. Nos experimentos o equipamento é capaz de medir a mobilidade, $\mu$, das partículas que se movimentam em um campo elétrico a partir da mudança de frequência da luz espalhada (Shimko et al , 2014).

Da Figura 7, podemos ver que com o campo elétrico ativado, a partícula ira migrar para o elétrodo de carga oposta com uma velocidade de deslocamento, $\vec{v}_{d}$, e consequen- 


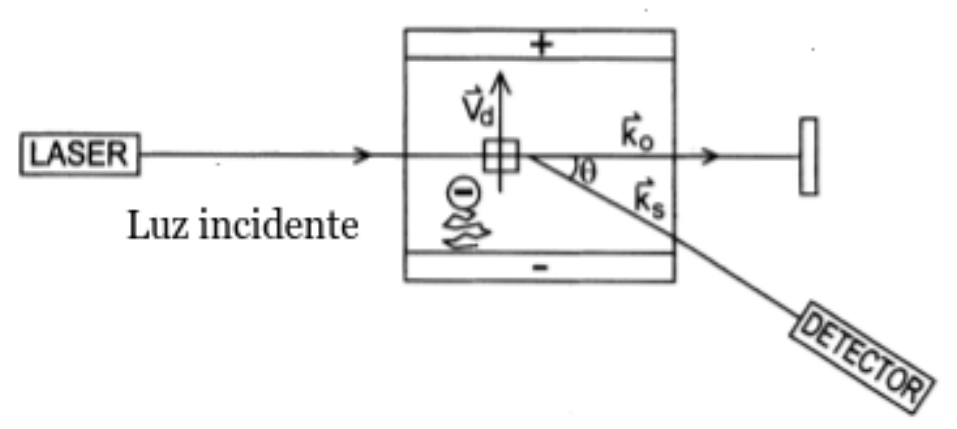

Figura 7: Representação esquemática do espalhamento de luz eletroforética para uma amostra de partículas. Adaptada de (Ware e Flygare, 1971).

temente a frequência da luz espalhada se tornará modificado (veja os espectros da Figura 8). Da figura, podemos ver que com o campo elétrico desligado a frequência da luz espalhada não é alterada. No entanto, com o campo elétrico ligado a frequência é modificada, sendo esta proporcional ao produto escalar da velocidade de deslocamento e ao vetor de espalhamento, $\Delta \omega=\vec{q} \cdot \vec{v}_{d}$, (Ware e Flygare, 1971).
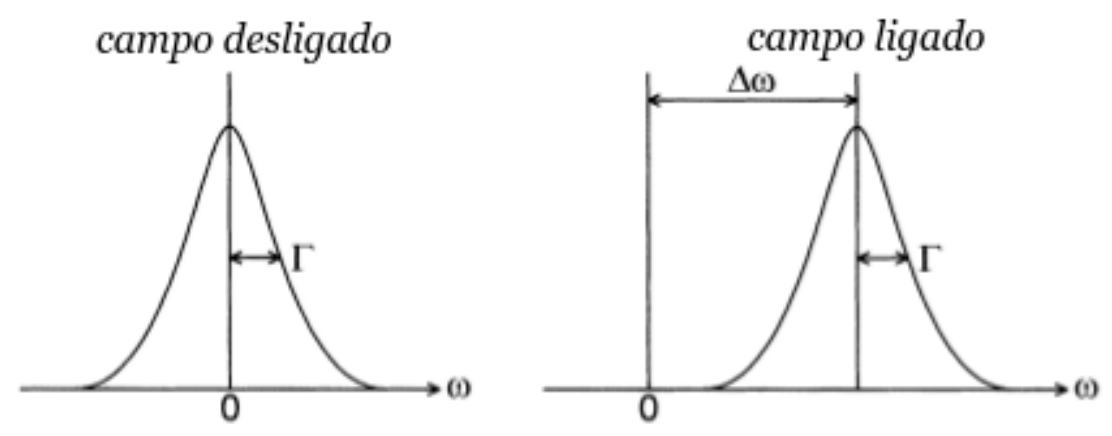

Figura 8: Espectro de frequência da intensidade da luz espalhada com o campo elétrico desligado e ligado. Adaptada de (Ware e Flygare, 1971).

A variação da frequência poder ser escrita como, $\Delta \omega=q \cdot v_{d} \cos (\theta / 2)$ ( Figura 9). Além disso, usando a relação, $\omega=2 \pi \nu$, temos que a magnitude da velocidade de movimento da partícula é dada pela equação abaixo:

$$
v_{d}=\frac{2 \pi \Delta \nu}{q \cos (\theta / 2)}
$$

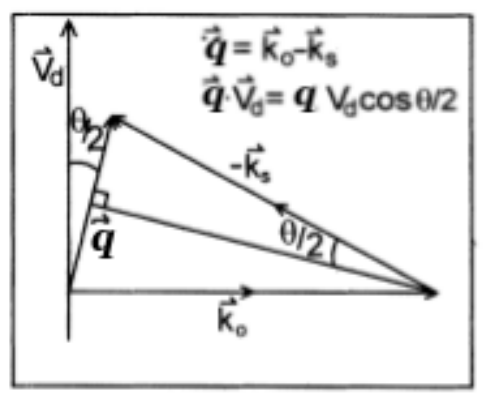

O modulo da velocidade que as partículas adquirem,

Figura 9: Relação do vetor de espalhamento, $\vec{q}$, e a velocidade de desplasamento, $\vec{v}_{d}$. 
$v_{d}$, se relaciona com o modulo do campo elétrico aplicado, $E$, através da mobilidade eletroforética, $\mu$, segundo a expressão:

$$
\mu=\frac{v_{d}}{E}
$$

Para medir a mobilidade eletroforética em nosso experimento, será utilizada a técnica de Electroforesis Laser Doppler, baseada no princípio básico do efeito Doppler (Doppler et. al.,1843), que supõe a variação da frequência de qualquer tipo de onda emitida ou recebida por uma partícula em movimento (por tanto a equação (2.17) não devera ser tomada em conta, já que não foi de nosso uso. No entanto, servira de modo de orientação para o leitor de como poderia ser calculado o valor da mobilidade, segum Ware e Flygare, 1971).

\subsubsection{Mobilidade eletroforética relacionada ao potencial -zeta}

Na Figura 10, estão ilustradas as várias camadas que são frequentemente referidas na descrição de partículas em solução.

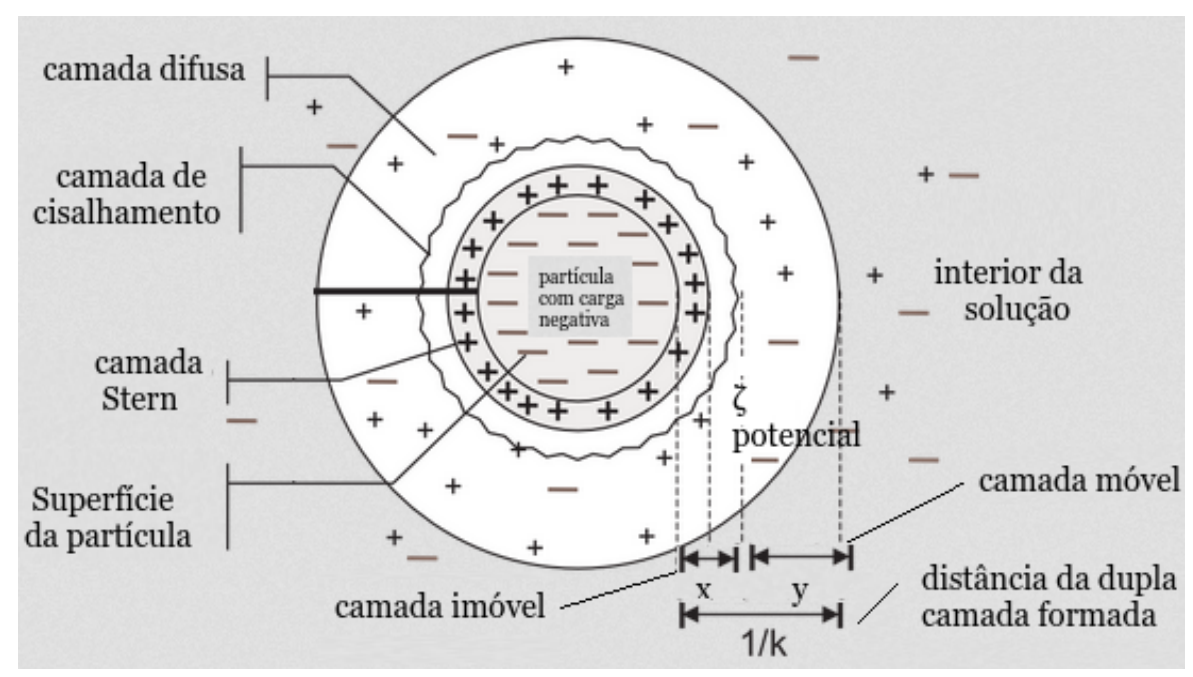

Figura 10: Esquema da distribuição de cargas na vizinhança de uma partícula carregada (adaptado de Jafelicci e Laudemir , 1999).

Podemos ver que dentro da camada imóvel (distância $x$ ) encontra-se a superfície da partícula carregada negativamente e a camada de Stern, formada pela adsorção de íons positivos na superfície da partícula. Já na camada móvel (distancia y) encontra-se a 
camada difusa, formada por íons positivos e negativos da solução. A distância da dupla camada formada ao redor da partícula (camada imóvel e camada móvel) terá um valor de $1 / k$.

Na fronteira entre a camada móvel e a camada imóvel, encontrasse a camada de cisalhamento (Figura 10), onde o potencial zeta, $(\zeta)$, pode ser determinado e uma densidade de carga pode ser inferida. (Hotza, 1997; Adamsom, 1982).

O potencial zeta $(\zeta)$ esta relacionado com a mobilidade eletroforética, $\mu$, e pode ser obtida de distintas formas, em função do tamanho da partícula. Os três modelos mais utilizados para relacionar o potencial zeta e mobilidade eletroforética são: Aproximação de Smoluchowski, aproximação de Hückel e a equação de Henry. No entanto, nesta dissertação só estamos interessados na primeira aproximação, bastante utilizada em nossas análises.

Aproximação de Smoluchowski (Hiemenz, 1986): é a primeira aproximação que se faz para calcular o potencial zeta a partir de medidas experimentais de mobilidade. Nesta aproximação, consideramos que as partículas coloidais são esféricas e que seu raio, $a$, é muito maior que a espessura da dupla camada formada, $1 / k$, tal como representada Figura 11.

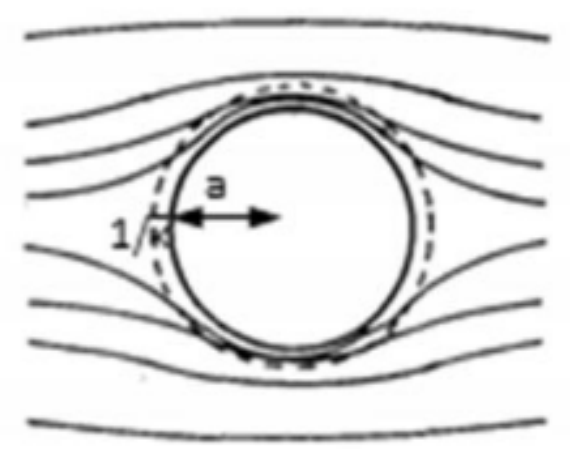

Figura 11: Distorção do campo elétrico aplicado sobre uma partícula esférica de raio a. As linhas tracejadas representam a espessura da camada dupla, 1/k. (Hiemenz, 1986)

Sob estas condições, o campo elétrico aplicado afeta o movimento da partícula, já que esta experimenta um campo distorcido, e o potencial zeta na camada de cisalhamento é encontrada segum a expressão (para maiores detalhes da obtenção do potencial, revisar o autor Hiemenz, 1986):

$$
\zeta=\frac{\eta \cdot v_{d}}{\epsilon \cdot E}
$$


onde, $v_{d}$,é a velocidade relativa entre a partícula e o meio circundante, $\epsilon$, a constante dielétrica e, $\eta$, a viscosidade do solvente. Em termos de mobilidade eletroforética, torna-se a Equação de Smoluchowski :

$$
\mu=\frac{v_{d}}{E}=\frac{\epsilon \zeta}{\eta}
$$

Existe, portanto uma expressão para descrever a relação entre a mobilidade de uma partícula (um valor experimental) e o potencial zeta.

\subsection{Espalhamento de raios-X a baixo ângulo}

A técnica de espalhamento de raios-X a baixos ângulos (SAXS) (Small angle X-Ray Scattering) está baseada na análise do espalhamento de raios-X de um material a ângulos muito pequenos. Qualquer evento de espalhamento é caracterizado por uma lei recíproca entre tamanho da partícula e ângulo de espalhamento (Glatter e Kratky, 1982).

O espalhamento de raios-X a baixo ângulo tem sido amplamente utilizado para estudos estruturais de macromoléculas de interesse biológico e proteínas (Feigin e Svergun, 1987). Nesta seção, apresentamos as equações básicas necessárias para entender os princípios dessa técnica. Informações mais detalhadas podem ser encontradas em livros didáticos (Glatter e Kratky, 1982; Schmidt, 1995).

Nos experimentos de SAXS, um feixe de raios-X policromático que sai da fonte do aparelho atravessa um monocromador responsável por selecionar uma pequena faixa de comprimentos de onda da ordem de $0.1 \mathrm{~nm}$ aproximadamente. Então, o feixe monocromático passa por um colimador com um vetor de onda, $\vec{k}_{0}$, e interage com os eléctrons da amostra fazendo com que os mesmos oscilem senoidalmente. A radiação emitida de cada elétron é espalhada, sendo cancelada em algumas direções e em outras superpostas (interferência construtivas). Quando as ondas interferem construtivamente, a diferença de fase entre os feixes espalhados com vetor de onda, $\vec{k}_{s}$ é considerada pequena. Além disso, a intensidade do feixe detectado alcança seu valor máximo para um ângulo de espalhamento, 20, conforme ilustra a Figura 12.

O espalhamento de raios-X a baixos ângulos é considerado como elástico, pois $k_{0}$ $\equiv k_{s}$.

Agora, introduziremos a densidade eletrônica, $\rho(\vec{r})$, como o número de elétrons 


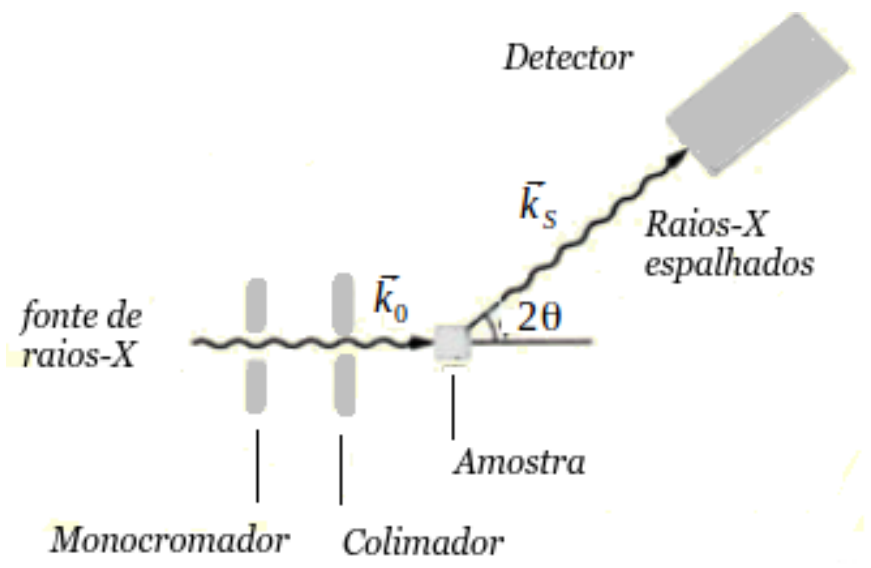

Figura 12: Esquema ilustrativo da medida de SAXS

por unidade de volume na posição, $r$, de uma partícula que está fixa no espaço. Portanto, a amplitude de espalhamento total, $A(\vec{q})$, irradiada pelos elétrons, contidas na partícula de volume, $\mathrm{V}$,é dada pela Transformada de Fourier da densidade eletrônica :

$$
A(\vec{q})=A_{e} \int_{V} \rho(\vec{r}) \cdot e^{i \vec{q} \cdot \vec{r}} d \vec{r}
$$

onde, $A_{e}$, denota a amplitude de espalhamento de um elétron.

A intensidade espalhada pela partícula, $I_{0}(\vec{q})$, pode ser mensurada por meio do produto da amplitude pela amplitude complexa, $A(\vec{q})^{*}$,

$$
I_{0}(\vec{q})=A(\vec{q}) \cdot A(\vec{q})^{*}=I_{e} \int_{V} \rho(\vec{r}) \cdot \rho\left(\overrightarrow{r^{*}}\right) \cdot e^{-i \vec{q} \cdot\left(\vec{r}-\vec{r}^{*}\right)} d \vec{r} d \overrightarrow{r^{*}}
$$

onde a intensidade de espalhamento do elétron, $I_{e}$, pode ser dada pela fórmula de Thomson, veja ( Laue, 1960). Definimos, $\rho^{2}(\vec{r})=\int_{V^{*}} \rho(\vec{r}) \cdot \rho\left(\vec{r}-\overrightarrow{r^{*}}\right) d \overrightarrow{r^{*}}$, como o quadrado da convolução (Bracewell, 1986), portanto, a equação 2.22 se reduz para a equação (2.23).

$$
I_{0}(\vec{q})=I_{e} \int_{V} \rho^{2}(\vec{r}) e^{-i \vec{q} \cdot\left(\vec{r}-\vec{r}^{*}\right)} d \vec{r}
$$

Até agora as considerações feitas foram para uma partícula fixa no espaço. No entanto, em sistemas reais, as partículas não estão fixas. Portanto, devemos tomar a média sobre todas as orientações da partícula. No espaço recíproco isso é feito facilmente tomando-se a média sobre o ângulo sólido $\Omega$, o qual leva, $\left\langle e^{i \vec{q} \cdot \vec{r}}\right\rangle_{\Omega}=\frac{\sin (q r)}{q r} d r$, (Debye, 
1915) e a equação 2.23 se reduz a forma :

$$
I_{0}(q)=4 \pi \int_{0}^{\infty} p(r) \frac{\sin (q r)}{q r} d r
$$

onde a função, $p(r)=r^{2} \Delta \rho^{2}(r)$, é chamada de distribuição de pares de distâncias, e é uma função no espaço real que fornece informações sobre a forma das partículas a partir da intensidade espalhada $I_{0}(q)$.

O modelo tratado até agora foi para o espalhamento de uma única partícula. Para um sistema de partículas em solução, aleatoriamente orientadas, a intensidade espalhada pelo sistema é escrita pela equação,

$$
I(q)=N\langle P(q)\rangle \cdot\langle S(q)\rangle
$$

onde N corresponde ao número de partículas alvo, e $P(q)=\langle P(q)\rangle$ e $S(q)=\langle S(q)\rangle$, são os fatores de forma da partícula e estrutura, respectivamente.

O fator de forma depende apenas da forma das partículas. Se o sistema for monodisperso, a forma das partículas não muda e $P(q)=I_{0}(q)$. Se o sistema for polidisperso, o fator de forma incluirá a média sobre todas as possíveis formas, tamanhos e densidades eletrônicas das partículas.

O fator de estrutura está relacionado a interações entre partículas e as possíveis estruturas que elas podem formar devido a isso. Para sistemas diluídos (não interagentes), $S(q) \rightarrow 1$ e a intensidade espalhada só dependerá do fator de forma, $I(q) \sim P(q)$. Para sistemas concentrados, $S(q)$, deve ser levado em conta, a fim de que a intensidade espalhada seja perfeitamente entendida.

Para a análise de nossos dados de SAXS, levaremos em consideração a contribução do DODAB e ODN. 


\subsection{Calorimetria diferencial de varredura}

A técnica de calorimetria diferencial de varredura (DSC) tem sido extensivamente aplicada no estudo de sistemas biológicos (Heerklotz, 2004), sendo capaz de fornecer informações termodinâmicas, tais como, a temperatura de transição de fase gel-fluido, $T_{m}$ , a variação da entalpia de transição, $\Delta H$, e o grau de cooperatividade, $\Delta T_{1 / 2}$, do sistema investigado.

\subsubsection{Transição gel-fluido}

Sistemas lipídicos que compõem uma única fase são aqueles nos quais ocorre o mesmo tipo de agregação ou propriedades físico-químicas semelhantes. Pode-se caracterizar diferentes propriedades e estados de agregação, que serão distintos dependendo da fase lipídica estudada. Por exemplo, na fase gel, (Figura 13) os lipídios estão empacotados mais rigidamente (a área superficial por molécula é menor) e suas cadeias laterais encontram-se muito mais organizadas e estendidas em relação a outro estado físico (em razão da interação de van der waals). Por outro lado, na fase fluida os lipídios não compõem uma rede ordenada e suas cadeias hidrocarbônicas apresentam configurações desordenadas. Além disso, nesta fase, as cadeias não estão estendidas ao máximo, o lipídio apresenta uma maior área ocupada com uma espessura de bicamada menor que na fase gel, conforme ilustra a Figura 13.

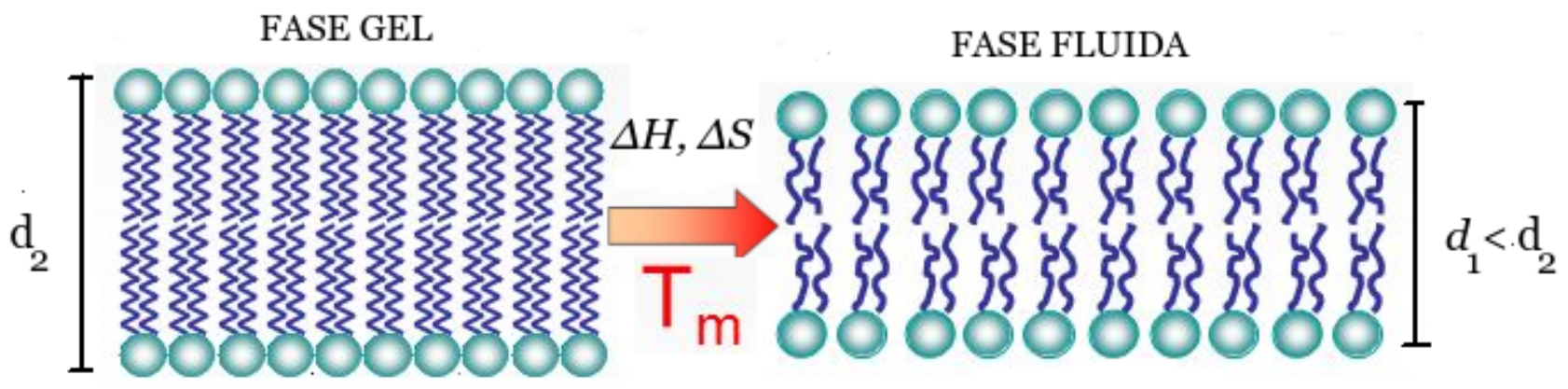

Figura 13: Representação ilustrativa da transição gel-fluido em sistemas lipídicos. O sistema organizado caracteriza a fase gel, enquanto o sistema desorganizado caracteriza fase fluida. Cabe ressaltar que após a transição a área ocupada por cada lipídio da bicamada aumenta e sua espessura, $d_{2}$, diminui.

Portanto, a transição gel-fluido das bicamadas lipídicas pode ser caracterizada por uma transição de um sistema ordenado com mobilidade restrita para outro desordenado 
com alto grau de mobilidade, na temperatura, $T_{m}$.

Como mencionado na seção 1.2.1 vesículas de DODAB apresentamtram histerese do comportamento termotrópico. Este fenômeno consiste na variação da temperatura de transição de fase gel-fluido, $T_{m}$, quando a amostra é aquecida e resfriada. No entanto, esta temperatura de transição não é uma característica das vesículas de DODAB, pois depende do método de preparação e da concentração do DODAB em dispersão aquosa.

Tendo em vista algumas propriedades da transição de fase do lipídio DODAB, vamos discutir como as medidas da temperatura de transição de fases e a variação da entalpia são realizadas.

\subsubsection{Cálculo do calor específico}

A capacidade térmica à pressão constante é definida como a razão entre quantidade de calor fornecida a um sistema, dQ, e a variação de temperatura desse sistema, dT (Salinas, 2008):

$$
C_{p}=\left(\frac{d Q}{d T}\right)_{p}
$$

No entanto, do ponto de vista físico, a grandeza mais fundamental é o calor específico, $c_{p}$, o qual define-se como a capacidade térmica por partícula, ou seja:

$$
c_{p}=\frac{1}{N} C_{p}=\frac{1}{N}\left(\frac{d Q}{d T}\right)_{p}
$$

Utilizando uma transformação de Legendre, podemos relacionar o calor específico com a entalpia, da seguinte forma:

$$
\begin{gathered}
H(S, p)=U+p V \\
d H=d Q+V d p
\end{gathered}
$$

sendo a pressão e número de partículas mantidas constantes, $d H=d Q$, e de acordo com a equação (2.27), temos que:

$$
c_{p}=\frac{1}{N}\left(\frac{d H}{d T}\right)_{p, N}
$$

Portanto, conhecendo-se o calor específico é possível obter informações termodinâmicas da variação da entalpia, $\Delta H$, integrando-se sob a curva de $c_{p}$ em função 
da temperatura correspondente à variação de entalpia envolvida na transição de fase.

$$
\Delta H=\int_{T_{0}}^{T} c_{p} \cdot d T
$$

Neste contexto, a técnica de calorimetria diferencial de varredura, DSC, permite medir o calor específico ou capacidade térmica de um sistema fechado à pressão constante.

A apresentação esquemática do equipamento mostrado na Figura 14, consiste de duas celas dentro de um invólucro de isolamento térmico.

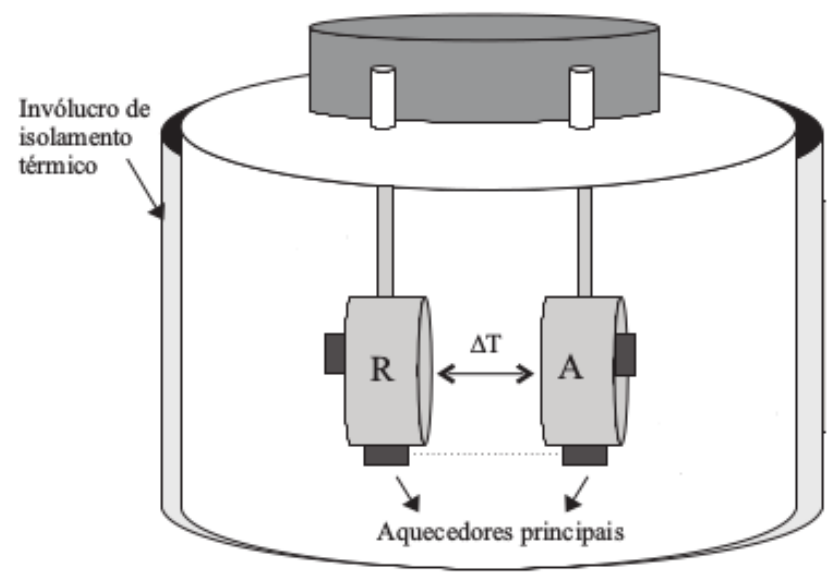

Figura 14: Representação esquemática de um calorímetro diferencial de varredura. Sendo $R$, a cela de refêrencia e A a cela da amostra. Figura extraída de (Barroso, 2010).

A primeira cela, chamada de referência, contém uma solução que será utilizada como referência na medida. A outra cela, será preenchida pela amostra da qual deseja-se medir o calor específico. A medida é feita esquentando-se as celas com aquecedores a uma taxa constante no tempo $\left({ }^{\circ} \mathrm{C} / \mathrm{h}\right)$. Além disso, a diferença de temperatura entre as duas celas, $\Delta T$, será mantida nula. Porém, quando a amostra passa por uma transição de fase, será necessário fornecer mais calor à cela da amostra, para que ambas apresentem o mesmo aumento de temperatura. Deste modo, a potência na cela da amostra será maior que na cela de referência .

A diferença de potência entre as duas celas será registrada em função da temperatura, e o software apresentará um gráfico desta diferença de potência, em $(\mathrm{Cal} / h)$, em função da temperatura.

Posteriormente este valor $(\mathrm{Cal} / \mathrm{h})$ será dividido pela taxa de aquecimento $\left({ }^{\circ} \mathrm{C} / h\right)$, para obter a capacidade térmica, dada em unidades de $\left(\mathrm{Cal} /{ }^{\circ} \mathrm{C}\right)$. Finalmente, para 
obter o calor específico, dividimos a capacidade térmica pelo número de mols da amostra (concentração lipídica/volume da cela), e temos assim um resultado em unidades de calor específico, $\left(\mathrm{Cal} /{ }^{\circ} \mathrm{C} / \mathrm{mol}\right)$.

\subsection{Absorção Óptica da Luz}

A incidência de radiação electromagnética na matéria pode resultar em dois processos de interação: (1) ela pode ser espalhada e sua direção de propagação é modificada, ou (2) ela pode ser absorvida, transferindo energia para a matéria.

No processo de absorção da radiação, a energia a ser absorvida pela matéria está relacionada com a frequência, $\nu$, desta radiação, através da relação da equação 2.32 ,

$$
E=h \nu_{a}
$$

onde, $h$, é a constante de Planck. A equação (2.32), postulada por A. Einstein (Eisberg e Resnick, 1979) implica, o caráter corpuscular da luz e a quantização dos níveis de energia do átomo ou molécula, existindo assim valores determinados de energia.

Nesta dissertação, não iremos deduzir os níveis de energia permitidos, mas podemos recorrer a um modelo simplificado de uma molécula diatômica para uma melhor compreensão do ponto de vista qualitativo.

A Figura 15 mostra uma molécula diatômica, $A-B$, onde, para um dado estado, a energia potencial dependerá da distância entre os núcleos. A abscissa representa a separação entre os dois átomos, com o átomo, $A$, colocado na origem. A ordenada representa a energia potencial.

Desta forma, no seu estado de menor energia, a molécula, $A-B$, é representada pelos pontos colocados como, $A$ e $B$, na abscissa, onde o átomo, $A$, é considerado parado e o átomo, $B$, pode estar oscilando dentro da curva de potencial (cor preta). As linhas horizontais dentro da curva indicam diferentes níveis de energia vibracional permitidos, e entre estes últimos, encontramos ainda, os níveis de energia rotacionais.

Uma molécula excitada, é uma molécula, na qual, um elétron foi levado para um nível de maior energia. Tal molécula tem a sua própria curva de energia potencial caraterística (curva vermelha, Figura 15). Por exemplo, a absorção de energia na faixa das micro-ondas levará a transições que envolvem os níveis rotacionais, enquanto a faixa 


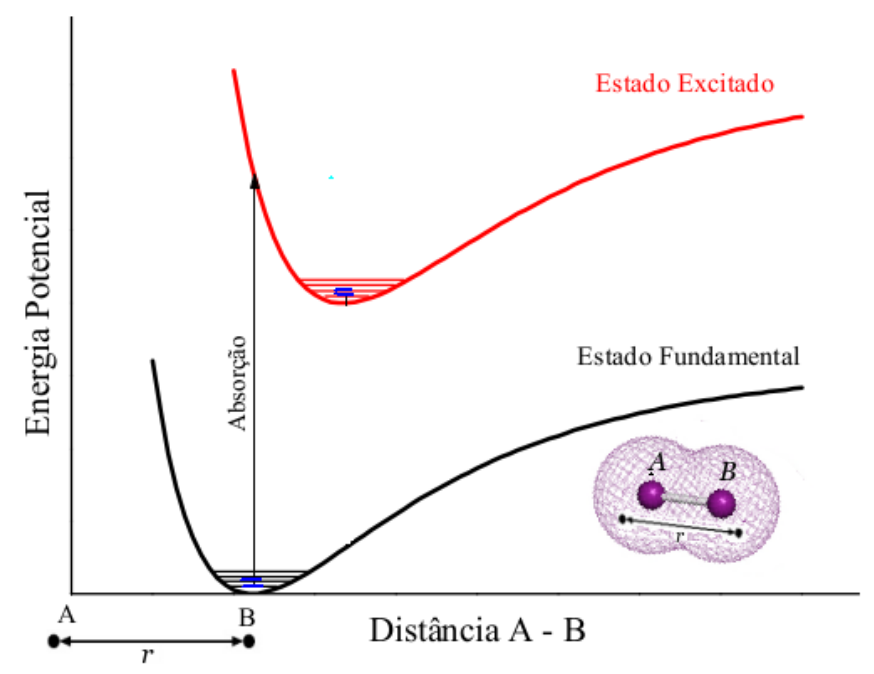

Figura 15: Níveis de energia de uma molécula diatômica, A-B, simples. Figura baseada do texto Takara, 2006.

do infravermelho promoverá transições entre estados vibracionais. Já a absorção na faixa do ultravioleta e visível, abrangerá transições eletrônicas e constituem o estúdo da técnica espectroscópica de absorção óptica.

De acordo como a mecânica quântica, uma transição eletrônica ocorre quando um elétron sai de um orbital do estado fundamental de energia, $E_{1}(r)$, e vai para um orbital desocupado de maior energia, $E_{2}(r)$, através da absorção de um fóton com energia, $h \nu_{a}$ . Em sistemas moleculares, os orbitais no estado fundamental de energia são chamados HOMO (Highest Ocuppied Molecular Orbital) e podem ser classificados como, $\sigma$ e $\pi$. Enquanto, no estado excitado, os orbitais são chamados LUMO (Lowest Ocuppied Molecular Orbital) e são classificados como, $\sigma^{*}$ e $\pi^{*}$. Por exemplo, a absorção de um fóton de energia, $h \nu_{a}$, poderá levar um elétron do orbital, $\pi$, para um orbital desocupado, $\pi^{*}$, e essa transição será chamada de, $\pi \rightarrow \pi^{*}$, veja a equação 2.33 (Vequi-Suplyci, 2010).

$$
\nu_{a}=\frac{E_{\pi} *(r)-E_{\pi}(r)}{h}
$$

A transição eletrônica acontece em tempo muito curto, $10^{-15}$ segundos , durante o qual as posições nucleares não se alteram enquanto os elétrons assumem configurações do estado exitado. É por isso que na Figura 15, essa transição é representada por uma linha vertical. Esse princípio é conhecido como princípio de Frank-Condon (Frank, 1926; Condon, 1928). 


\subsubsection{Lei de Lambert-Beer}

Experimentalmente, a luz absorvida por uma molécula pode ser analisada através de medidas de absorbância em função do comprimento de onda da luz incidente. Lambert observou empiricamente, que é possível relacionar a absorbância com a concentração da amostra e o caminho percorrido pela luz dentro da mesma. A partir das observações fenomenológicas de Lambert e Beer (Beer, 1852), foi possível deduzir uma equação denominada Lei de Lambert-Beer.

Considere um feixe de luz que transporta energia com comprimento de onda, $\lambda$, e tem intensidade $I^{0}$, conforme a Figura 16. O feixe incide em uma amostra contida em um recipiente de caminho óptico, $d$. O diferencial de intensidade, $d I$, ao longo do caminho percorrido pela luz, pode ser escrito como,

$$
d I(y)=-\epsilon C I(y) d y
$$

onde, $\epsilon$, é uma constante de proporcionalidade chamada coeficiente de absorção molar, que depende apenas da molécula absorvedora e, $C$, refere-se à concentração dessas moléculas na amostra.

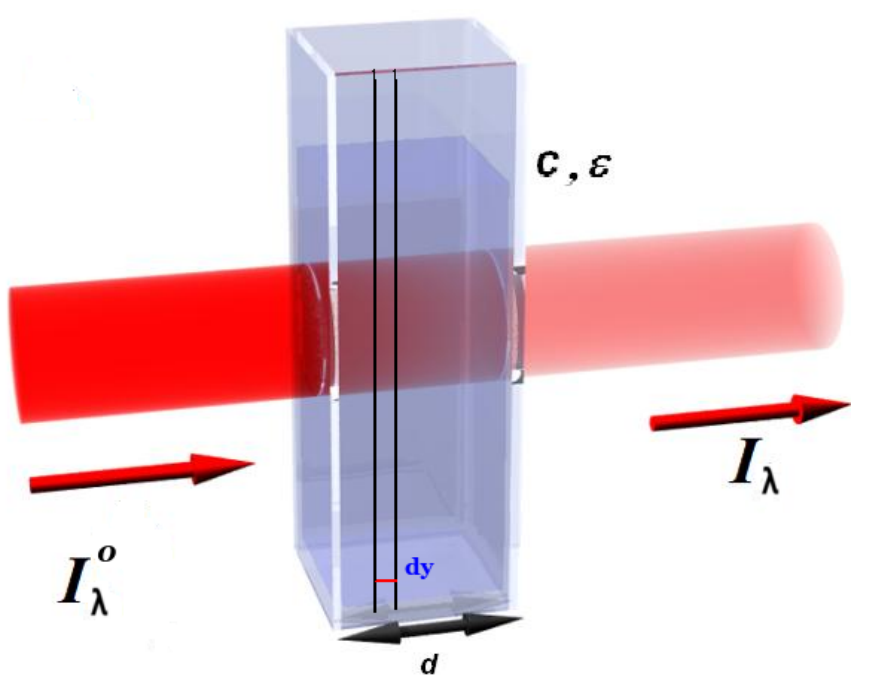

Figura 16: Ilustração da atenuação da luz incidente no recipiente de caminho ótico d.

Integrando a equação (2.34) para toda a extensão da amostra, o lado esquerdo de, 
$I_{\Lambda}$, até, $I_{\lambda}^{0}$, visto que, $I_{\Lambda} \leq I_{\lambda}^{0}$, e o lado direito de, 0 a $d$, encontramos,

$$
\ln \left(\frac{I_{\lambda}^{0}}{I_{\Lambda}}\right)=\epsilon C d
$$

Define-se, a absorbância, $A(\lambda)$, como ,

$$
A(\lambda)=\log \left(\frac{I_{\lambda}^{0}}{I_{\Lambda}}\right)
$$

e convertendo para o logaritmo na base 10, a equação (2.35), temos:

$$
A(\lambda)=\left(\frac{\epsilon}{\log 10}\right) \cdot C d=\epsilon^{\bullet} \cdot C d
$$

portanto, encontra-se a absorbância como,

$$
A(\lambda)=\log \left(\frac{I_{\lambda}^{0}}{I_{\Lambda}}\right)=\epsilon^{\bullet} . C d
$$

onde, $\epsilon^{\bullet}$, é novamente o coeficiente de absorção molar (em, $\left.L . m o l^{-1} . \mathrm{cm}^{-1}\right), C$ é a concentração (em, mol. $\left.L^{-1}\right)$ de especies absorvedoras e, $d$, (em $\mathrm{cm}$ ) é o caminho óptico por onde a luz foi absorvida, ou seja, a espessura da amostra (Cantor et al., 1980).

\subsection{Fluorescência Estática}

Como descrito na seção anterior, na absorção de luz a energia absorvida promove transições eletrônicas do estado fundamental para estados exitados de maior energia. Os eletrons da molécula, que passam a popular os estados excitados, relaxam para o primeiro estado excitado e, a partir deste, decaem ao estado fundamental. Quando esse decaimento ocorre com a emissão de fótons, temos o fenômeno conhecido por luminescência.

O fenômeno de luminescência é dividido em duas categorias, fluorescência e fosforescência, dependendo do estado excitado. Na fluorescência ou estado excitado singleto, o elétron excitado apresenta spin oposto a um segundo elétron que está no estado fundamental. Consequentemente, retornar ao estado fundamental é muito rápido e pode ocorrer com a emissão de um fóton. As taxas de emissão da fluorescência são da ordem de, $10^{9} \mathrm{~s}^{-1}$ - A fosforescência é a emissão de luz do estado excitado tripleto, no qual o elétron excitado tem a mesma orientação de spin que o elétron do estado fundamental. As transições para 
o estado fundamental são proibidas em primeira ordem e as taxas de emissão são muito lentas (em torno de $10^{3}$ até $1 \mathrm{~s}^{-1}$ ), então o tempo de vida da fosforescência é da ordem de milisegundos a segundos.

O diagrama de Perrin-Jabloski, Figura 17.a, é uma maneira de visualizar esses processos.

Os estados eletrônicos singletos são chamados de $S_{0}$ (estado fundamental), $S_{1}, S_{2}$, ... e os estados tripletos são chamados de $T_{1}, T_{2}$, e os níveis vibracionais, associados a cada estado, são representados pelas linhas finas. O decaimento de elétrons em estados exitados de ordens maiores, para o primeiro estado exitado, $S_{1}$, é denominado, conversão interna (IC), e em geral, é um processo não radiativo. O cruzamento entre sistemas (ISC) ocorre quando o elétron passa de um estado singleto para um estado tripleto, de forma não radiativa.

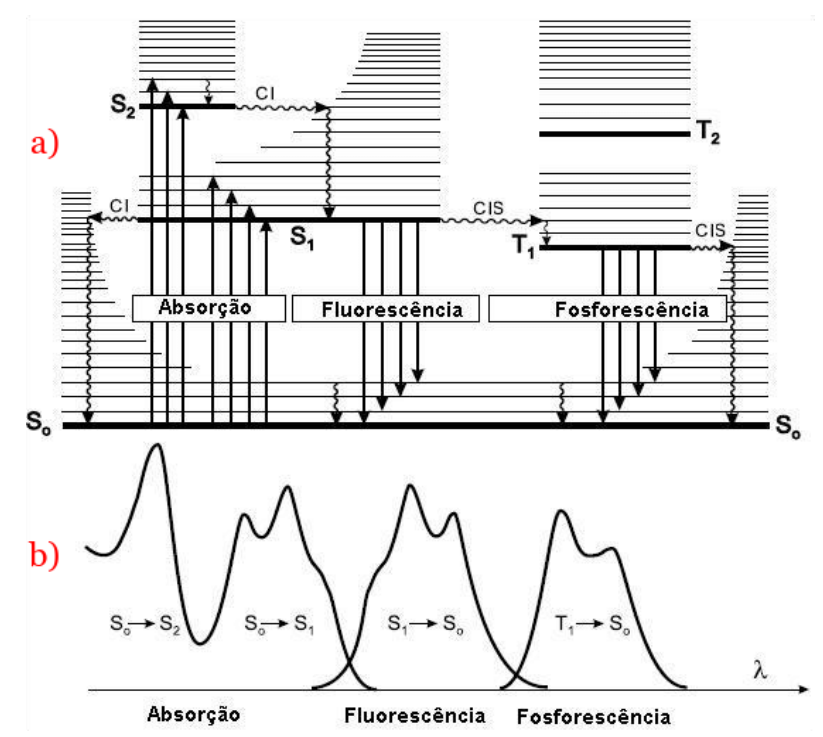

Figura 17: Diagrama de Perrin-Jablonski e a ilustração da posição relativa dos espectros de absorção, fluorescência e fosforescência, onde IC (Internal Conversion) significa conversão interna e ISC (InerSystem Crossing) significa cruzamento de sistemas. Figura baseada no texto Moreira, 2009 (original de Valeur, 2001).

\subsubsection{Deslocamento de Stokes}

Em soluções, Stokes observou que o espectro de emissão fluorecente ocorre sempre em comprimentos de onda maiores do que a absorção eletrônica, ou seja em energias menores, considerando absorção de um único fóton (Figura 17.b). Essa regra, denominada deslocamento de Stokes (Stokes, 1852) é verdadeira pois a molécula absorvedora sempre 
perde energia no estado excitado devido à relaxação vibracional (IC), mesmo sem considerar a interação com o solvente, ou seja, a molécula isolada. O efeito do solvente pode modificar o deslocamento de Stokes.

\subsubsection{Efeito do solvente}

A polaridade do meio que circunda um fluoróforo, influencia o espectro de emissão fluorescente, isto é observado pelas diferentes posições espectrais das bandas de emissão, em diferentes solventes. Os efeitos dos solventes nos espectros de fluorescência podem ser separados em efeitos gerais e efeitos específicos.

Os efeitos específicos se referem às interações envolvendo as estruturas eletrônicas das moléculas do solvente e do fluoróforo, que levam à formação de pontes de hidrogênio ou formação de complexos. Entretanto, os efeitos gerais resultam das interações entre os momentos de dipolo do fluoróforo e do solvente, e sua descrição da dependência do espectro de emissão com o solvente é dada pela equação de Lippert-Mataga (equação 2.39) (Lippert, 1955; Mataga et al., 1956).

Nessa teoria, supõe-se que o fluoróforo no seu estado fundamental apresenta um momento de dipolo dado por, $\mu_{G}$, num meio homogêneo e de constante dielétrica uniforme (Figura 18). Quando este fluoróforo absorve um fóton e muda para o estado exitado, seu momento de dipolo passa a ser, $\mu_{E}$.

Há então, um rearranjo eletrônico, muito rápido, da ordem de $10^{-15} \mathrm{~s}$, assim como um rearranjo molecular do solvente com o fluoróforo no estado exitado, da ordem de $10^{-9}$ s. Esse rearranjo tem um custo energético não radiativo, por isso, a relaxação com o solvente diminui a energia do fóton emitido. Após a emissão fluorescente, o momento de dipolo da molécula volta à, $\mu_{G}$, e há um novo rearranjo molecular do solvente até a molécula voltar completamente ao estado fundamental.

O deslocamento de Stokes vem da diferença entre a energia da radiação absorvida e da radiação emitida, $h \nu_{a b}-h \nu_{e m}$,

$$
h \nu_{a b}-h \nu_{e m}=\frac{2 \Delta f}{h c a^{3}}\left(\mu_{E}-\mu_{G}\right)^{2}+\text { constante }
$$

onde, $\Delta f$, é a função de polarizabilidade orientacional do solvente (dependente do índice de refração, $n$, e da constante dielétrica do solvente, $\epsilon$ ), $a$, é o raio da cavidade do 


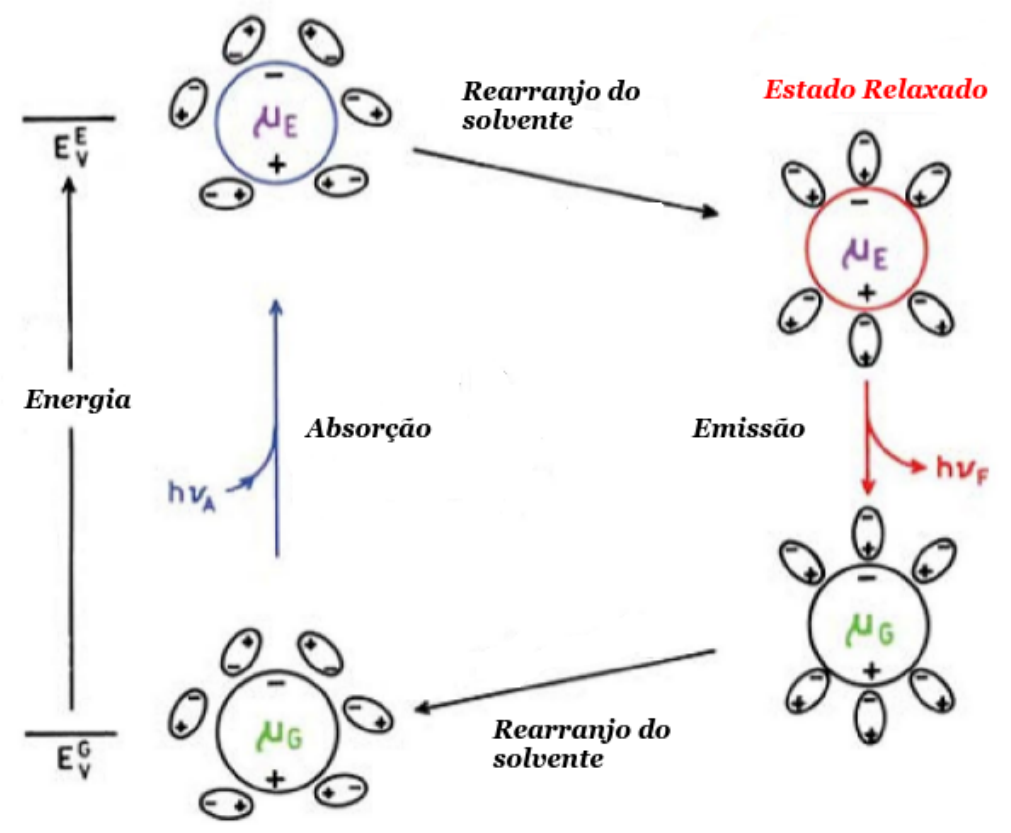

Figura 18: Ilustração do modelo de Lippert, de campos elétricos de reação em interação com dipolos da molécula no estado fundamental, $\mu_{G}$, e no estado exitado, $\mu_{E}$. Figura extraída de Lakowicz, 2006 (modificada).

fluoróforo e , c, a velocidade da luz. A equação descreve o deslocamento de Stokes através da variação do momento dipolar da molécula e das características do solvente, como constante dielétrica $(\epsilon)$ e índice de refração $(n)$.

Esse modelo é muito útil para entender deslocamentos nos espectros de emissão fluorescente, pois quanto maior a relaxação da molécula com o meio, menor será a energia do fóton emitido e, consequentemente, o espectro de emissão será observado em altos comprimentos de onda (deslocamento para o vermelho). Por sua vez, menores relaxações da molécula com o meio, levam a maiores diferenças de energias entre o estado excitado e o estado fundamental, ou seja, maior será a energia do fóton emitido, então o espectro de emissão será observado em baixos comprimentos de onda (deslocamento para o azul).

\subsubsection{Correção dos espectros de fluorescência}

A seguir descreveremos brevemente as correções de filtro interno aplicadas aos espectros de emissão, a fim de obter valores mais precisos para a intensidade de fluorescência e a posição espectral.

Os efeitos de filtros internos são observados e estudados há muito tempo. Conforme reportado por (Luciani et al., 2009), concentrações elevadas de centros espalhadores ou 
mudanças nas propriedades estruturais desses centros pode levar ao aumento do espalhamento, resultando em uma diminuição da intensidade de fluorescência e na alteração do espectro de emissão.

O efeito ocorre devido à luz incidente ser parcialmente absorvida ou espalhada antes de chegar ao ponto onde a fluorescência é observada (efeito de filtro interno primário), outra parte significativa da luz emitida, também é reabsorvida antes desta sair da cubeta (efeito de filtro interno secundário), levando a um aparente decréscimo da intensidade de fluorescência.

Em geral, há dois métodos para reduzir o efeito de filtro interno: a diluição ou a correção matemática das intensidades. Este último método assume que todas as sondas fluorescentes emitem, aproximadamente, a mesma radiação que aquelas localizadas no centro da cubeta. Portanto, baseado-nos neste método, os espectros de emissão fluorescente do Laurdan foram corrigidas através da equação abaixo,

$$
F=F_{0} \cdot 10^{\left(A_{e x c} \cdot x\right)} \cdot 10^{\left(A_{e m i} \cdot y\right)}
$$

onde, $F_{0}$ e $F$ são as intensidades de fluorescência medida e corrigida; $A_{e x}$ e $A_{e m}$ são os valores de absorbância por unidade de caminho óptico nos comprimentos de onda da excitação e emissão. Neste trabalho a correção primária de filtro interno na excitação e a correção secundária de filtro interno na emissão foi considerado como, $x=0.5 \mathrm{~cm}$ e $y=0.1$ cm. Luciani e colaboradores (Luciani eta al., 2009) mostraram que a equação (2.40) apresenta resultados satisfatórios, mesmo desprezando a dimensão da região excitada.

\subsubsection{Anisotropia de fluorescência}

Muitas amostras, quando são excitadas por uma luz polarizada, emitem, também luz polarizada. O grau de polarização é descrito em termos da grandeza conhecida por anisotropia, r. As amostras com anisotropia diferente de zero são interpretadas como tendo uma emissão polarizada. Em uma solução homogênea, as sondas em seu estado fundamental se encontram orientados aleatoriamente. Quando estas são expostas à luz polarizada, as sondas, que apresentam seus momentos de transição de absorção orientados na mesma direção do vetor campo elétrico da luz incidente, são preferencialmente excitadas. Com isso, a população no estado excitado não é aleatoriamente orientada, 
pois há um número maior de sondas excitadas que possuem seus momentos de transição orientados na direção do vetor campo elétrico da luz polarizada.

A despolarização da luz emitida, pode ser causada por um grande número de fenômenos; o mais comum é a difusão rotacional. As medidas de anisotropia, revelam uma média da movimentação angular da sonda que ocorre entre a absorção, e a consequente emissão do fóton. A difusão rotacional depende da viscosidade do solvente e da dimensão da molécula, assim uma variação na viscosidade do solvente pode alterar a anisotropia de fluorescência.

Uma medida experimental de anisotropia é ilustrada na Figura 19. A amostra é excitada por um feixe de luz verticalmente polarizado (paralelo ao eixo z). Então, são registradas, as intensidades de emissão fluorescente com orientação paralela ao feixe incidente, $I_{/ /}$, e a intensidade de emissão com orientação perpendicular ao feixe incidente, $I_{\perp}$. As medidas são feitas com um polarizador acoplado antes do detector. Por fim, a anisotropia é calculada com uso da equação 2.41,

$$
r=\frac{I_{/ /}-I_{\perp}}{I_{/ /}+2 I_{\perp}}
$$

O valor calculado na equação 2.41 é adimensional e independente da intensidade total da amostra.

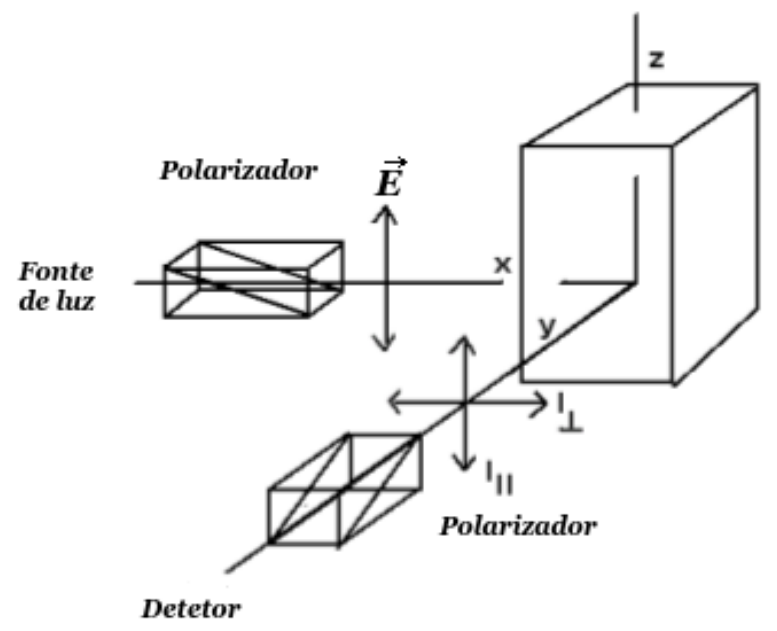

Figura 19: Diagrama esquemático para a medida de anisotropia de fluorescência. Adaptada de (Valeur, 2001).

Se analisarmos alguns casos para a anisotropia, teremos que, se a luz observada 
através de um polarizador de emissão é totalmente polarizada, então $I_{\perp}=0$ e $r=1.0$. Agora, se a emissão é completamente despolarizada, nesse caso $I_{/ /}=I_{\perp}$ e $r=0$. Maiores detalhes sabre esta técnica podem ser encontradas nas referências: (Lakowiscz, 2006; Valeur, 2001). 


\section{CAPÍTULO 3}

"Estamos en este mundo para convivir en armonia. Quienes lo saben no luchan entre sí

Gautama Buda 


\section{MATERIAIS E MÉTODOS}

Neste capítulo, serão descritos o preparo das amostras utilizadas e como as medidas foram realizadas. Também será descrita a sequência a qual as medidas foram realizadas através de controles de tempo após a incubação do arranjo.

\subsection{Materiais}

Lipídio: Brometo de dioctadecildimetilamônio (DODAB) 99\% puro foi adquirido da Avanti Polar Lipids Inc. (Birmingham, AL, USA). Oligonucleotídeo: 5-AAAAAAAAAA3 (ODN) foi adquirido de tecnologia DNA - IDT (Coraville, IA,USA). Sonda fluorescente: 2-dimetilamino-6-lauroilnaftaleno (Laurdan), foi adquirido da Molecular Probes Inc. (Eugene, OR, USA). Tampão: (4-(2-hidroxiwtil)-piperazim-1-etanosulfônico) (HEPES), adquiridos da Sigma-aldrich Chemical Co. Água ultrapura padrão Milli-Q (Milipore) e Clorofórmio padrão analítico foram usados em todos os experimentos. As estruturas químicas das moléculas primárias usadas são colocadas na figura 20.

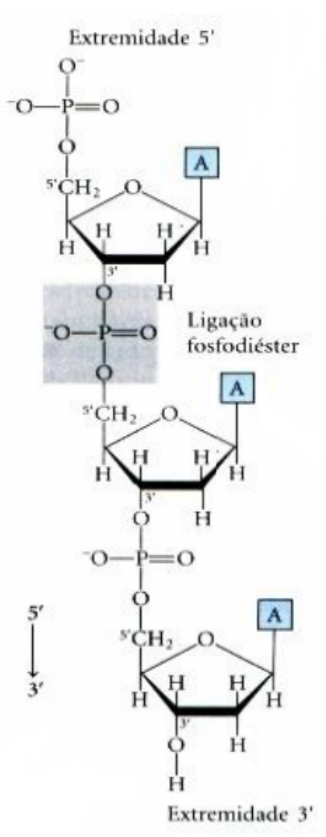

(a)

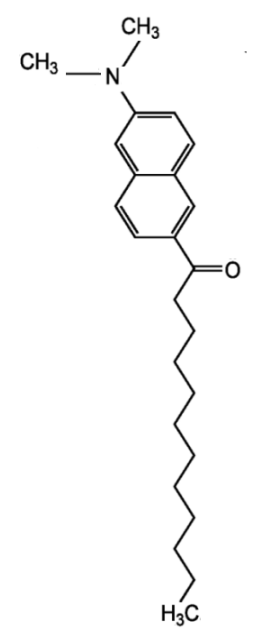

(b)

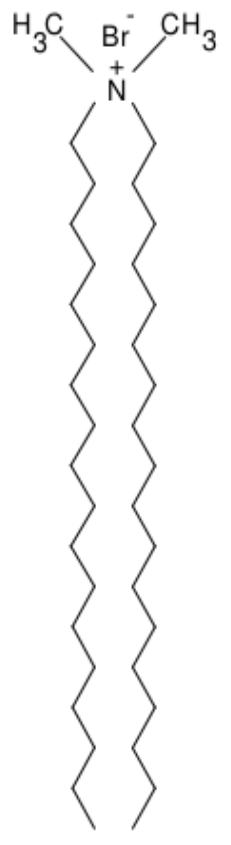

(c)

Figura 20: Moléculas utilizadas neste trabalho. (a) oligonucleotídeo, (b) sonda fluorescente Laurdan, e (c) lipídio DODAB. 


\subsection{Preparação das amostras}

\subsubsection{Preparação da dispersão lipídica}

O protocolo de preparo de vesículas unilamelares de DODAB, consiste em pesar o lipídio DODAB em pó para a obtenção da massa necessária, e em seguida solubilizar o lipídio em um volume de clorofórmio adequado para obter uma solução lipídio/clorofórmio visualmente transparente, ao mesmo tempo esta solução é vigorosamente agitada com agitador mecânico tipo Vortex, para garantir sua uniformidade. Uma solução estoque de sonda fluorescente em clorofórmio com concentração de $15.46 \mathrm{mM}$ foi usada. Dessa solução foi retirado o volume necessário para obter-se uma concentração de Laurdan de 0,01 $m M$ em um volume de $2 \mathrm{ml}$ de tampão. O volume retirado de Laurdan em clorofórmio foi misturado com a solução de lipídio/clorofórmio e foi agitada para garantir sua uniformidade. Em seguida, a solução foi evaporada sob fluxo de nitrogênio gasoso e simultaneamente sob agitação, formando um filme (DODAB+Laurdan) na parede do tubo de ensaio. Os filmes foram mantidos à baixa pressão por 3 horas, para que qualquer traço de solvente orgânico fosse removido. A solução de vesículas de DODAB em presença de Laurdan era preparada com a adição de tampão Hepes $(10 m M$ à $p H \approx 7.4)$ ao

filme lipídico e, posteriormente, intercalando por três vezes, ciclos de agitação mecânica e aquecimento em banho maria a $60^{\circ} \mathrm{C}$ de $\approx 6$ minutos, cada. Sendo a concentração final usada de $1 \mathrm{mM}$ de lipídio DODAB e $0.01 \mathrm{mM}$ de sonda Laurdan.

\subsubsection{Preparação da solução estoque do oligonucleotídeo}

Soluções estoque do oligonucleotídeo liofilizados foram preparadas através da solubilização em tampão Hepes. O método consiste na diluição do ODN com um volume adequado de tampão Hepes, a $60^{\circ} \mathrm{C}$, em seguida, aplica-se uma leve agitação com uma pipeta para ressuspender o ODN, retornando a solução ao aquecimento por 2 minutos, este processo se repete até remover totalmente o ODN do fundo do frasco. Sendo a concentração final da solução estoque de 11.9 mM de ODN em $100 \mu l$ de tampão. Em seguida, alíquotas desta solução estoque foram distribuídas em diferentes frascos, com as dosagens desejadas, considerando as proporções molares do lipídio/ODN. 


\subsection{Controles}

Nesta seção, apresentamos alguns controles específicos do nosso trabalho para o preparo do complexo DODAB/ODN, e a estabilidade deste em função do tempo. Definimos como controles, protocolos independentes, os quais serão utilizados para elaborar o melhor arranjo para uma correta obtenção dos dados experimentais. Desse modo, os resultados aqui apresentados estão diretamente ligados aos resultados que serão discutidos no capítulo 4.

\subsubsection{Vesículas extrusadas}

Para evitar a formação de vesículas multilamelares e uniformizar o tamanho das vesículas formadas, seguimos um protocolo de extrusão de todas as soluções de vesículas de DODAB com Laurdan. Para isso, utilizamos um extrusor "Home made" adaptado com peças da Avanti Polar Lipids, Inc, que nos permite passar as soluções de vesículas por um filtro de policarbonato com poros de diâmetro de $100 \mathrm{~nm}$ de forma completamente automizada. Esse processo é repetido 23 vezes a uma temperatura de $55{ }^{\circ} \mathrm{C}$ para formar vesículas unilamelares (LUVs) de tamanhos aproximados ao diâmetro dos poros do filtro.

Após a extrusão da solução de vesículas de DODAB com Laurdan, oito concentrações diferentes de ODN foram adicionadas às soluções lipídicas, formando assim, as seguintes amostras:

controle

DODAB +Laurdan.

Baixas concentrações de $O D N$

DODAB +Laurdan $+[0.00625 m M]$ ODN

DODAB +Laurdan $+[0.0125 m M]$ ODN

DODAB +Laurdan $+[0.025 m M]$ ODN

DODAB +Laurdan $+[0.05 m M]$ ODN 
DODAB +Laurdan $+[0.075 m M]$ ODN

DODAB +Laurdan $+[0.1 m M]$ ODN

DODAB +Laurdan $+[0.15 m M]$ ODN.

DODAB + Laurdan $+[0.2 m M]$ ODN

\subsubsection{Protocolo de Incubação vs Sequências de técnicas}

O protocolo utilizado, para o tempo de incubação de uma amostra do complexo DODAB/ODN, e o momento em que esta mesma amostra foi utilizada nas diferentes técnicas exposta é resumido a seguir:

- Após a adição de ODN nas dispersões lipídicas de DODAB, deixamos o complexo incubando por 30 minutos. Ao final deste período, registramos uma fotografia da amostra.

- Já com o complexo DODAB/ODN incubado, por 30 min realizamos a primeira medida usando a técnica de DLS,

- A segunda medida foi feita com a técnica do Potencial-zeta, após $~ 70$ minutos da incubação.

- A terceira medida foi feita com a técnica do DSC, após 110 minutos da incubação. Como essa técnica é muito demorada, uma alíquota da amostra foi reservada somente para esta medida.

- A quarta medida foi feita com as técnicas de absorção ótica e emissão fluorescente, após 130 minutos da incubação.

- A sexta medida foi feita com a técnica de anisotropia, após 190 minutos da incubação.

- Ao final da sexta medida, tiramos a segunda fotografia após 4 horas de incubação.

- A amostra, então, foi deixada incubando por 7 dias à temperatura ambiente. Após este período, realizamos uma medida com a técnica de DLS e em seguida tiramos a última fotografia da amostra. 
As medidas com a técnica de espalhamento de raios-X a baixos ângulos (SAXS), não fez parte deste protocolo, já que ela foi realizada em ocasião especial. No entanto, estas medidas foram feitas após $3 h$ de incubação do complexo DODAB/ODN.

\subsection{Métodos Experimentais}

\subsubsection{Espalhamento de Luz Dinâmico}

As medidas de espalhamento de luz dinâmico (DLS) foram realizadas no equipamento Zetasizer Malvern, modelo Nano - ZS $S^{90}$, Worcestershire, UK, do Laboratório de BioMembranas, IFUSP. A cubeta de quartzo de caminho ótico $10 \mathrm{~mm}$, desenhada para esse equipamento, foi preenchida com um volume de $1 \mathrm{~mL}$ da dispersão lipídica de DODAB $(1 \mathrm{mM})$ mais o Laurdan $(0.01 \mathrm{mM})$, na ausência ou presença de ODN.

As medidas foram realizadas com um ângulo fixo de $90^{\circ}$, a uma temperatura fixa de $20^{\circ} \mathrm{C}$. A função de auto-correlação da intensidade da luz espalhada, $g^{(2)}(\tau)$, da equação 2.5 (seção 2.1) foi diretamente obtida pelo correlator da Malvern.

A função de auto- correlação do campo elétrico, $g^{(1)}(\tau)$, foi analisada pelo método dos cumulantes de segunda ordem (Koppel,1975), equação 2.16 (seção 2.1).

O coeficiente de difusão translacional, $D$, foi obtido pelo programa de aquisição, com o uso da equação 2.14, $\left(\Gamma=D q^{2}\right)$.

Por fim, a dimensão dos centros espalhadores pode ser obtida em termos de um raio efetivo, com a relação de Stokes-Einstein (equação 2.3).

\subsubsection{Potencial - zeta}

As medidas do potencial-zeta foram realizadas no equipamento Zetasizer Malvern modelo Nano - Z $S^{90}$, Worcestershire, UK, do Laboratório de BioMembranas, IFUSP. A cubeta de plástico, modelo Folded Capillary-DTS1060 desenhada para esse equipamento, foi preenchida com um volume de $600 \mu L$ da dispersão lipídica de DODAB (1mM) mais o Laurdan (0.01 $m M)$, na ausência ou presença de ODN.

As medidas foram realizadas com um comprimento de onda de $633 \mathrm{~nm}$, com um ângulo de detecção fixo a $17^{\circ}$ e temperatura fixa a $20^{\circ} \mathrm{C}$.

Como mencionado na seção 2.2, a mobilidade eletroforética, $\mu$, das partículas que 
se movimentam num campo elétrico, foi diretamente coletada pelo equipamento atravès da mudança de frequência da luz laser espalhada. Conhecendo-se a mobilidade eletroforética, $\mu$, foi possível calcular o potencial de superfície junto ao plano de cisalhamento da partícula, também chamado de potencial-zeta $(\zeta)$. Para isso, usa-se a aproximação de Smoluchowski ( equação 2.20).

\subsubsection{Espalhamento de raios-X a baixo ângulo}

As medidas de espalhamento de raios-X a baixos ângulos (SAXS) foram realizadas usando o equipamento Xenocs modelo Xeuss ${ }^{T M}$, do Laboratório de Fluidos Complexos, IFUSP. As medidas foram cordialmente realizadas pelo estudante de doutorado Msc. Pedro L.O. Filho sob a supervição do prof.Dr Cristiano L.P de Oliveira. As amostras foram mantidas em capilares de quartzo reutilizável com diâmetro médio de $1.5 \mathrm{~mm}$.

As distâncias de repetição, $d$, foram calculadas usando a distância de repetição para estruturas lamelares, $d=\frac{2 \pi}{q}$, onde, o intervalo efetivo do módulo do vetor de espalhamento, $d=\frac{4 \pi}{\lambda} \sin (\theta)$, experimentalmente, foi $0.001-0.45 \AA^{-1}$. As medidas foram feitas em duas temperaturas: $30{ }^{\circ} \mathrm{C}$ e $60{ }^{\circ} \mathrm{C}$, controladas com o auxílio de um banho térmico acoplado ao porta amostras $\left(\mathrm{Julabo}^{T M}\right)$.

As intensidades da radiação espalhada em função do módulo do vetor de espalhamento, $q$, foram obtidas e corrigidas usando o espalhamento de fundo, capilar vazio e transmissão da amostra, passando pela posterior normalização para escala absoluta usando como padrão a água. Para o tratamento dos dados utilizou-se o pacote SUPERSAXS (Oliveira e Pedersen, 2009).

\subsubsection{Calorimetria diferencial de varredura}

As medidas de calorimetria (DSC) foram realizadas em um microcalorímetro da Microcal, modelo VP-DSC, Northamptom, MA, EUA, do Laboratório de BioMembranas, IFUSP. A amostra foi, inicialmente, submetida a um ciclo de aquecimento rápido de 90 ${ }^{\circ} C / h$ e então resfriada. Após a estabilização da temperatura, realizamos 4 varreduras a $20{ }^{\circ} \mathrm{C} / \mathrm{h}$, intercalando aquecimento e resfriamento num intervalo de temperatura de 20 a $60{ }^{\circ} \mathrm{C}$. A cela da amostra, com um volume de $500 \mu \mathrm{L}$, foi preenchida com a dispersão lipídica e usando a concentração de ODN desejada. A cela de referência foi preenchida com o tampão Hepes (10 mM-pH =7.44). As análises dos dados de DSC foram realizadas 
utilizando o programa Microcal Origin V7.0, o qual possui um módulo adicional de DSC desenvolvido pela própria Microcal para esse tratamento.

Na Figura 21, observa-se a sequência de tratamentos nos dados de um termograma típico. A análise é feita normalizando a curva pela taxa de aquecimento/resfriamento e subtraindo a linha de base do tampão (a) em seguida, normalizada pela concentração da dispersão lipídica que foi de $1 \mathrm{mM}$ (b). Feito isso, utilizando o software cria-se uma linha de base ligando dois segmentos através de um polinômio de ordem três, linha vermelha (Riske et al., 2009) (c), para, ao final, ser subtraída da curva original (d) resultando na curva corrigida de DSC, conforme podemos observar na Figura 21.

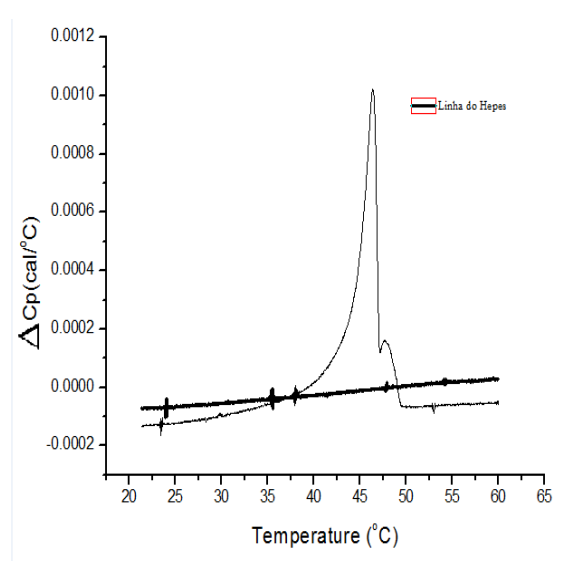

(a)

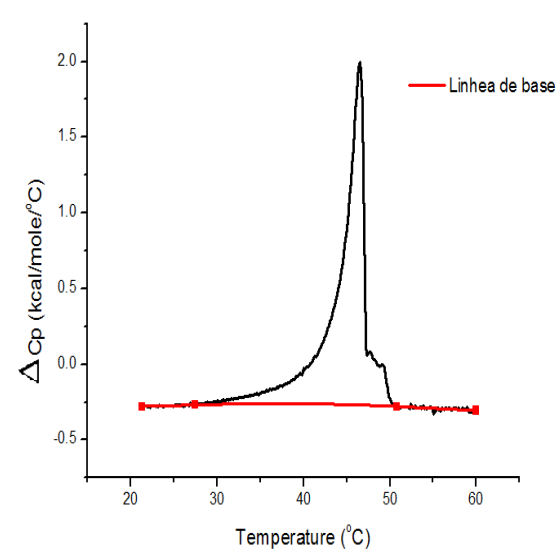

(c)

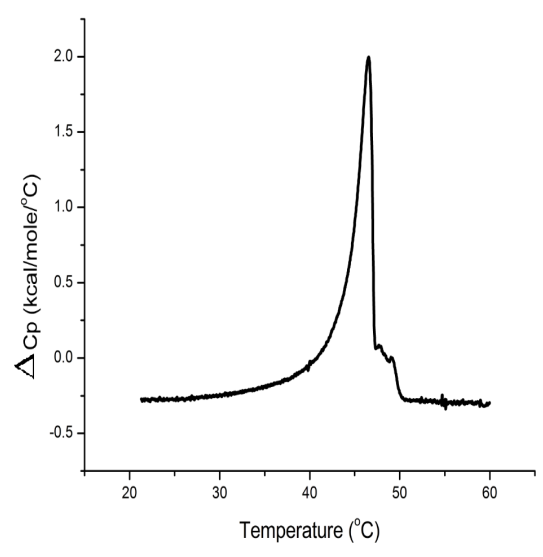

(b)

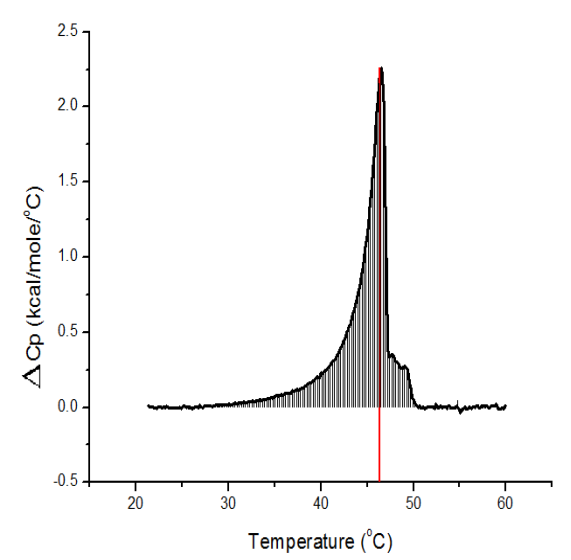

(d)

Figura 21: Tratamento dos dados de um experimento de DSC para $1 \mathrm{mM}$ de vesículas extrusadas de DODAB em presença de ODN. (a) Normalização a uma taxa de aquecimento/resfriamento de $20^{\circ} \mathrm{C} / \mathrm{h}$. e subtração da linha de base do tampão. (b) Normalização pela concentração do lípido. (c) Criação da linha de base. (d) Curva de DSC final após a subtração da linha de base da curva.

Após os tratamentos mencionados, integrando-se a área sob a curva, obtemos: a variação da entalpia $(\Delta H)$, a largura a meia altura do pico que esta diretamente relaci- 
onada à cooperatividade entre as moléculas lipídicas $\left(\Delta T_{1 / 2}\right)$, e a posição de máximo do pico, indicada com uma linha tracejada corresponde à temperatura de transição de fase gel-fluido $\left(T_{m}\right)$.

Os perfis calorimétricos que serão mostrados na seção 4.2, representam curvas típicas obtidas. Pelo menos três medidas foram realizadas para cada amostra.

\subsubsection{Absorção óptica do Laurdan}

As medidas de absorção do Laurdan foram realizadas com o uso de um espectrofotômetro, marca Varian, modelo Cary 50, Santa Clara, CA, EUA, do Laboratório de BioMembranas, IFUSP. As amostras contendo $500 \mu L$ de dispersão lipídica foram colocadas em uma cubeta de quartzo $(0.2 \times 1.0 \mathrm{~cm})$ com caminho ótico de $0.2 \mathrm{~cm}$. As medidas foram realizadas com controle de temperatura do tipo Peltier thermostatte, instalado no próprio aparelho, com precisão de $\pm 0.1{ }^{\circ} \mathrm{C}$. Medimos a absorbância das vesículas de DODAB com Laurdan em presença e ausência de ODN, com comprimento de onda de luz incidente variando de 200 a $800 \mathrm{~nm}$ e temperaturas entre 20 e $60{ }^{\circ} \mathrm{C}$, variando em intervalos de $10^{\circ} \mathrm{C}$.

Em todas as medidas, o espectro do tampão Hepes foi subtraído da medida com DODAB/ODN e Laurdan, para eliminar a absorbância do Hepes e da cubeta. Esse tratamento matemático foi realizado usando o programa Origin V7.0 e foi analisado da seguinte maneira:

- Medimos o espectro do tampão puro, nas mesmas temperaturas que as amostras lipídicas, para obtermos a curva do solvente com a cubeta de quartzo (linha Preta, Figura 22.a).

- Mediamos o espectro da sonda Laurdan inserida no DODAB/ODN em tampão na mesma cubeta de quartzo (linha vermelha, Figura 22.a ).

- Subtraímos o espectro do tampão puro do espectro da sonda Laurdan inserido no DODAB/ODN mais tampão e obtínhamos apenas o espectro do Laurdan inserido no DODAB/ODN, naquele solvente (linha vermelha, Figura 22.b ). 


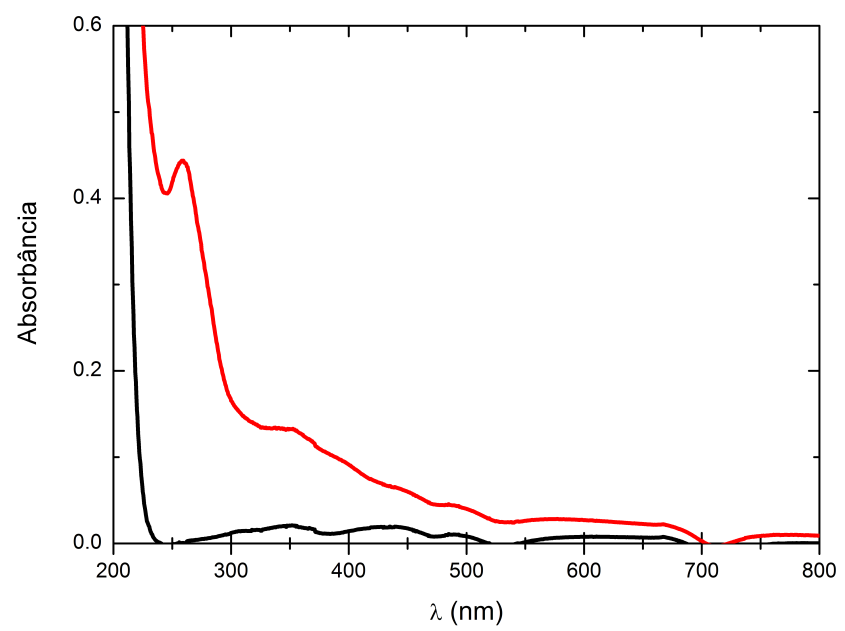

(a)

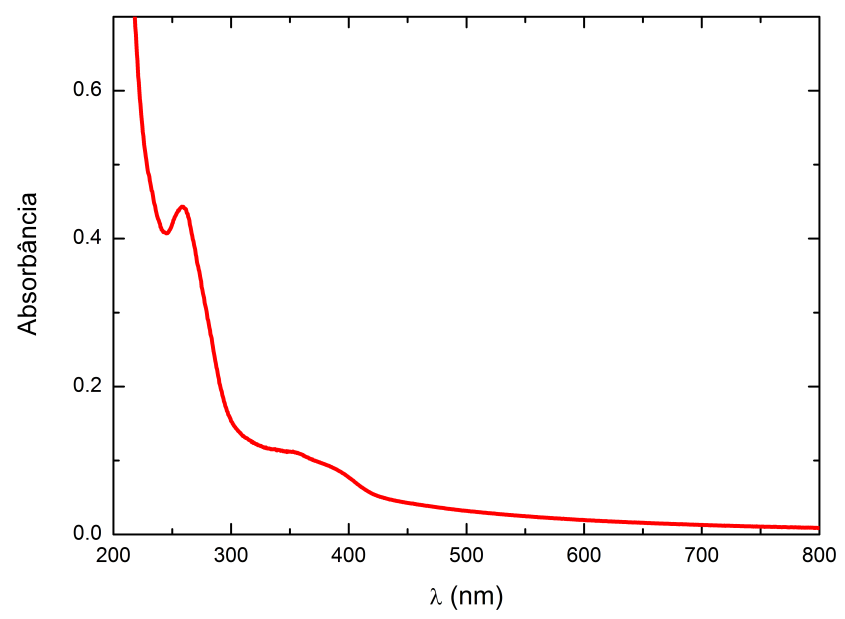

(b)

Figura 22: Demostração da análise do espectro de absorção do Laurdan inserido no complexo DODAB/ODN. (a) Espectros medidos para o tampão puro (linha preta) e para Laurdan inserido no DODAB/ODN (linha vermelha). (b) Espectro do Laurdan inserido no DODAB/ODN já subtraído do tampão, espectro final.

\subsubsection{Fluorescência estática e Anisotropia de Laurdan}

Espectros de emissão fluorescente do Laurdan foram obtidos no espectrômetro de fluorescência, marca Varian, modelo Cary Eclipse, Santa Clara, CA,EUA, existente no Laboratório de BioMembranas, IFUSP. As amostras contendo $500 \mu L$ de dispersão lipídica são colocadas em uma cubeta de quartzo $(0.2 \times 1.0 \mathrm{~cm})$ com caminho ótico de incidência de luz de $1.0 \mathrm{~cm}$ e um caminho ótico de detecção de $0.1 \mathrm{~cm}$. As medidas de fluorescência 
do Laurdan inserido nas vesículas de DODAB na ausência e presença de ODN, foram realizadas a um comprimento de onda de excitação de $350 \mathrm{~nm}$, nas temperaturas de T $=20,30,40,50$ e $60^{\circ} \mathrm{C}$. A temperatura foi controlada com uso de um termostato tipo Peltier.

Além disso, conforme descrito na seção 2.6, medidas de anisotropia de fluorescência do Laurdan, foram feitas utilizando-se o mesmo comprimento de onda de excitação mencionado, em três comprimentos de onda de emissão diferentes ( 370, 380 e $390 \mathrm{~nm}$ ).

Na Figura 23, podemos ver os espectros de absorção do Laurdan incoporado em vesículas de DODAB. A figura mostra que a sucessiva adição de ODN na dispersão lipídica de DODAB leva ao aumento do espalhamento da dispersão e do aumento de suas bandas de absorção..

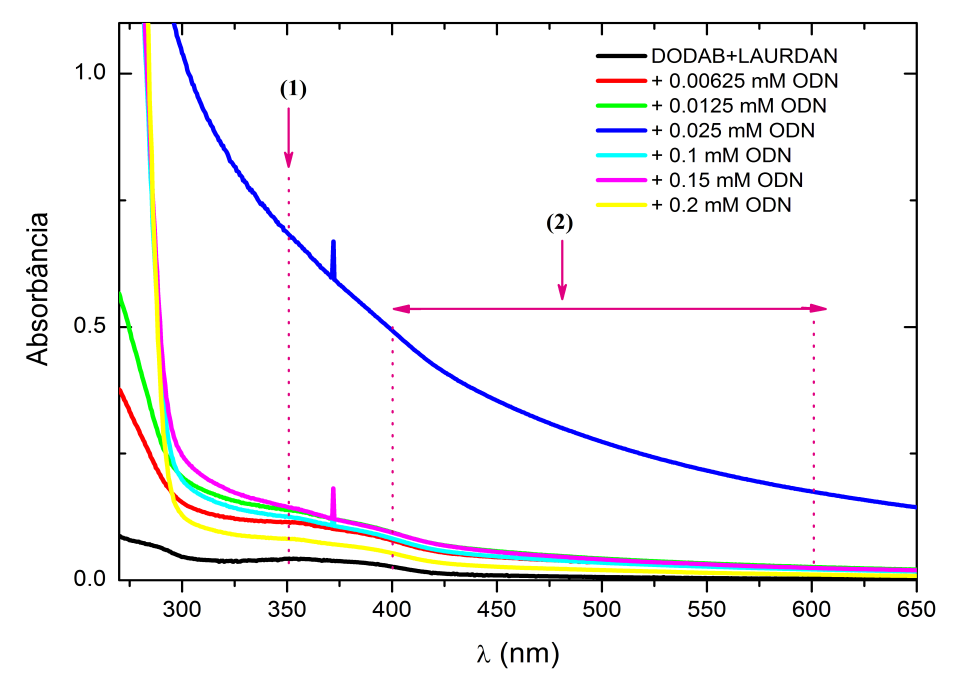

Figura 23: Espectro de absorção do Laurdan incorporado en vesículas de DODAB em presença e ausencia de ODN. As setas apontam a excitação (1) e a região de emissão do Laurdan (2).

Portanto, ressaltamos a importância de fazer a correções dos espectros de fluorescência do Laurdan pelo efeito de filtro interno (Inner filter efects) (Larsson et al., 2006; Luciani et al., 2009). As setas apontadas no gráfico da Figura 23, ilustram os valores a serem considerados na correção de filtro interno para espectroscopia de fluorescência $\lambda_{e x}=350 \mathrm{~nm}$ e $\lambda_{e m}=400-600 \mathrm{~nm}$.

Nos resultados de emissão fluorescente do Laurdan, seção 4.3.2, optamos em mostrar os espectros normalizados pela amplitude de cada espectro do Laurdan em DODAB 
na ausência e presença de ODN.

\subsubsection{Reprodutibilidade dos experimentos}

Todas as medidas discutidas nesta dissertação de mestrado foram reproduzidas três vezes ou mais. As incertezas experimentais apresentada nos gráficos em todas as figuras do capítulo 4, foram estimadas de acordo com o desvio padrão das amostras e foi calculado pela fórmula:

$$
\sigma=\frac{1}{\sqrt{n}} \sqrt{\frac{1}{(n-1)} \sum_{i=1}^{n}\left(x_{i}-\bar{x}\right)^{2}}
$$

onde $n$ é o número de medidas, $x$ é o valor de uma dada medida e $\bar{x}$ é a média de $n$ medidas de $x\left(\bar{x}=\frac{1}{n} \sum_{i=1}^{n} x_{i}\right)$. 


\section{CAPÍTULO 4}

"No escuchar, ver o decir lo que te lleve a hecer malas acciones" Nikko Tosho-gu 


\section{RESULTADOS}

Neste capítulo apresentamos os resultados obtidos nesta dissertação, e as discussões sobre os mesmos. Este foi divido em três partes: na primeira, analisamos o efeito do oligonucleotídeo (ODN) sobre a estabilidade coloidal das vesículas de DODAB, que são em seguida caracterizadas (seção 4.1); na segunda parte, analisamos o efeito do ODN sobre a transição de fase das bicamadas de DODAB (seção 4.2). Finalmente, na terceira parte, verificamos a sensibilidade da sonda Laurdan em monitorar alterações na superfície das vesículas de DODAB, causadas pelo ODN (seção 4.3).

\subsection{Efeito do ODN sobre as vesículas de DODAB}

\subsubsection{Estabilidade coloidal}

A estabilidade coloidal das vesículas extrusadas de DODAB em presença de ODN foi investigada através de imagens de turbidez a olho nu. A Figura 24 mostra fotografias das dispersões de DODAB e DODAB/ODN nas cubetas para medidas espectroscópicas, após manter as dispersões incubadas por 30 minutos a $20^{\circ} \mathrm{C}$, como detalhado na seção 3.3.2.

A Fig. 24.A, refere-se ao arranjo de DODAB sem ODN. As fotografias seguintes correspondem às oito concentrações de ODN estudadas; onde a Fig. 24.B, mostra o arranjo a baixas concentrações e a Fig. 24.C, mostra a altas concentrações.

Da Figura 24, podemos ver que em presença de material genético, a turbidez aumenta com a adição de baixas concentrações de ODN (Fig. 24.B) até atingir um máximo de turbidez, na presença de $0.05 \mathrm{mM}$. Este resultado sugere que em concentrações baixas o oligonucleotídeo é capaz de gerar atração entre as vesículas de DODAB, mudando a estabilidade coloidal do arranjo para um sistema que apresenta agregação.

Com a adição de concentrações altas de ODN no arranjo de DODAB (Fig. 24.C), o complexo mostrou uma reversão da turbidez, apresentando uma redução na turbidez para $0.15 m M$ e $0.2 m M$ de ODN, as maiores concentrações estudadas. Este resultado, sugere 


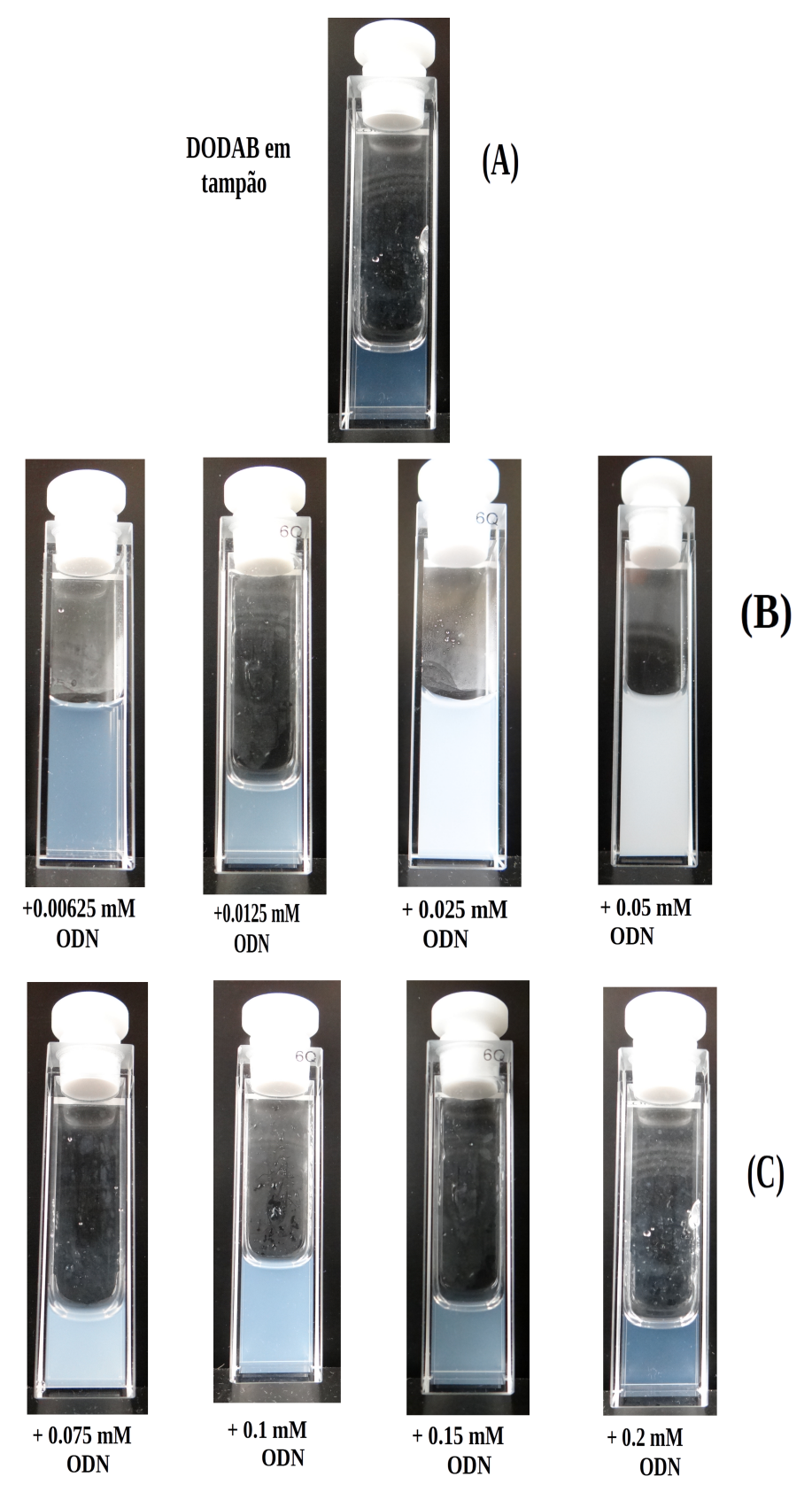

Figura 24: Avaliação da turbidez para $1 \mathrm{mM}$ de vesículas extrusadas de DODAB em presença de ODN, após 30 minutos de incubação a T: $20^{\circ} \mathrm{C}$.

que em concentrações superiores a $0.075 \mathrm{mM}$ o oligonucleotídeo é capaz de gerar repulsão entre as vesículas de DODAB, reestabelecendo a estabilidade coloidal do sistema. No entanto, a repulsão entre as vesículas de DODAB em solução não garante a estabilidade do sistema, pois, na prática, o complexo pode agregar com o passar do tempo ou com mudanças na temperatura da dispersão DODAB/ODN.

Como descrito na seção 3.3.2, foram obtidas fotografias das amostras após mantêlas incubando por outros 2 períodos: por 4 horas e por 7 dias. Devido à grande semelhança 
entre as imagens, serão mostradas apenas estas ultimas. Na Figura 25, podemos observar as fotografias das dispersões DODAB/ODN nas cubetas espectroscópicas, obtidas após um ciclo de aquecimento de $60^{\circ} \mathrm{C}$ por $5 \mathrm{~min}$, e, então, resfriamento a $20^{\circ} \mathrm{C}$, imediatamente antes de iniciar a seção de fotos a $20^{\circ} \mathrm{C}$.
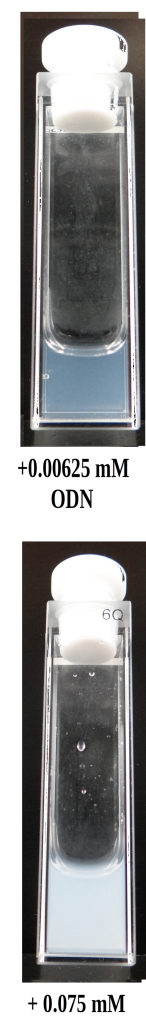

ODN
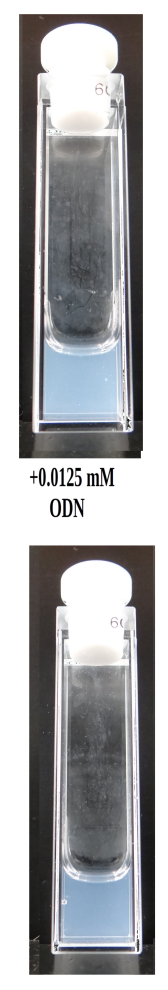

$+0.1 \mathrm{mM}$
ODN

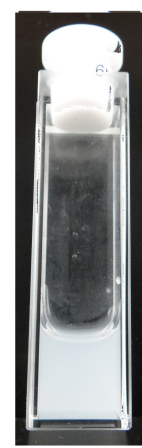

$+0.025 \mathrm{mM}$ ODN

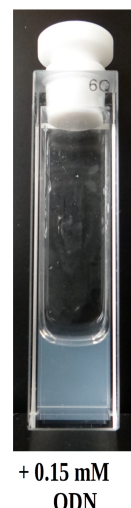

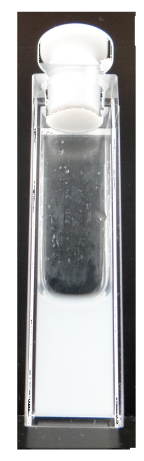

(A) ODN

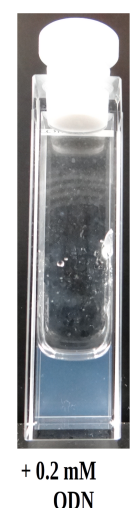

(B)

Figura 25: Avaliação da turbidez para $1 \mathrm{mM}$ de vesículas extrusadas de DODAB em presença de ODN, após 7 dias de incubação.

Da Figura 25, podemos ver que as amostras sob estas condições de tempo e temperatura mencionadas, apresentaram o mesmo comportamento na turbidez observado na Figura 24. A baixas concentrações de ODN (Fig 25.A) a turbidez aumenta até a presença de $0.05 \mathrm{mM}$, e a altas concentrações de ODN (Fig 25.B), o complexo mostrou uma reversão na turbidez, até atingir um mínimo na presença de $0.2 \mathrm{mM}$ de oligonucleotídeo. O aumento e a diminuição na turbidez observada com adição do ODN devem estar relacionados com a blindagem das cargas positivas da superfície externa da vesícula pelo oligonucleotídeo, e o aparecimento de cargas negativas devido à presença de ODN ( Weisman et al., 2004).

Além disso, na Figura 25.B, podemos ver, que a amostra na concentração de 0.075 $m M$ de ODN apresenta uma mudança na turbidez a respeito da turbidez mostrada na 
Figura 24.C para a mesma concentração do ODN.

Estes resultados mostram que a adição de ODN na dispersão lipídica de DODAB, nos intervalos entre $0.00625 \mathrm{~m} M-0.0125 \mathrm{mM}$ e $0.1 \mathrm{mM}-0.2 \mathrm{mM}$, apresentam um aumento e diminuição de turbidez respectivamente, que se mantêm estável com o passar do tempo e com mudanças na temperatura. Entretanto, o intervalo entre $0.025 \mathrm{mM}$ $0.075 \mathrm{mM}$, é uma região, onde a dispersão é instável coloidalmente, sob estas condições de tempo e temperatura.

\subsubsection{Caracterizações das vesículas de DODAB}

O objetivo de o estudo a seguir é caracterizar as vesículas de DODAB na ausência e presença de diferentes concentrações de ODN. A caracterização dos arranjos foi realizada através de ensaios de espalhamento de luz dinâmico (DLS), para a determinação do diâmetro médio, $d_{Z}$, e medidas de mobilidade eletroforética, para obtenção do potencialzeta $(\zeta)$, à temperatura de $20^{\circ} \mathrm{C}$. É importante mencionar que a caracterização do arranjo a $60^{\circ} \mathrm{C}$, não foi possível realizar por problemas de aquecimento na cubeta de plástico para a técnica de potencial-zeta.

A caracterização também foi feita com ensaios de espalhamento de raios-X a baixos ângulos (SAXS), nas temperaturas de $20^{\circ} \mathrm{C}$ e $60^{\circ} \mathrm{C}$.

\subsubsection{Espalhamento de luz Dinâmico e Potencial- zeta}

As medidas experimentais do diâmetro médio e potencial-zeta mostradas na Figura 26 foram obtidas a partir do lipídio puro de DODAB e em presença de ODN, após 30 e 70 minutos de incubação, respectivamente, para cada técnica (ver a seção 3.3.2).

Da Figura (26.a), podemos ver que, com a adição de baixas concentrações de ODN no arranjo de DODAB, os diâmetros médios aumentam até atingir um máximo em $420 \pm$ $50 \mathrm{~nm}$ na presença de $0.05 \mathrm{mM}$ ODN (Tabela 1). Além disso, observa-se ( Figura 26.b ) que esse aumento de diâmetro é acompanhado por uma pequena diminuição do potencial zeta na presença de $0.05 \mathrm{mM}$ ODN (Tabela 1).

Esses resultados mostram que a sucessiva adição de carga negativa ao arranjo é capaz de blindar parte das cabeças positivas da superfície externa da vesícula de DODAB. No caso do diâmetro médio, a blindagem de carga contribui para que a interação vesículavesícula, inicialmente fortemente repulsivas, mudasse para menor repulsão. Isto permite o 


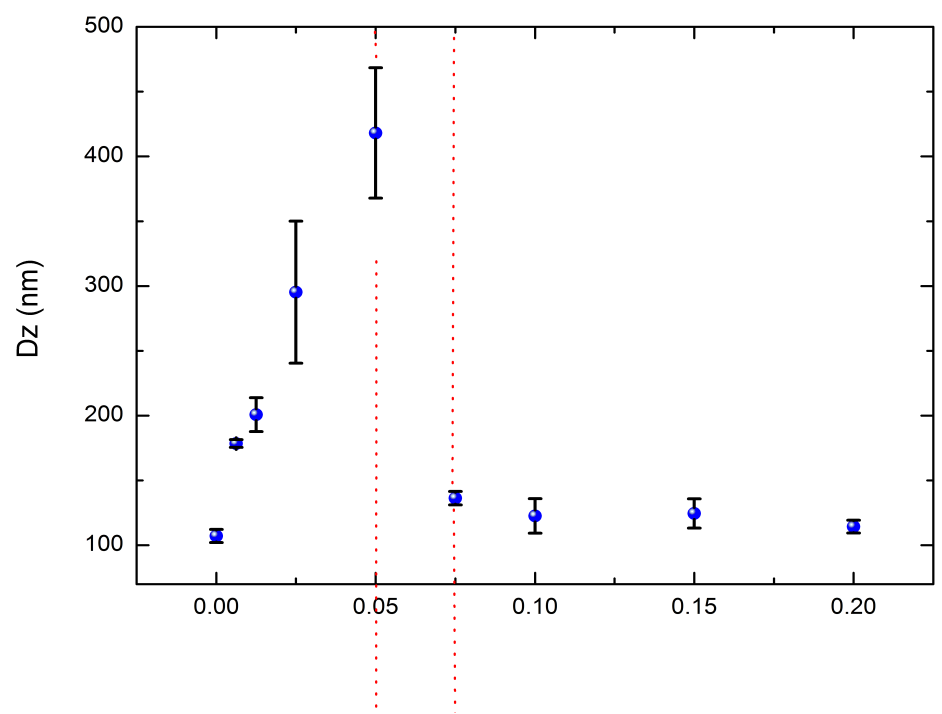

(a)

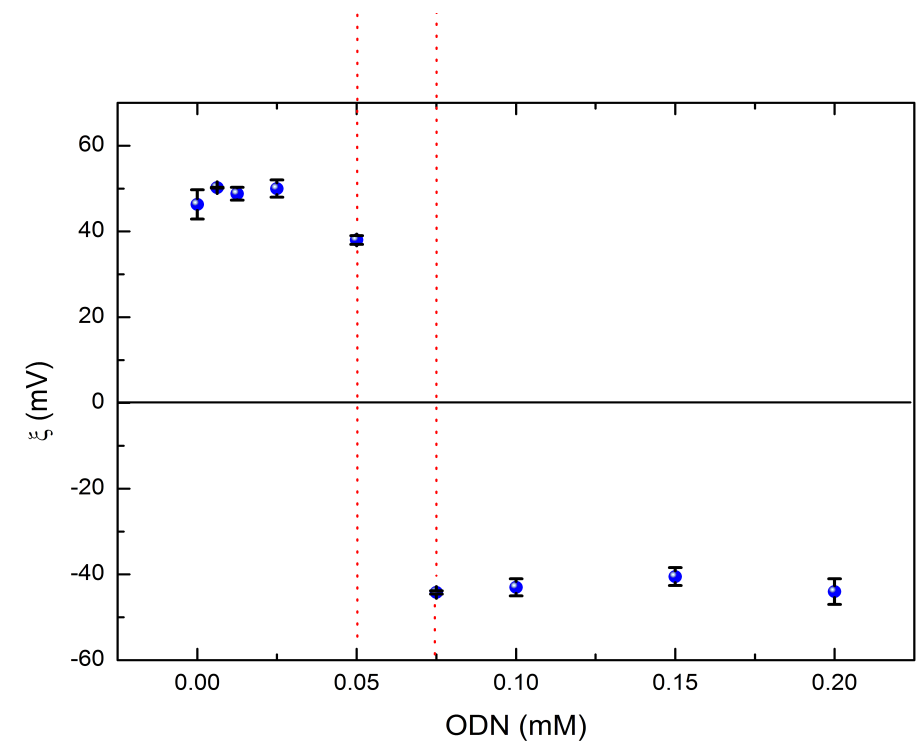

(b)

Figura 26: Efeito da concentração de ODN sobre os diâmetro médios (a) e os potenciaiszeta (b) de DODAB, após 30 e 70 minutos de incubação respectivamente, para cada técnica.

aumento do diâmetro médio da vesícula. No caso do potencial zeta, a blindagem é capaz de gerar mudança na concentração de carga positiva na superfície da vesícula do DODAB, percebido como uma pequena redução do potencial elétrico na superfície do DODAB para o denominado potencial-zeta.

É interessante observar que com adição de pequenas concentrações de ODN, observase uma grande mudança no diâmetro médio enquanto o potencial de superfície é quase 
constante. Uma possível explicação pode ser o efeito de repulsão dos contra-íons presentes no DODAB $([\mathrm{Br}-])$ com as cargas negativas dos grupos fosfato presentes no ODN. Em outros trabalhos encontrados na literatura (Rozenfeld et al., 2010; Saveyn et al., 2007), foi concluído a ideia de que as vesículas de DODAB, ao contrario dos fragmentos de bicamada, possuem só a superfície externa exposta ao oligonucleotídeo. Isto pelo fato de que a neutralização de cargas em fragmentos de bicamada ocorre na proporção de 1:10 moléculas (ODN:DODAB) e em vesículas de DODAB na proporção de 1:20 moléculas (ODN:DODAB), lembrando que o ODN tem 10 cargas negativas. No entanto, em nossos resultados da Figura (26.b), podemos ver que o potencial não é neutro $\sim(+38 \pm 1 \mathrm{mV}$ para $1 m M$ de DODAB e $0.05 m M$ ODN), o qual, novamente poderia ser um efeito dos contra-íons ([Br-]) presentes no DODAB ou um problema na medida, dado que a turbidez é significativa (ver Fig. 24.B) .

Da Figura (26.a), podemos ver, também, que com a adição de altas concentrações de ODN no DODAB, os diâmetros médios diminuem de tamanho até atingir um mínimo ao redor de $114 \pm 5 \mathrm{~nm}$ na presença de $0.2 \mathrm{mM}$ ODN (Tabela 1). Além disso, observa-se ( Figura 26.b ) que essa diminuição de diâmetro é acompanhada por uma mudança da polaridade do potencial zeta, para valores negativos, até atingir um mínimo ao redor -44 $\pm 3 \mathrm{mV}$ na presença de $0.2 \mathrm{mM}$ ODN (Tabela 1 ).

Esse resultado nos mostra que adição de altas concentrações de ODN pode blindar completamente a superfície externa da vesícula, gerando um arranjo com excesso de cargas negativas no meio, portanto partículas repulsivas. No caso do potencial zeta, este efeito será percebido pela mudança da polaridade do potencial.

É interessante observar que os diâmetros médios na região de altas concentrações de ODN são aproximadamente iguais daqueles para DODAB em tampão Hepes (Figura 21.a). Rosenfeld e colaboradores (2013) descreveram um comportamento similar do ODN interagindo com vesículas catiônicas na fase gel do lipídio diC14-amidine: na região de supercompensação de cargas os diâmetros das partículas são quase iguais.

Na Figura 27, mostra-se uma comparação do efeito da concentração de ODN sobre o diâmetro médio $(\mathrm{nm})$ após 30 minutos ( medida azul ) e após 7 dias (medida vermelha) da incubação do complexo DODAB/ODN a $20^{\circ} \mathrm{C}$. É importante mencionar que a medida após 7 dias de incubação foi submetida a um aquecimento a $60{ }^{\circ} \mathrm{C}$ por 5 minutos, e então resfriada por $20^{\circ} \mathrm{C}$, antes iniciar a medida de DLS a $20{ }^{\circ} \mathrm{C}$. 


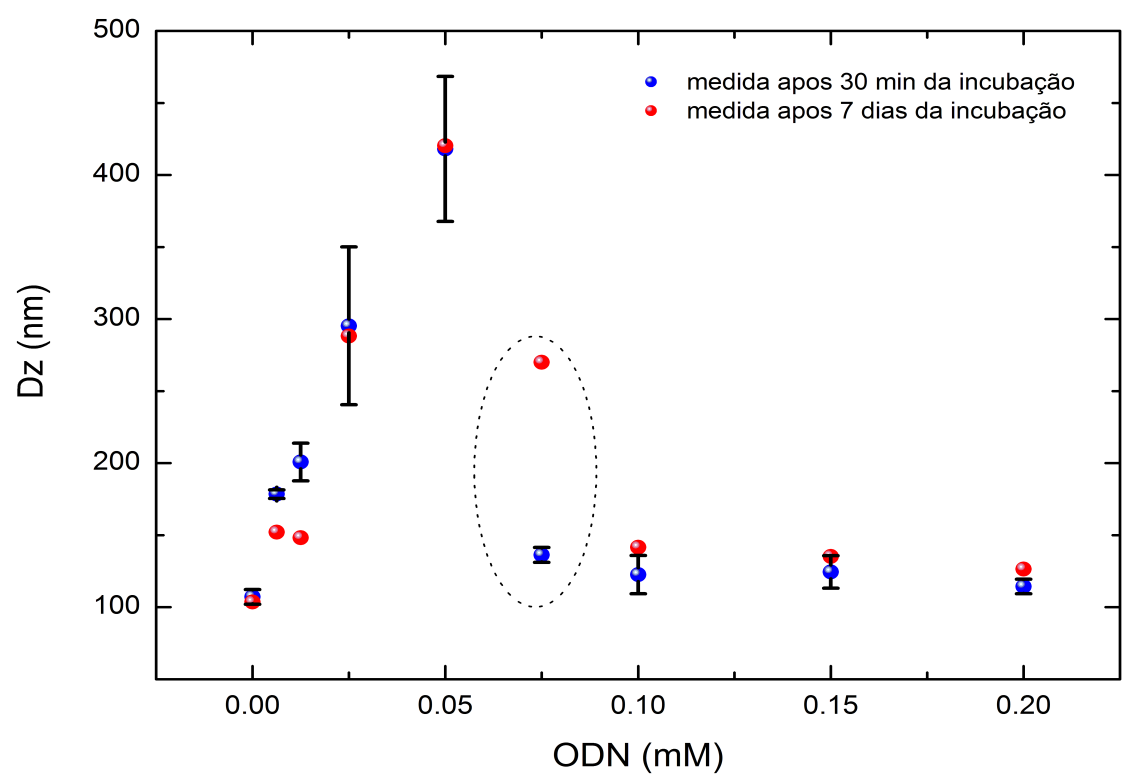

Figura 27: Efeito da concentração de ODN sobre os diâmetros médios (nm) após 30 minutos e 7 dias da incubação do complexo DODAB/ODN.

Da Figura, podemos ver que os diâmetros médios após 7 dias de incubação, nas concentrações de: 0.0 - $0.05 m M$ e 0.1 - $0.2 m M$, estão dentro do margem de erro comparado com os diâmetros médio obtido das amostras incubadas por 30 minutos (pontos azuis). Esses resultados nos mostram que as dispersões nestas concentrações mantêm uma estabilidade de tamanho com o passar do tempo e com a variação da temperatura.

Um resultado diferente é observado na concentração de $0.075 \mathrm{mM}$ de ODN, na qual, o diâmetro médio aumenta 140 vezes mais com respeito ao diâmetro obtido após 30 minutos. Este resultado corrobora o já comentado nas fotografias de turbidez na pg.68 (linha 15), mostrando novamente que nesta concentração o arranjo se mostra instável com o passar do tempo e com a variação da temperatura.

Pelos resultados encontrados até agora de diâmetro médio e turbidez, podemos dizer que o intervalo entre, $0.025 \mathrm{mM}-0.075 \mathrm{mM}$, é uma região na qual a dispersão se mostra instável. Essa instabilidade poderia ser um efeito da neutralização de cargas entre os polieletrólitos, já que é uma região na qual o ODN é capaz de blindar por completo as cabeças de cargas positivas da superfície externa do DODAB, alcançando assim a neutralização de carga, [DODAB+] $\sim$ [ODN-] $0.0 m V$, ( veja-se a Figura 26.b do potencial-zeta) (Dautzenberg et al., 1994; Correira et al., 2004; Araujo et al., 2005; 
Sybachin et al., 2007).

Tabela 1: Valores de diâmetro médio e potencial-zeta de dispersão, em diferentes concentrações a, $20^{\circ} \mathrm{C}$, para três ou mais amostras diferentes.

\begin{tabular}{lcc}
\hline Disperção & $D_{Z}(\mathrm{~nm})$, após 30 min & $\zeta(\mathrm{mV})$, após $70 \mathrm{~min}$ \\
\hline DODAB: Hepes & $107 \pm 5$ & $+47 \pm 4$ \\
DODAB + 0.00625 mM ODN & $178 \pm 3$ & $+50.2 \pm 0.1$ \\
DODAB + 0.0125 mM ODN & $200 \pm 30$ & $+49 \pm 2$ \\
DODAB + 0.025 mM ODN & $300 \pm 55$ & $+50 \pm 2$ \\
DODAB + 0.05 mM ODN & $420 \pm 50$ & $+38 \pm 1$ \\
DODAB + $0.075 m M$ ODN & $136 \pm 5$ & $-44.2 \pm 0.4$ \\
DODAB + $0.1 m M$ ODN & $122 \pm 15$ & $-43 \pm 2$ \\
DODAB + $0.15 m M$ ODN & $125 \pm 12$ & $-41 \pm 2$ \\
DODAB + $0.2 m M$ ODN & $114 \pm 5$ & $-44 \pm 3$ \\
\hline
\end{tabular}

Tabela 2: Valores de diâmetro médio (nm) após 30 min e 7 dias da incubação, do complexo DODAB/ODN a $20^{\circ} \mathrm{C}$.

\begin{tabular}{lcc}
\hline Disperção & $D_{Z}(\mathrm{~nm})$, após 30 min & $D_{Z}(\mathrm{~nm})$, após 7 dias \\
\hline DODAB: Hepes & $107 \pm 5$ & 103 \\
DODAB + 0.00625 mM ODN & $178 \pm 3$ & 152 \\
DODAB + 0.0125 mM ODN & $200 \pm 30$ & 150 \\
DODAB + 0.025 mM ODN & $300 \pm 55$ & 288 \\
DODAB + 0.05 $m M$ ODN & $420 \pm 50$ & 420 \\
DODAB + 0.075 mM ODN & $136 \pm 5$ & 270 \\
DODAB + 0.1 $m M$ ODN & $122 \pm 15$ & 136 \\
DODAB + 0.15 $m M$ ODN & $125 \pm 12$ & 130 \\
DODAB + $0.2 m M$ ODN & $114 \pm 5$ & 124 \\
\hline
\end{tabular}


4.1.2.2 Espalhamento de raios-X a baixos ângulos (SAXS)

Com o intuito de entender se a interação ODN:DODAB induz fusão de vesículas de DODAB, foram realizados experimentos utilizando a técnica de espalhamento de raios-X a baixos ângulos. As amostras escolhidas foram:

- DODAB em tampão Hepes (estado inicial).

- DODAB: + [0.0125 mM] ODN (estado estável, em baixa concentração).

- DODAB: + [0.1 mM] ODN (estado estável, em alta concentração).

Na Figura 28, podemos ver os perfis experimentais de SAXS obtidos, tanto na fase gel, $30^{\circ} \mathrm{C}$, como fluida, $60{ }^{\circ} \mathrm{C}$, das vesículas extrusadas de DODAB.

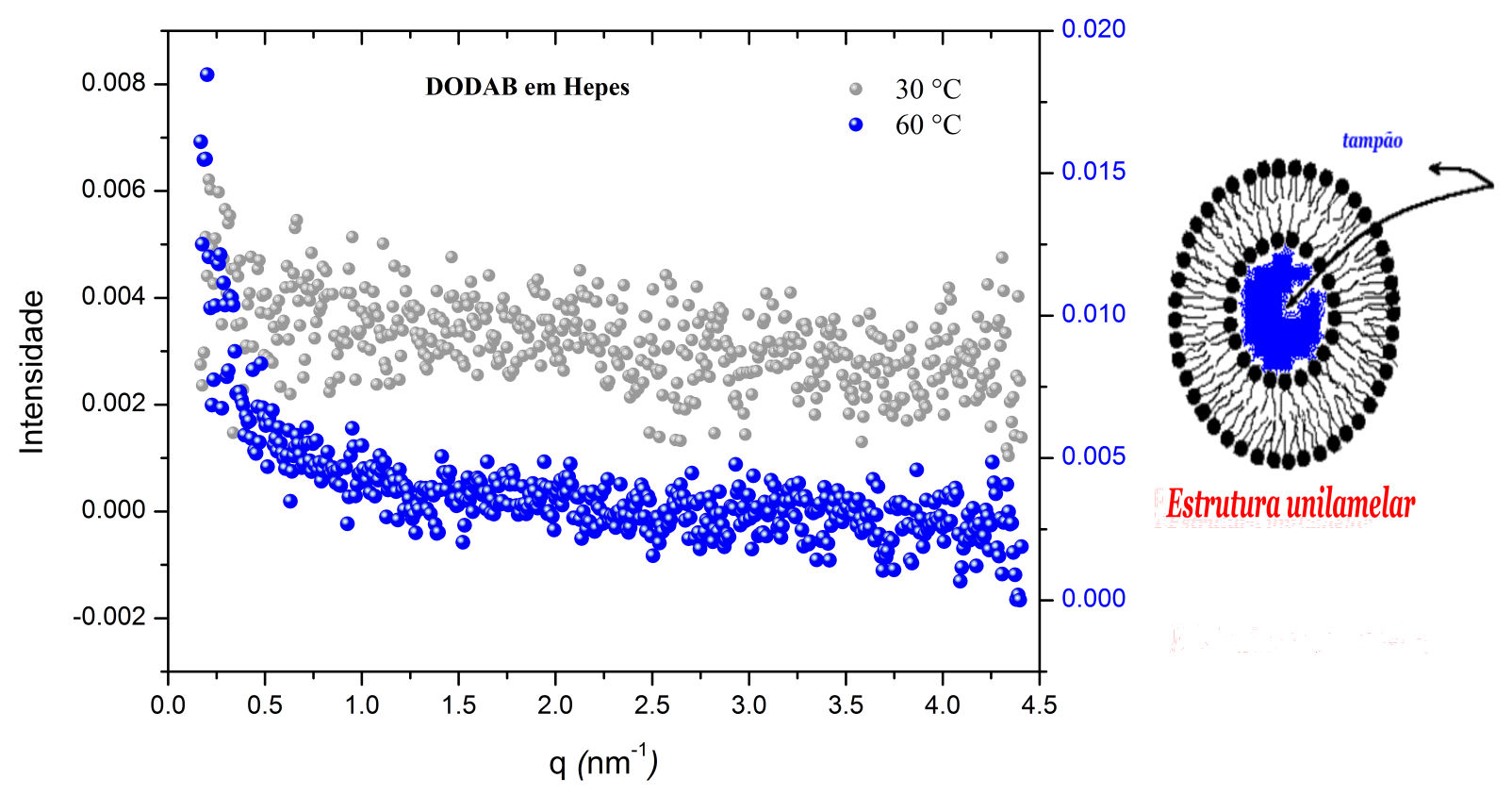

Figura 28: Curvas de SAXS para vesículas extrusadas de DODAB em tampão, medidas nas temperaturas de $30^{\circ} \mathrm{C}$ e $60^{\circ} \mathrm{C}$.

Pela baixa estatística dos dados, não é possível perceber a banda característica da bicamada lipídica, mas é possível notar, principalmente para a fase fluida do lipídio, que em baixo ângulo de espalhamento os pontos experimentais apresentam um rápido crescimento. Esse comportamento é característico de objetos espalhadores com tamanhos acima do limite da técnica, e é observado também nas figuras das outras duas amostras. 
Da figura pode-se ver também a ausência de picos de Bragg, que mostra que os perfis de espalhamento tanto na fase gel como fluida são caraterísticos de vesículas unilamelares.

Na Figura 29, mostramos as curvas de SAXS para vesículas extrusadas de DODAB em presença de $0.0125 \mathrm{mM}$ de oligonucleotídeo. Da figura, podemos ver que na fase gel do lipídio DODAB, $30{ }^{\circ} \mathrm{C}$, a primeira ordem de difração é observada em torno de $\mathrm{q}=1.4$ $n m^{-1}$, com uma distância de repetição de, $d=2 \pi / q=4.5 \mathrm{~nm}$ (Tabela 3 ) .

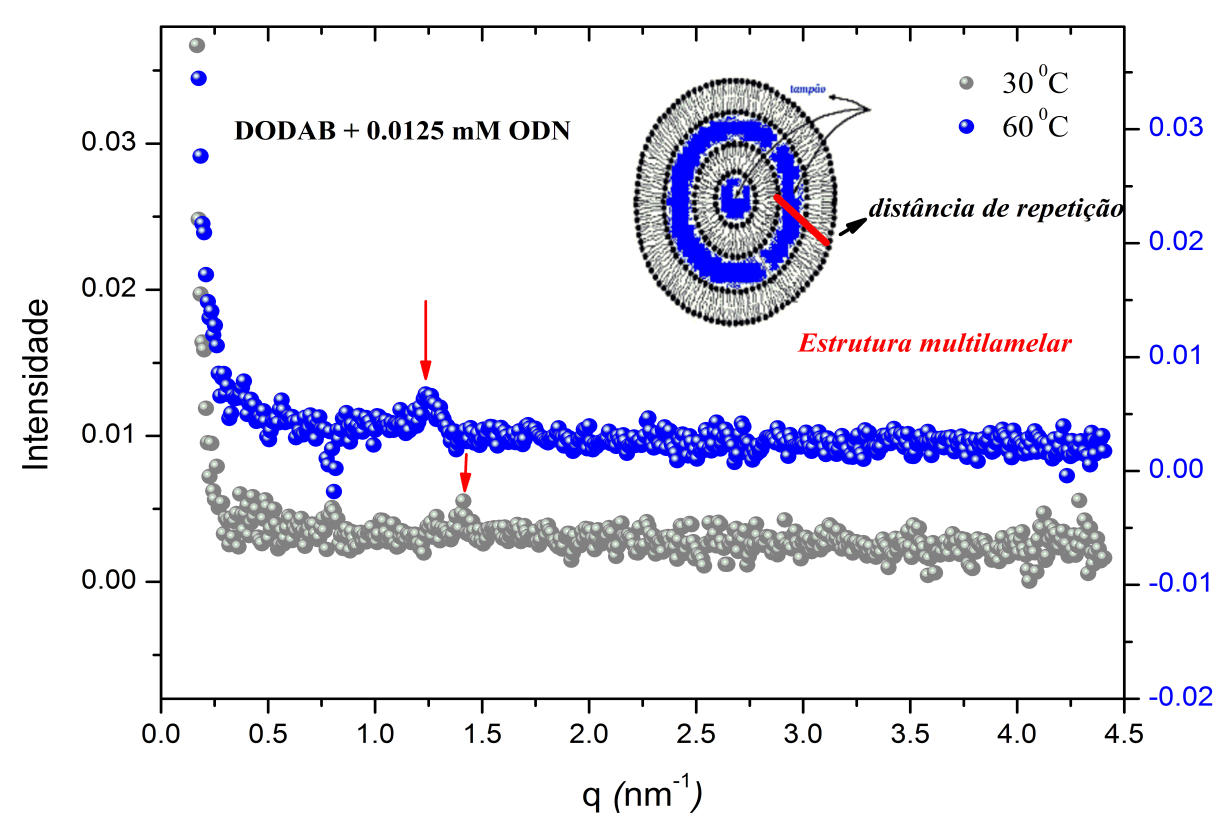

Figura 29: Curvas de SAXS para vesículas extrusadas de DODAB em presença de 0.0125 $m M$ de $O D N$, medidas nas temperaturas de $30{ }^{\circ} \mathrm{C}$ e $60^{\circ} \mathrm{C}$

Entretanto, na fase fluida do DODAB, $60{ }^{\circ} \mathrm{C}$, a primeira ordem de difração é levemente observada em torno de $q=1.3 \mathrm{~nm}^{-1}$, podendo-se calcular uma distância de repetição para estrutura lamelar de $4.8 \mathrm{~nm}$ (Tabela 3).

$\mathrm{Na}$ presença da alta concentração do ODN (0.1 $m M)$, as curvas de SAXS são mostradas na Figura 30. Da figura podemos ver que estes picos apresentam uma maior intensidade e nitidez nas duas temperaturas testadas, em comparação aos picos da baixa concentração de ODN. Na fase gel do lipídio DODAB, a primeira ordem de difração é observada em $1.4 \mathrm{~nm}^{-1}$, com uma distância de repetição de $4.5 \mathrm{~nm}$ (Tabela 3). Entretanto, na fase fluida do lípido, a primeira ordem de difração é observada em $1.3 \mathrm{~nm}^{-1}$, resultando numa distância de repetição de 4.8 nm (Tabela 3). 


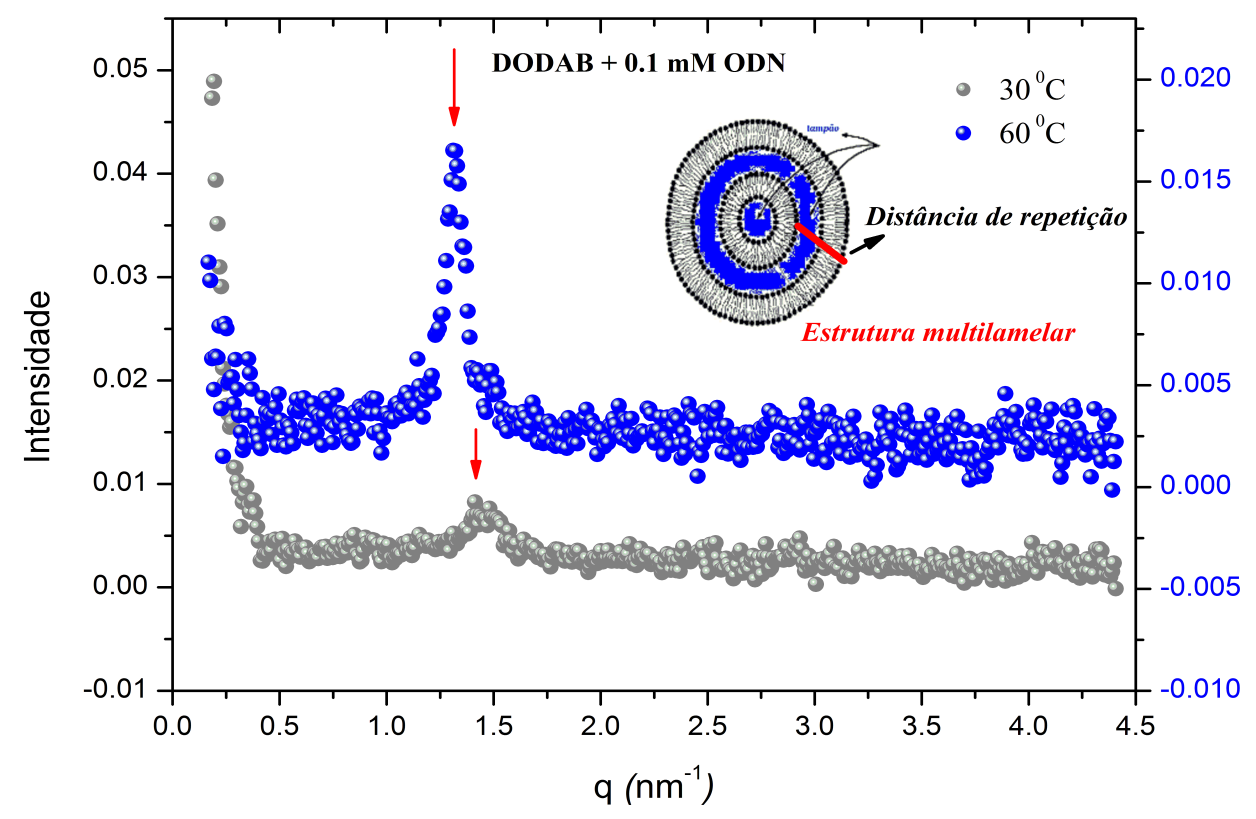

Figura 30: Curvas de SAXS para vesículas extrusadas de DODAB em presença de 0.1 $m M$ de ODN, medidas nas temperaturas de $30^{\circ} \mathrm{C}$ e $60^{\circ} \mathrm{C}$.

Essas distâncias de repetição mostradas, tanto em baixas como em altas concentrações de ODN, referen-se à espessura da bicamada e da camada de água entre bicamadas consecutivas (ver Figura 29 e 30 ). Portanto, pode-se estimar que, tanto para baixas concentrações como em altas concentrações de ODN, a ordem de difração mostrada é característica de vesículas multilamelares (Glatter e O. Kratky, 1982). Portanto, o ODN causa reestruturação das vesículas, isto tanto na fase gel como na fase fluida do lipídio.

Trabalhos feitos ( Rozenfeld et al.,2015) descreveram um comportamento similar para vesículas não extrusadas de DODAB interagindo com altas concentrações de ODN, mostrando uma distância de repetição $4.5 \mathrm{~nm}$ na fase gel e uma distância de repetição de $4.8 \mathrm{~nm}$ na fase fluida. Aqui nós mostramos que essas distâncias já podem ser determinadas em baixas concentrações de ODN. Interesante que a presença de vesículas multilamelares de $D O D A B+O D N$ resultem em estruturas com dimensões semelhantes à vesículas de puro DODAB (Fig.27)

Trabalhos feitos por (Fu-Gen Wu et al., 2009; Fu-Gen Wu et al., 2011) descreveram um comportamento interessante para vesículas multilamelares de DODAB em água, as quais, foram obtidas segundo o método de preparo dos autores.

Através de experimentos de SAXS, eles determinaram as distâncias de repetição 
lamelar tanto para fase fluida $(9.2 \mathrm{~nm})$ como para fase gel $(7.5 \mathrm{~nm})$ e coagel $(3.7 \mathrm{~nm})$ do DODAB, mostrando que na conversão da fase fluida para gel e por último a coagel, vão com uma diminuição drástica do valor da distância de repetição. Com esses resultados, eles mencionam que essa diminuição é devida à perda de água entre as bicamadas interlamelares, causando assim uma desidratação parcial dos lipídios de DODAB (veja-se a Figura 31).

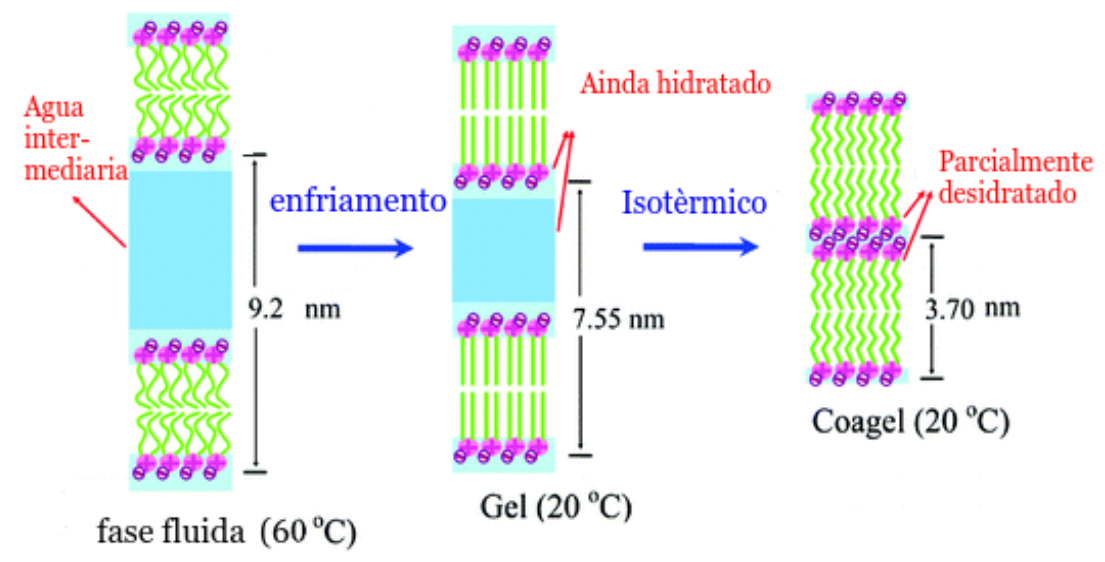

Figura 31: Diminuição do valor da distância de repetição, $d$, na conversão da fase fluida para gel e por último a coagel. Figura extraída de Fu-Gen Wu, 2009.

Portanto, pelos resultados encontrados até agora, se poderia dizer que o ODN tem a capacidade de induzir perda de Tampão na bicamada multilamelar de DODAB. Essa desidratação é reforçada pela distância similar de $3.7 \mathrm{~nm}$ da fase coagel com os $4.5 \mathrm{~nm}$ e $4.8 \mathrm{~nm}$ obtidos experimentalmente na fase gel e fluida do DODAB interagindo com ODN.

Tabela 3: Valores de SAXS, das propriedades físicas de dispersão, em diferentes temperaturas e concentração.

\begin{tabular}{l|c|c|c}
\hline & DODAB: Hepes & DODAB $+0.0125 \mathrm{mM}$ ODN & DODAB $+0.1 \mathrm{mM}$ ODN \\
\hline Temperatura & $q\left(\mathrm{~nm}^{-1}\right) \rightarrow d(\mathrm{~nm})$ & $q\left(\mathrm{~nm}^{-1}\right) \rightarrow d(\mathrm{~nm})$ & $q\left(\mathrm{~nm}^{-1}\right) \rightarrow d(\mathrm{~nm})$ \\
\hline $30^{\circ} \mathrm{C}$ & - & $1.4 \rightarrow 4.5$ & $1.4 \rightarrow 4.5$ \\
$60^{\circ} \mathrm{C}$ & - & $1.3 \rightarrow 4.8$ & $1.3 \rightarrow 4.8$ \\
\hline
\end{tabular}




\subsection{Efeito do ODN sobre a transição de fase das bicamadas de DODAB}

A transição de fase de sistemas lipídicos pode ser afetada devido à presença de um componente externo. A presença de um agente externo na bicamada lipídica pode perturbar a ordem das cadeias laterais, e também o arranjo das cabeças polares dos lipídios. Nos resultados descritos na seção 4.1, mostra-se que os lipoplexes formados pela interação das vesículas de DODAB com ODN apresentam diferentes propriedades conforme é feita a adição de ODN. Prosseguindo com a investigação de como o ODN perturba a organização dos lipídios de DODAB, apresentamos nas Figuras seguintes os perfis calorimétricos obtidos por DSC, tanto para o processo endotérmico como exotérmico do DODAB/ODN. Além disso, para mostrar a reprodutibilidade das medidas, os perfis calorimétricos ao longo desta seção serão apresentados em forma de duplicatas das amostras. Através desses perfis, e seguindo a metodologia descrita na seção 3.4.4, podemos inferir os valores dos parâmetros termodinâmicos $\Delta H$ e $T_{m}$, associados à transição de fase. Esses dados serão encontrados nas Tabelas 4 e 5 .

Um resultado típico de calorimetria diferencial de varredura para duas amostras diferentes de vesículas extrusadas de DODAB em Hepes é mostrado na Figura 32 (medida 1 e 2$)$.

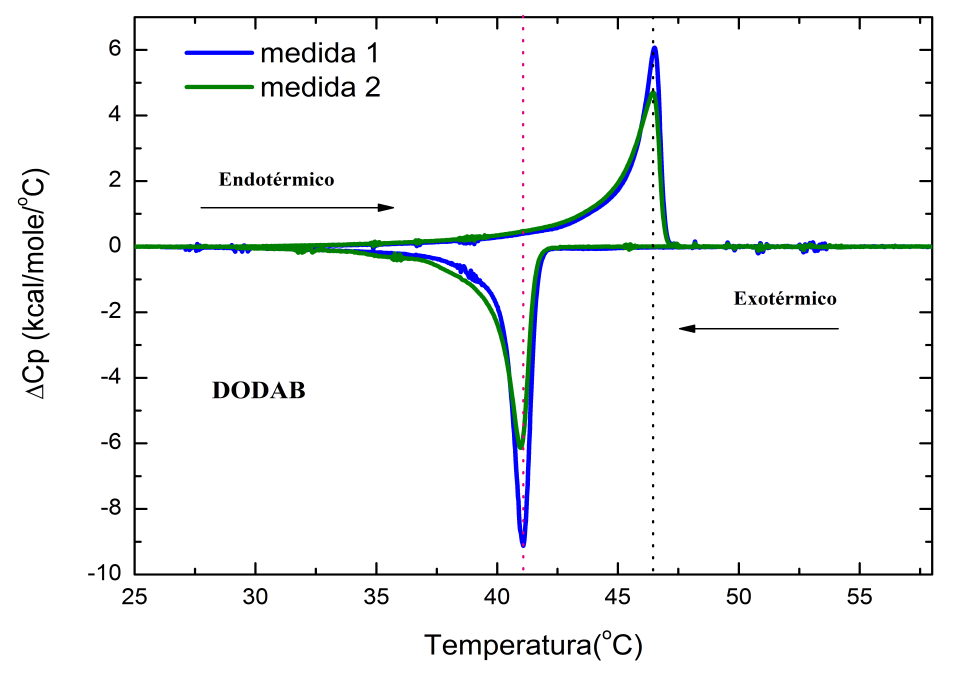

Figura 32: Termogramas de $1 \mathrm{mM}$ de vesículas extrusadas de DODAB em tampão. As linhas tracejadas marcam os máximos dos picos para os dois processos, de aquecimento e resfriamento. 
Neste gráfico, pode-se ver que os perfis calorimétricos tanto para o processo de aquecimento como para o resfriamento de duas amostras diferentes são razoavelmente reprodutíveis. Esse resultado nos garante a confiabilidade dos parâmetros termodinâmicos, os quais serão apresentados a seguir.

Dos perfis endotérmicos e exotérmicos (Fig.32), pode-se ver que a transição de fase das vesículas extrusadas por filtro de $100 \mathrm{~nm}$, aqui usadas, ocorre entre $35-47^{\circ} \mathrm{C}$ e 30-42 ${ }^{\circ} C$, respetivamente. Além disso, com uma linha vertical tracejada, indicamos a posição de máximo do pico, $T_{m}$, que identificamos com a temperatura de transição da fase gel para a fase fluida, tanto no processo de aquecimento (linha preta) como no resfriamento (linha vermelha) da amostra. No processo endotérmico, a amostra apresenta um pico definido e intenso em $46.5^{\circ} \mathrm{C}$, enquanto que para o processo exotérmico a temperatura diminui para $41^{\circ} \mathrm{C}$.

Este resultado é esperado para vesículas de DODAB, visto que a histerese é uma das propriedades que as caracteriza (Alvez, 2008). Outra caraterística que se pode visualizar na Figura 32 é a largura estreita dos picos tanto no processo endotérmico como no exotérmico. Isso demonstra a alta cooperatividade de transição da amostra em ambos processos, $\Delta T_{1 / 2} \sim 1.0^{\circ} \mathrm{C}$, que pode ser explicada devido à forte interação lipídio-lipídio (Fu-Gen et al.,2011).

Finalmente, o fator termodinâmico de energia por mol, $\Delta H$, durante a transição de fase do DODAB, tanto para o processo endotérmico como para o exotérmico, foi de $9 \mathrm{kcal} / \mathrm{mol}$ e $10 \mathrm{kcal} / \mathrm{mol}$, respectivamente. Se levarmos em consideração os valores do erro das medidas (Tabela 4 e 5), esses resultados de entalpia serão idênticos.

Na Figura 33, mostramos os termogramas de DSC para vesículas extrusadas de DODAB em presença das quatro primeiras concentrações de oligonucleotídeo $(0.00625 \mathrm{mM}$, $0.0125 \mathrm{mM}, 0.025 \mathrm{mM}$ e $0.05 \mathrm{mM})$. Nessa figura podemos ver que os termogramas, nos processos endotérmico e exotérmico, apresentam perfis bastante reprodutíveis quando comparadas medidas com duas amostras diferentes.

No processo endotérmico, vemos que os três perfis térmicos $(0.00625 \mathrm{mM}, 0.0125 \mathrm{mM}$ e $0.025 \mathrm{mM}$ de ODN) apresentam dois picos de absorção de calor com intensidades diferentes. Devido a este resultado, a cooperatividade, $\Delta T_{1 / 2}$, nestas concentrações não será medida. Isso se deve ao fato desta análise não fazer sentido do ponto de vista físico, uma vez que existem dois eventos térmicos sobrepondo-se. 

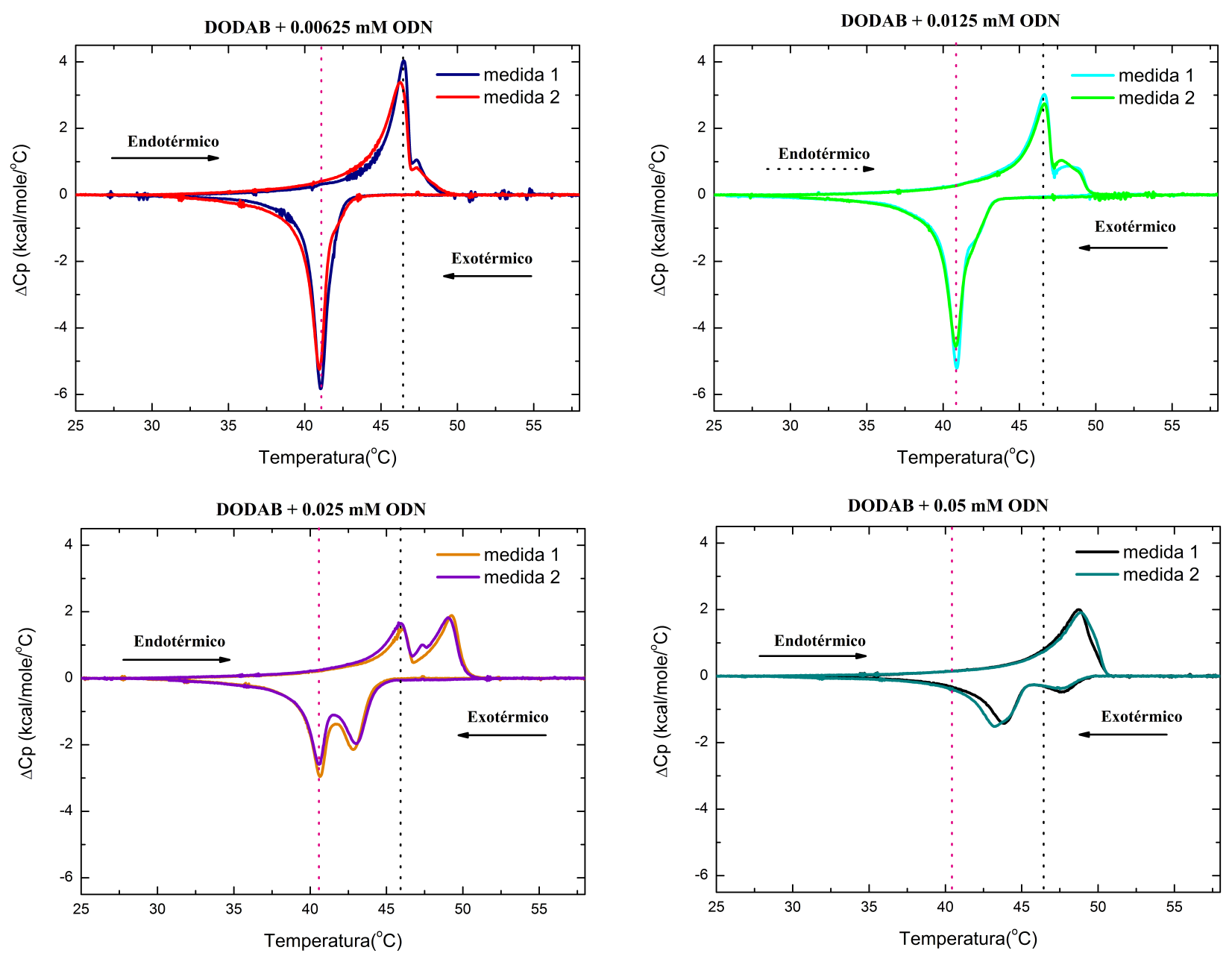

Figura 33: Termogramas de $1 \mathrm{mM}$ de vesículas extrusadas de DODAB em presença de $0.00625 \mathrm{mM}$; $0.0125 \mathrm{mM}$; $0.025 \mathrm{mM}$ e $0.05 \mathrm{mM}$ ODN. As linhas tracejadas são as mesmas mostradas na Figura 32, para comparação.

Em contraposição a isto, no processo exotérmico os dois primeiros arranjos apresentam picos de largura estreita que denotam a boa cooperatividade a $1.0^{\circ} \mathrm{C}$ para 0.00625 $m M$ ODN e $1.5^{\circ} \mathrm{C}$ para $0.0125 m M$ de ODN. Entretanto, para $0.025 m M$ ODN a cooperatividade não pode ser calculada (ver a Tabela 5).

Outro parâmetro termodinâmico que pode ser inferido da Figura 33, para as três primeiras concentrações de ODN na dispersão lipídica de DODAB, são as posições dos dois picos de absorção de calor.

No aquecimento da amostra podemos ver que as posições dos picos encontram-se em 46.5 e $47.7{ }^{\circ} \mathrm{C}$ para $0.00625 \mathrm{mM}$ ODN, e a 46.6 e $48.2^{\circ} \mathrm{C}$ para $0.0125 \mathrm{mM}$ ODN. Entretanto, para $0.025 \mathrm{mM}$ ODN as posições dos picos estão em 46.3 e $49.1{ }^{\circ} \mathrm{C}$. Para o resfriamento da amostra podemos ver que a posição do pico ocorre em $41.0{ }^{\circ} \mathrm{C}$ para 
$0.00625 m M$ e $0.0125 m M$ ODN. Posição muito semelhante à encontrada para vesículas de puro DODAB (Fig. 32). Entretanto, para $0.025 \mathrm{mM}$ ODN, aparece um segundo pico, e as posições dos picos estão em 41.0 e $43.0^{\circ} \mathrm{C}$.

Já a concentração de 0.05 mM de ODN em DODAB (Fig. 33), resulta na aparição, de um único pico de transição em $49{ }^{\circ} \mathrm{C}$ durante o aquecimento da amostra. Por outro lado, no resfriamento, dois picos são encontrados a $43.5^{\circ} \mathrm{C}$ e $47.4{ }^{\circ} \mathrm{C}$, respectivamente.

Esses resultados de variação da posição dos picos com uma adição de até $0.05 \mathrm{mM}$ de ODN, em ambos processos, são mais facilmente vistos na Figura 34.

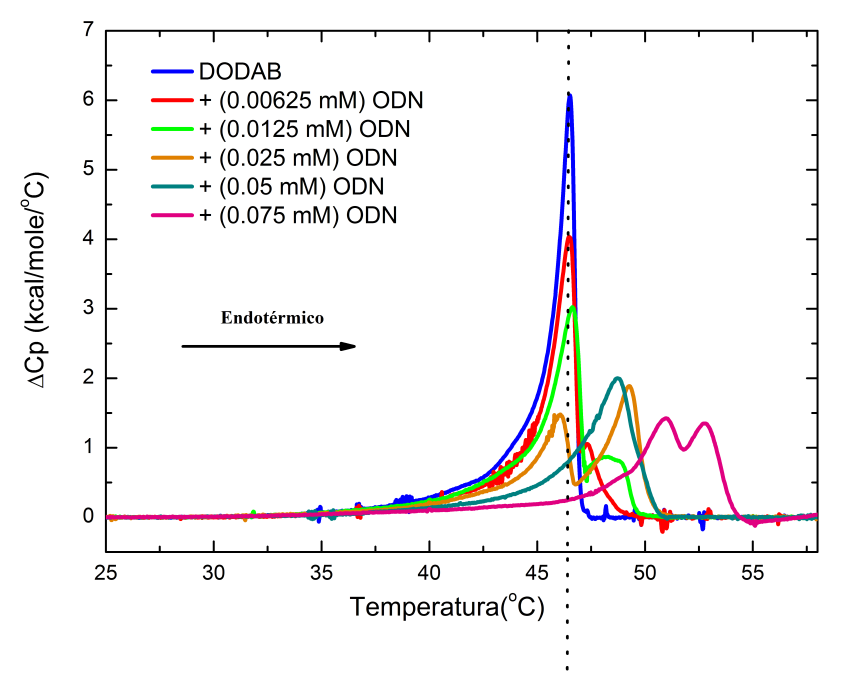

(a)

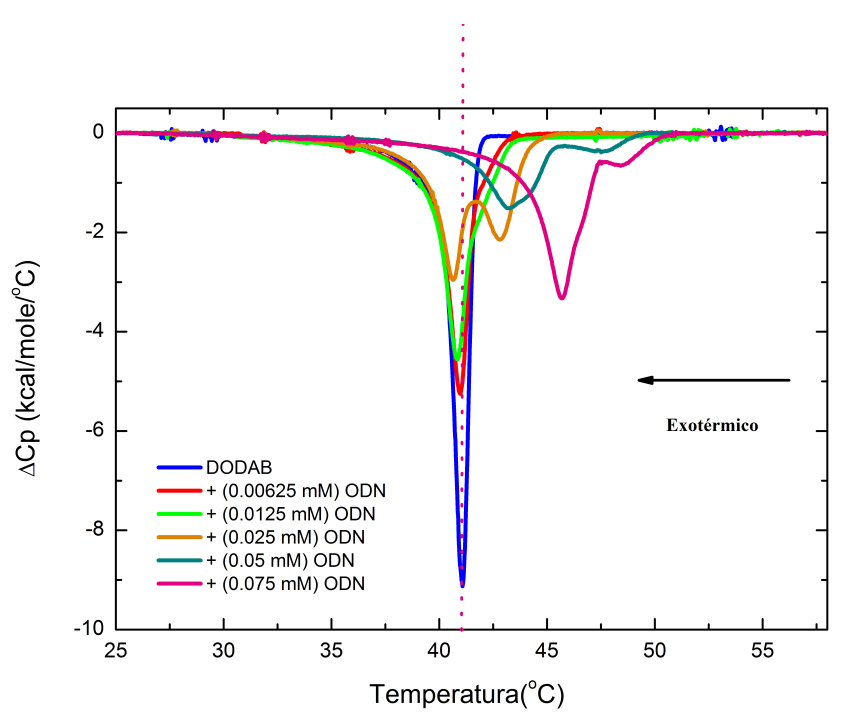

(b)

Figura 34: Comparação dos termogramas no processo endotérmico (a) e exotérmico (b) de $1 \mathrm{mM}$ de vesículas extrusadas de DODAB em presença de altas concentrações de ODN. $O$ perfil obtido para $[O D N]=0.075 \mathrm{mM}$ está também mostrado para comparação. 
Indicamos na Figura 34, as posições dos picos de transição de fase para o arranjo de DODAB na ausência de ODN com as linhas tracejadas verticais de cor preta e vermelha, para os processos endotérmico e exotérmico, respectivamente (ver os perfis azuis).

Dos perfis mostrados para ambos processos (fig 34.a e 34.b), pode-se ver que para as três menores concentrações de ODN existe um pico na mesma posição de transição do pico do arranjo do DODAB puro. Além disso, podemos ver que conforme é feita adição do ODN, a intensidade deste pico diminuí até o desaparecimento por completo em 0.05 $m M$ de ODN. Em paralelo, o segundo pico vai aumentando em intensidade até o máximo em $0.05 \mathrm{mM}$, atingindo assim uma posição de transição em temperaturas maiores (ver o perfil turquesa para ambos processos). Ainda na figura 34, o perfil obtido com [ODN] = $0.075 \mathrm{mM}$ foi colocado somente para comparação e será discutido abaixo.

Os perfis apresentados em concentrações menores que $0.05 \mathrm{mM}$ sugerem que o oligonucleotídeo é capaz de ligar-se em apenas parte da vesícula de DODAB, levando à coexistência de duas regiões com diferentes propriedades na mesma vesícula, na qual, a primeira região pertence aos lipídios de DODAB puro, e a segunda ao complexo DODAB/ODN. Curioso que no processo de resfriamento da vesícula, o pico relativo ao complexo DODAB/ODN esteja pouco presente para [ODN] $=0.0125 \mathrm{mM}$, diferente do observado na transição gel-fluido (aquecimento). Esta deve ser uma indicação da diferente ligação do ODN com DODAB nas fases gel e fluido. Após isso, já com a adição de $0.05 m M$, o oligonucleotídeo é capaz de perturbar por completo a bicamada de DODAB, mostrando assim a segunda região num só pico de absorção de calor.

Em seguida, os resultados que serão apresentados estarão em condições de altas concentrações de material genético nas dispersões lipídicas de DODAB. Na Figura 35, mostramos os termogramas para as concentrações de, $0.075 \mathrm{mM}, 0.1 \mathrm{mM}, 0.15 \mathrm{mM}$, e $0.2 \mathrm{mM}$ de ODN, para duas amostras diferentes. As linhas tracejadas são as mesmas das figuras anteriores, para facilitar a comparação entre todos os perfis.

Para o DODAB em presença de $0.075 \mathrm{Mm}$ de ODN, podemos ver a existência de dois picos de absorção de calor, a $50.5^{\circ} \mathrm{C}$ e $53{ }^{\circ} \mathrm{C}$, para o processo endotérmico, e a 46.0 ${ }^{\circ} \mathrm{C}$ e $49.0^{\circ} \mathrm{C}$, para o exotérmico. Este resultado nos mostra que nesta concentração a $T_{m}$ desloca-se para maiores temperaturas, comparativamente com à concentração anterior (0.05 mM ODN), veja a Figura 34 . Trabalhos de Rozenfeld e colaboradores (Rozenfeld et al.,2015), descreveram um aumento similar da temperatura de transição de fase, $T_{m}$, para 
vesículas não extrusadas de DODAB interagindo com altas concentrações de ODN. No entanto, neste trabalho podemos mostrar que a adição de baixas concentrações de ODN na dispersão lipídica de DODAB gera a mudança da temperatura de transição (Figura $34)$.
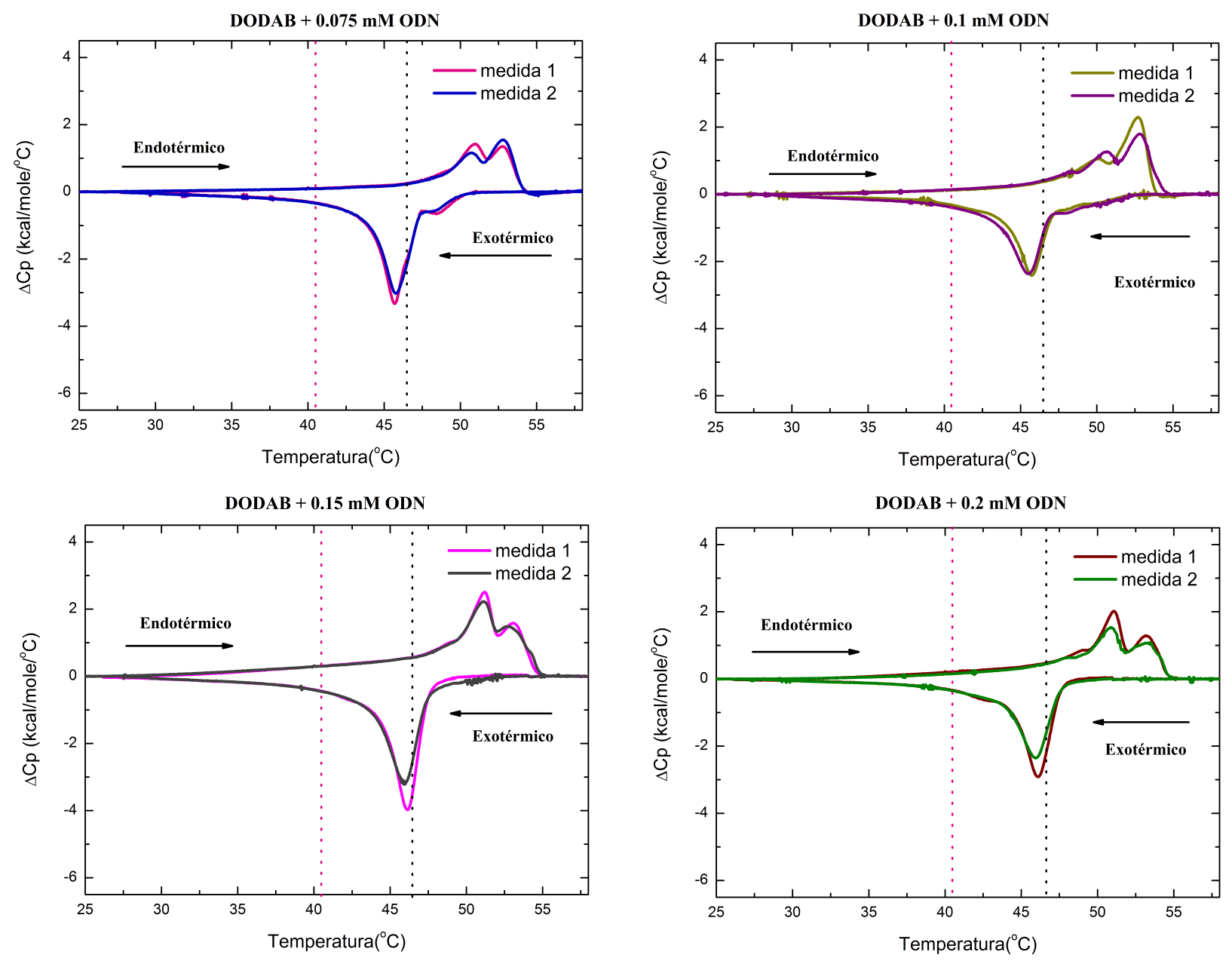

Figura 35: Termogramas de $1 \mathrm{mM}$ de vesículas extrusadas de DODAB em presença de $0.075 \mathrm{mM} ; 0.1 \mathrm{mM} ; 0.15 \mathrm{mM}$ e $0.2 \mathrm{mM}$ ODN. As linhas tracejadas são as mesmas mostradas nas Figuras anteriores, para comparação.

Com o aumento de material genético na dispersão lipídica (0.1, 0.15 e $0.2 \mathrm{mM}$ de ODN), podemos ver também uma transição de fase larga, $\Delta T_{1 / 2}$, para o processo exotérmico, a qual denota uma baixa cooperatividade, e permanece fixa a $2.2^{\circ} \mathrm{C}$ para: 0.1, 0.15 e $0.2 \mathrm{mM}$ de ODN (Tabela 5). Entretanto, para o processo endotérmico, a cooperatividade não pode ser calculada.

Da Figura 35, pode-se notar também que a posição dos picos de absorção de calor permanece fixa a $50{ }^{\circ} \mathrm{C}$ e $53{ }^{\circ} \mathrm{C}$ para o processo endotérmico, e $46{ }^{\circ} \mathrm{C}$ para o exotérmico. 
Esses resultados são mais bem percebidos na Figura 36, na qual, podemos, ver que os picos mostrados nos perfis roxo, preto e verde, tanto no processo endotérmico como exotérmico, apresentam flutuações nas intensidades com uma estabilidade na posição dos picos de transição em torno da posição dos picos na concentração de 0.075 mM de ODN.

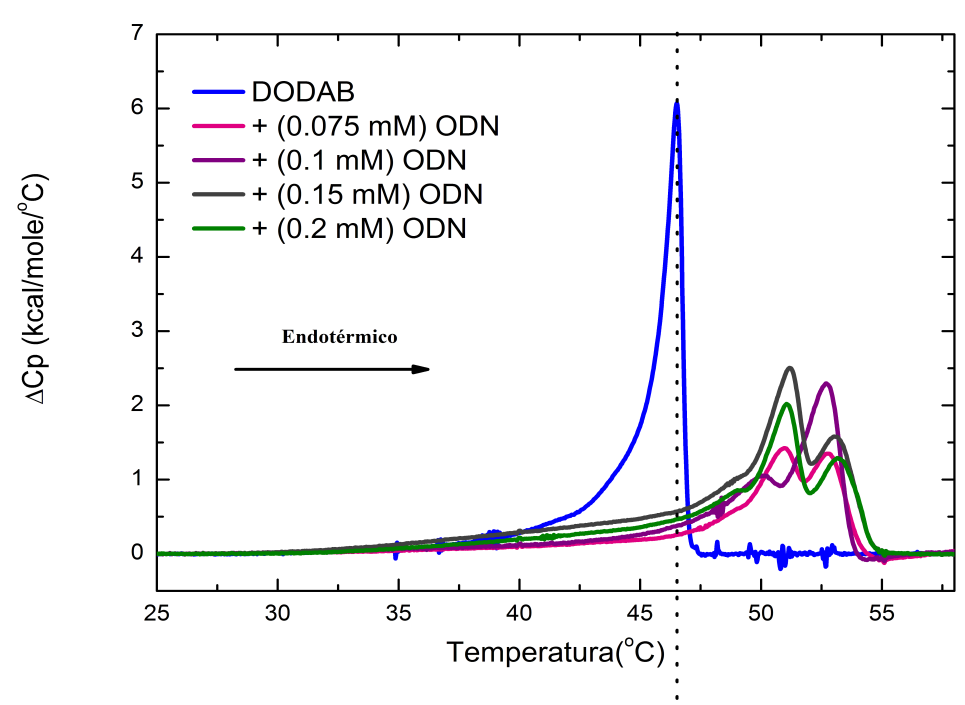

(a)

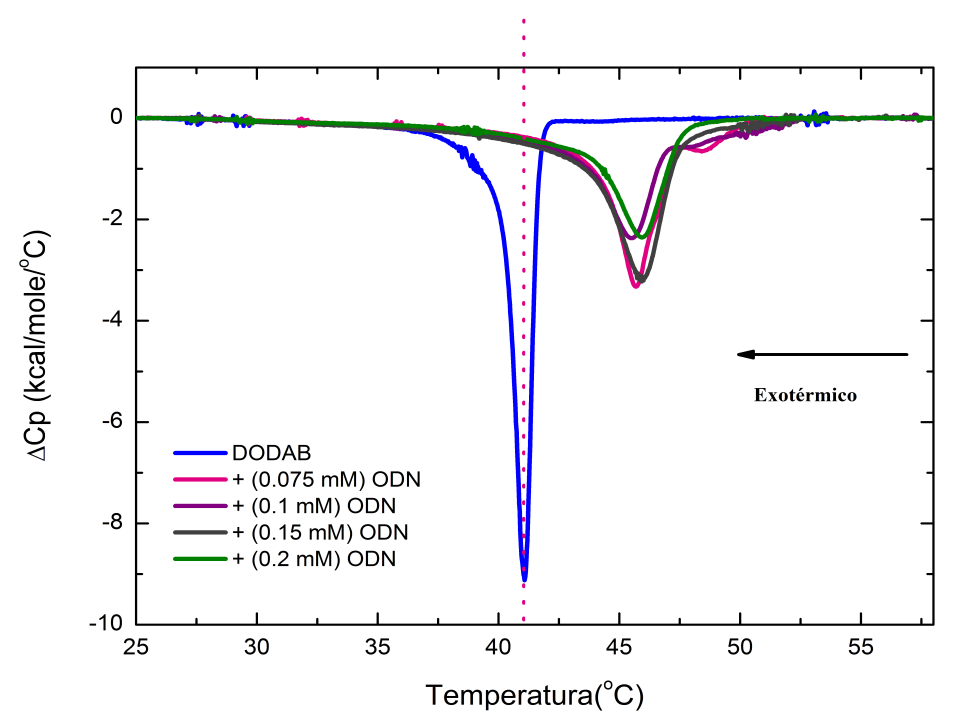

(b)

Figura 36: Comparação dos termogramas no processo endotérmico (a) e exotérmico (b) de $1 \mathrm{mM}$ de vesículas extrusadas de DODAB em presença de altas concentrações de ODN.

É interessante observar que esta estabilidade, tanto de $T_{m}$ como de $\Delta T_{1 / 2}$, para altas concentrações de ODN, é coerente com os resultados obtidos nas imagens de turbidez, diâmetro médio e o potencial-zeta, as quais não têm uma variação significativa de seus 
valores na região de supercompensação de carga (Figura 24.C, 25.B 26 e 27).

Esses resultados são reforçados pelos valores da entalpia mostrados na Figura 37 para ambos processos termodinâmicos. Apesar dos desvios nas medidas, da figura pode-se ver que na presença de ODN as entalpias diminuem até atingir um mínimo em $7 \mathrm{kcal} / \mathrm{mol}$ na presença de $0.05 \mathrm{mM}$, e aumentam em concentrações maiores de ODN até estabilizar a entalpia ao redor de $9 \mathrm{kcal} / \mathrm{mol}$ para o processo endotérmico (Tabela 4) e $11 \mathrm{kcal} / \mathrm{mol}$ para o processo exotérmico (Tabela 5). No entanto, esta diferencia de $9 \mathrm{kcal} / \mathrm{mol}$ para $11 \mathrm{kcal} / \mathrm{mol}$ mostrados pode ser um erro na subtração da linha e base.

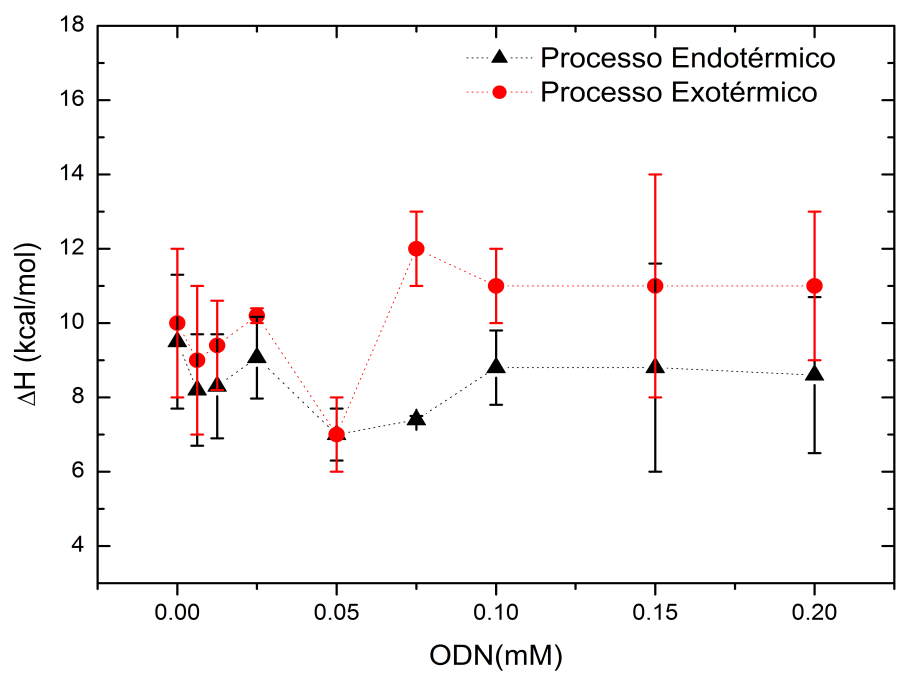

Figura 37: Efeito da concentração de ODN sobre o parâmetro termodinâmico da entalpia em $1 \mathrm{mM}$ de vesículas extrusadas de DODAB.

Portanto, destes resultados podemos dizer novamente que concentrações superiores a $0.075 \mathrm{mM}$ de ODN na dispersão lipídica saturam os parâmetros termodinâmicos com o excesso de carga negativa. Isso pode ser um indício de que os oligonucleotídeos não estão se ligando mais com os lipídios de DODAB, ficando cada vez mais no meio aquoso. 
Tabela 4: Valores dos parâmetros termodinâmicos de transição de fase, para o processo de aquecimento de $1 \mathrm{mM}$ de vesículas de DODAB em presença e ausência de ODN.

\begin{tabular}{|c|c|c|c|c|}
\hline Dispersão & $\begin{array}{c}\text { Intervalo de, } \mathrm{T}, \\
\text { para o calculo de } \\
\Delta H(\mathrm{Kcal} / \mathrm{mol})\end{array}$ & $\Delta H(\mathrm{Kcal} / \mathrm{mol})$ & $T_{m}\left({ }^{\circ} \mathrm{C}\right)$ & $\Delta T_{1 / 2}\left({ }^{\circ} C\right)$ \\
\hline DODAB: Hepes & $35-47$ & $9 \pm 2$ & $46.5 \pm 0.1$ & $1.0 \pm 0.2$ \\
\hline $\mathrm{DODAB}+0.00625 \mathrm{mM}$ ODN & $30-50$ & $8 \pm 2$ & $47.7 \pm 0.3$ & - \\
\hline $\mathrm{DODAB}+0.0125 \mathrm{mM}$ ODN & $30-50$ & $8 \pm 1$ & - & - \\
\hline $\mathrm{DODAB}+0.025 m M$ ODN & $30-50$ & $9 \pm 1$ & - & - \\
\hline $\mathrm{DODAB}+0.05 m M$ ODN & $35-52$ & $7 \pm 1$ & $49 \pm 1$ & - \\
\hline $\mathrm{DODAB}+0.075 m M$ ODN & $35-55$ & $7.4 \pm 0.1$ & - & - \\
\hline $\mathrm{DODAB}+0.1 m M \mathrm{ODN}$ & $35-55$ & $9 \pm 1$ & - & - \\
\hline $\mathrm{DODAB}+0.15 m M$ ODN & $35-55$ & $9 \pm 3$ & - & \\
\hline $\mathrm{DODAB}+0.2 m M$ ODN & $35-55$ & $9 \pm 3$ & - & \\
\hline
\end{tabular}

Tabela 5: Valores dos parâmetros termodinâmicos de transição de fase, para o processo de resriamento de $1 \mathrm{mM}$ de vesículas de DODAB em presença e ausência de ODN.

\begin{tabular}{|c|c|c|c|c|}
\hline Dispersão & $\begin{array}{c}\text { Intervalo de, } \mathrm{T}, \\
\text { para o calculo de } \\
\Delta H(\text { Kcal } / \mathrm{mol})\end{array}$ & $\Delta H(\mathrm{Kcal} / \mathrm{mol})$ & $T_{m}\left({ }^{\circ} \mathrm{C}\right)$ & $\Delta T_{1 / 2}\left({ }^{\circ} C\right)$ \\
\hline DODAB: Hepes & $30-42$ & $10 \pm 2$ & $41.0 \pm 0.1$ & $1.0 \pm 0.1$ \\
\hline $\mathrm{DODAB}+0.00625 m M$ ODN & $30-44$ & $9 \pm 2$ & $41.0 \pm 0.3$ & $1.0 \pm 0.1$ \\
\hline $\mathrm{DODAB}+0.0125 \mathrm{mM}$ ODN & $30-44$ & $9.4 \pm 1.2$ & $41.0 \pm 0.5$ & $1.5 \pm 0.1$ \\
\hline $\mathrm{DODAB}+0.025 m M$ ODN & $30-44$ & $10.2 \pm 0.2$ & - & - \\
\hline $\mathrm{DODAB}+0.05 m M$ ODN & $35-52$ & $7 \pm 2$ & & - \\
\hline $\mathrm{DODAB}+0.075 m M$ ODN & $35-52$ & $12 \pm 2$ & - & - \\
\hline $\mathrm{DODAB}+0.1 m M$ ODN & $30-55$ & $11 \pm 2$ & $46.0 \pm 0.5$ & $2.2 \pm 0.1$ \\
\hline $\mathrm{DODAB}+0.15 m M$ ODN & $30-55$ & $11 \pm 3$ & $46.0 \pm 0.3$ & $2.2 \pm 0.1$ \\
\hline $\mathrm{DODAB}+0.2 m M$ ODN & $30-55$ & $11 \pm 3$ & $46.0 \pm 0.3$ & $2.3 \pm 0.2$ \\
\hline
\end{tabular}




\subsection{Sensibilidade da sonda Laurdan em monitorar alterações nas vesículas de DODAB causadas pelo ODN}

Dando prosseguimento a este estudo, nas vesículas de DODAB foi inserida a sonda fluorescente Laurdan. Esta sonda é um fluoróforo que apresenta uma grande sensibilidade em presença de mudanças como a polaridade ou viscosidade do meio que a circunda. Portanto, nesta terceira parte, aproveitando a localização do Laurdan na superfície da vesícula de DODAB (Musukawa et al. 2016), determinaremos, através de técnicas como a fluorescência estática e a anisotropia de fluorescência, se o Laurdan é capaz de monitorar as modificações estruturais e esta possível "desidratação" causada por oligonucleotídeos na superfície das vesículas de DODAB (seção 4.1 e 4.2).

Além disso, como visto na seção 3.4.6, os espectros de absorbância nos ajudaram a corrigir os espectros de fluorescência pelo método de filtro interno.

Para facilitar o estudo do efeito causado pelo Oligonucleotídeo (ODN) em vesículas de DODAB, os resultados foram divididos em três partes: medidas de absorção óptica, emissão e anisotropia de fluorescência, na fase gel $\left(30^{\circ} \mathrm{C}\right)$ e na fase fluida $\left(60^{\circ} \mathrm{C}\right)$ do DODAB.

\subsubsection{Espectros de absorção óptica do Laurdan inserido em DODAB em presença de $O D N$}

Através dos experimentos de turbidez (veja a seção 4.1.1), observamos que a adição de 0.05 e $0.075 \mathrm{mM}$ de ODN na dispersão lipídica induzia agregação, esta agregação inviabiliza as medidas de Absorbância. Portanto, depois que nos asseguramos que possuímos um controle na estabilidade das dispersões, iniciamos os experimentos com as concentrações restantes.

Na Figura (38.a), mostra-se o espectro de absorção das vesículas de DODAB em Hepes nas fases gel e fluida. Observa-se que o espectro apresenta um forte aumento nos valores de Absorbância em comprimentos de onda menores, atribuído exclusivamente ao espalhamento da luz incidente pelas vesículas de DODAB. Na Figura (38.b), são apresentados os espectros de absorção de $0.025 \mathrm{mM}$ ODN em Hepes nas temperaturas de $30{ }^{\circ} \mathrm{C}$ e $60{ }^{\circ} \mathrm{C}$. Este oligonucleotídeo, como mencionado anteriormente, possui em sua estrutura bases tipo adenina, constituídas por anéis aromáticos caraterísticos de cromóforos que 


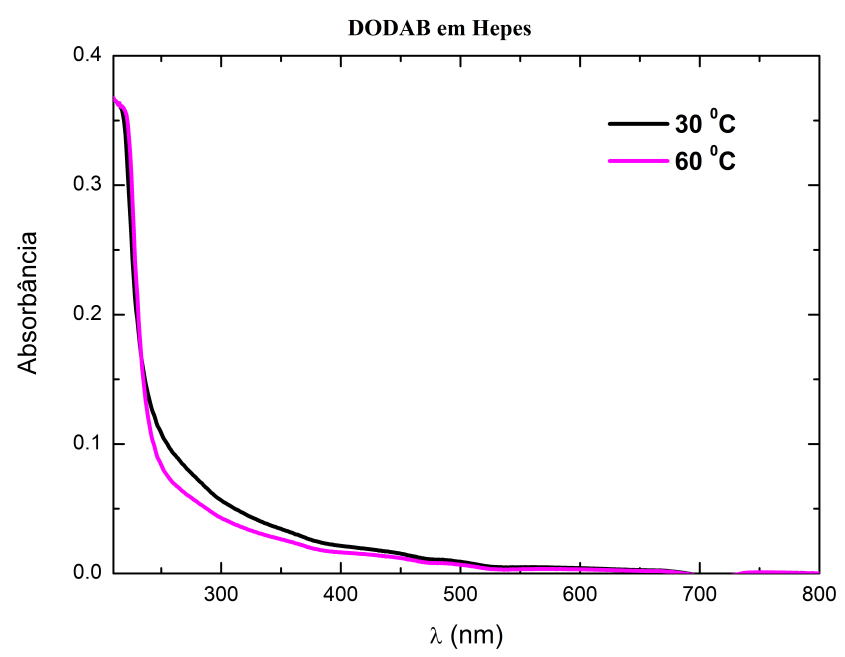

(a)

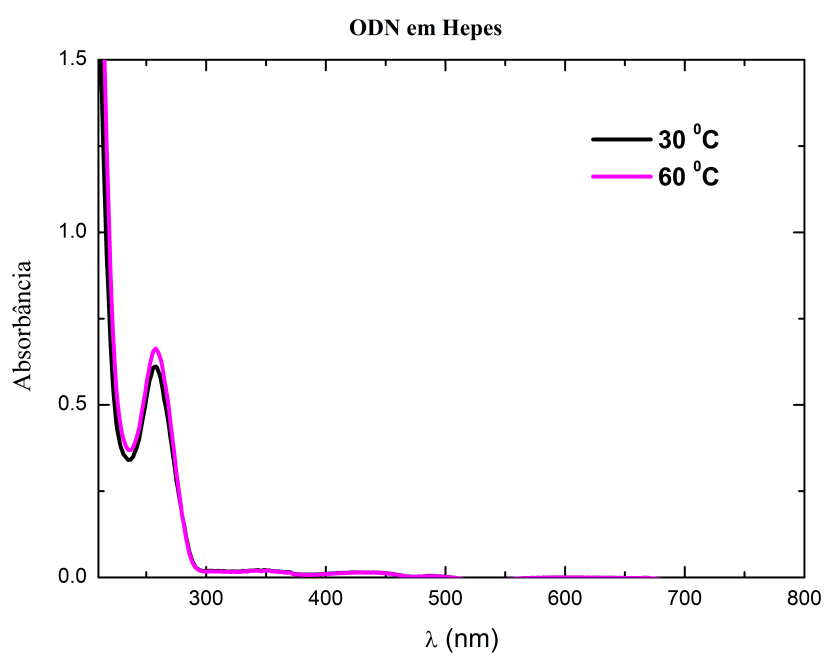

(b)

Figura 38: (a) espectros de absorção na fase gel e fluida do DODAB em Hepes. (b) espectros de absorção de $0.025 \mathrm{mM}$ de ODN disperso em Hepes.

absorvem luz (Smithh. L. M et al., 1986). É importante mencionar que o processo de volta do estado excitado para o estado fundamental dos elétrons excitados da adenina é um processo não radiativo, pois a energia é perdida catalisando uma reação entre bases nitrogenadas próximas (Alves e Sousa, 2013). Da figura (38.b) podemos ver que no intervalo de 300 a 800 nm, o ODN não apresenta valores de Absorbância. No entanto, no intervalo entre 230 e $300 \mathrm{~nm}$, podemos ver um aumento nos valores da Absorbância, a qual se deve exclusivamente a uma absorção de transições de níveis eletrônicos dos elétrons delocalizados da adenina. Este resultado nos mostra que o ODN apresenta ab- 
sorção eletrônica somente até $300 \mathrm{~nm}$, e que devido a isto, os resultados dos espectros de emissão da sonda fluorescente Laurdan na região entre 400-600 nm, (de interesse em nosso estudos) se devem exclusivamente ao Laurdan pois esta sonda foi excitada em 350 $n m$.

Na Figura 39, são mostrados os espectros de absorção do Laurdan inserido nas vesículas de DODAB, em ausência e presença de baixas concentrações de ODN, para 30 ${ }^{\circ} \mathrm{C}$ e $60{ }^{\circ} \mathrm{C}$ (reproduzidos para três ou mais amostras diferentes). Da figura podemos ver

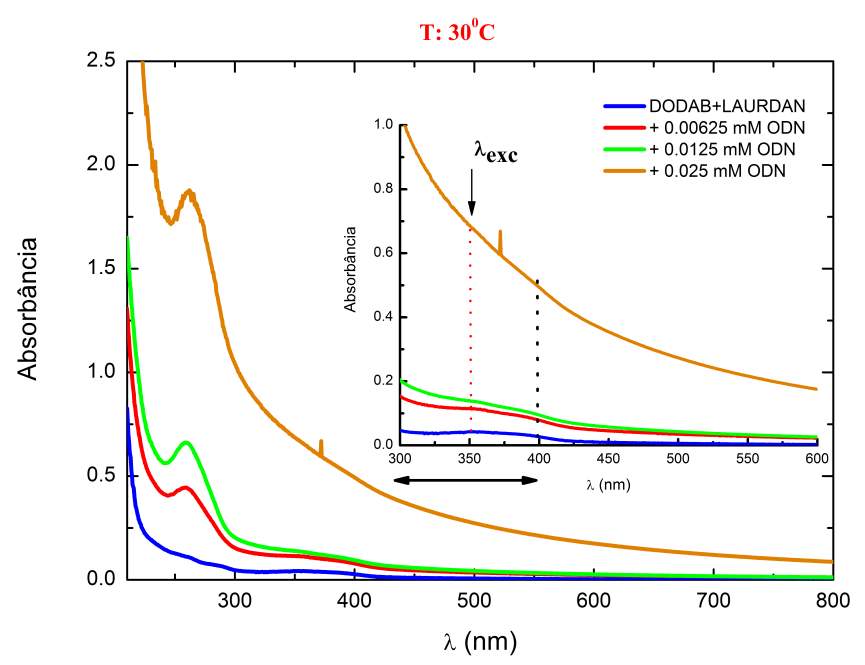

(a)

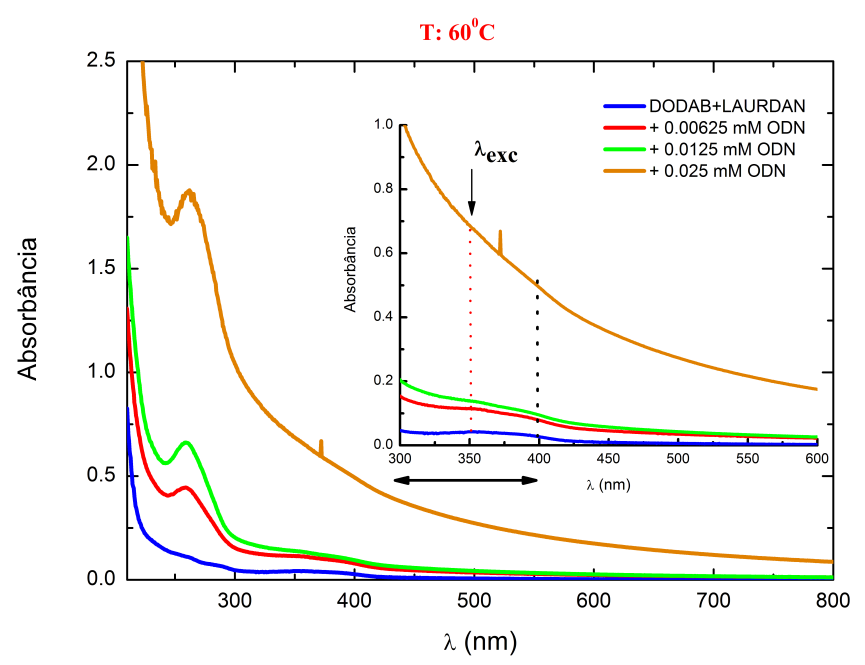

(b)

Figura 39: espectros de absorção do Laurdan inserido nas vesículas de DODAB em ausência e presença de baixas concentrações de ODN (a) na fase gel e (b) fluida do DODAB. Espectros reproduzidos para três ou mais amostras diferentes.

que conforme é feita a adição de ODN na dispersão lipídica, para ambas temperaturas 
(fig 39.a e 39.b), a banda característica de absorção eletrônica do Laurdan, a qual se encontra na região entre 300-400 nm, aumenta seus valores de Absorbância. Além disso, pode-se ver também que o comprimento de onda de excitação (350 $\mathrm{nm}$ ) e a banda de emissão (400-600 $\mathrm{nm}$ ) do Laurdan, para nossas medidas de fluorescência aumentam seus valores de Absorbância (fig 39.a e 39.b). Outro resultado que pode ser inferido da Figura (39.a) e (39.b) é o aumento dos valores de Absorbância na banda caraterística de absorção eletrônica do ODN, como esperado.

Esses resultados de aumento dos valores de Absorbância mostrados tanto na banda de absorção do Laurdan e na banda do ODN pode ser um efeito de um maior de espalhamento da luz incidente pelas vesículas de DODAB. Este resultado de um maior espalhamento é concluído e reforçado pelas imagens de turbidez (obtidas após 4 horas de incubação a $30{ }^{\circ} \mathrm{C}$, veja a Figura 40) e pelos resultados de DLS encontrados na seção 4.1.2.1, na qual a turbidez aumenta e as vesículas de DODAB mudam sua estrutura para maiores tamanhos conforme é feita a adição de baixas concentrações de ODN na dispersão lipídica.

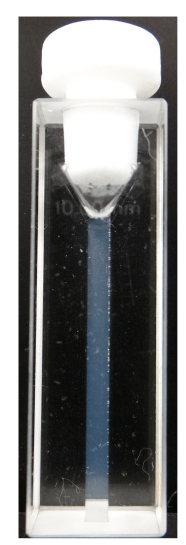

DODAB+ Laurdan
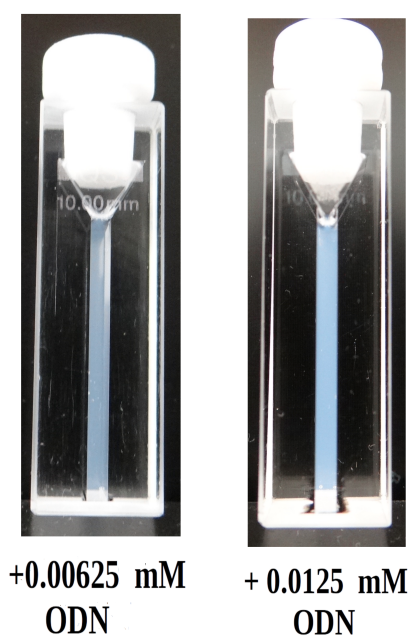

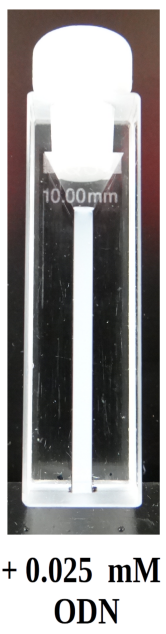

ODN

Figura 40: Avaliação da turbidez para $1 \mathrm{mM}$ de vesículas extrusadas de DODAB em presença de baixas concentrações de ODN, após 4 horas de incubação a T: $30^{\circ} \mathrm{C}$.

Na Figura 41, são mostrados os espectros de absorção do Laurdan inserido nas vesículas de DODAB em ausência e presença de altas concentrações de ODN, para 30 ${ }^{\circ} \mathrm{C}$ e $60{ }^{\circ} \mathrm{C}$. Da figura podemos ver que com a adição de ODN na dispersão lipídica para ambas temperaturas (fig 41.a e 41.b), a banda característica de absorção eletrônica do Laurdan, a qual, se encontra na região entre 300-400 nm, diminui seus valores de 


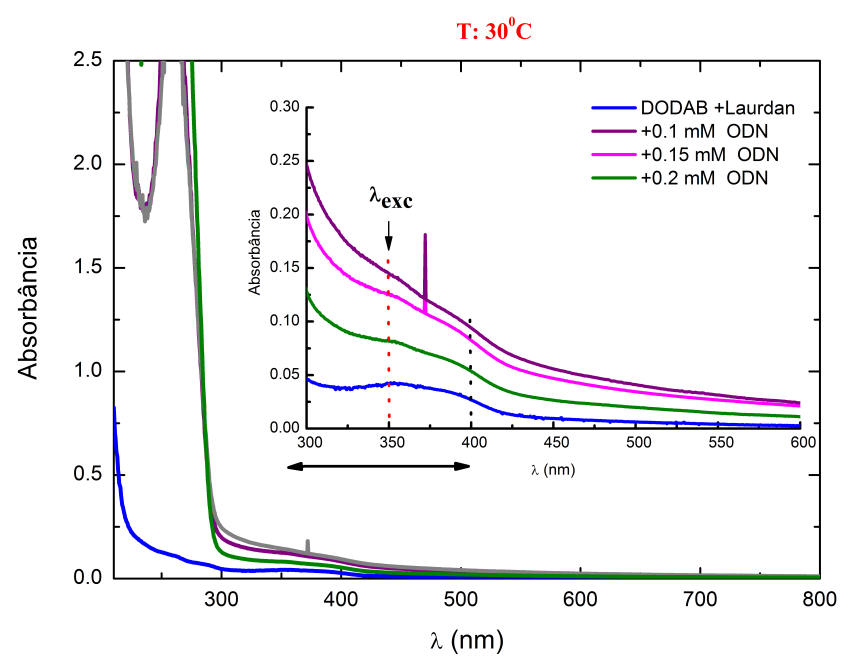

(a)

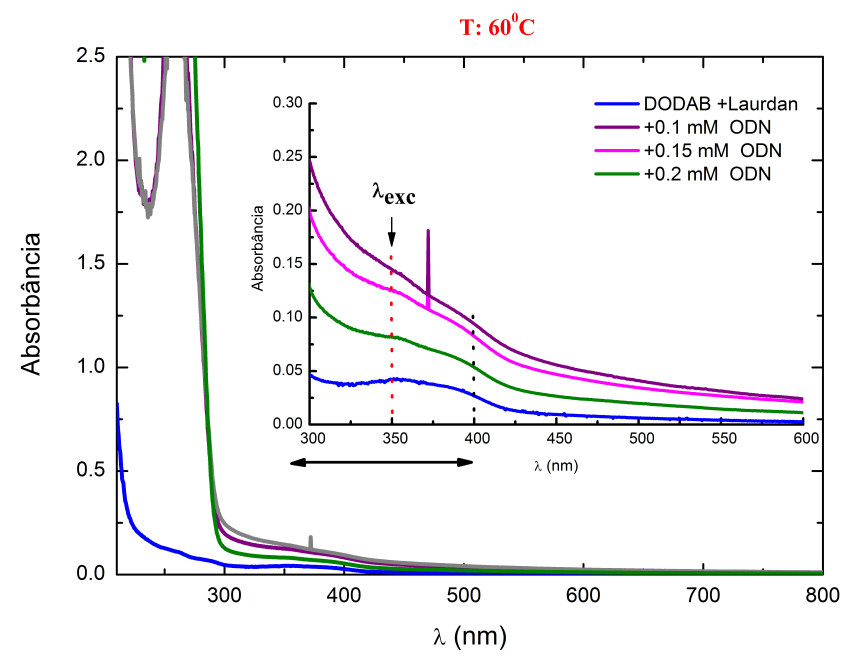

(b)

Figura 41: espectros de absorção do Laurdan inserido nas vesículas de DODAB em ausência e presença de altas concentrações de ODN (a) na fase gel e (b) fluida do DODAB. Espectros reproduzidos para três ou mais amostras diferentes.

Absorbância em relação ao valor da absorbância de 0.025 mM de ODN (fig 39.a e 39.b), mas mantêm o aumento de seus valores em relação ao puro DODAB. Este mesmo efeito dos valores de Absorbância é observado para o comprimento de onda de excitação (350 $\mathrm{nm}$ ) e a banda de emissão (400-600 $\mathrm{nm}$ ) do Laurdan, para nossas medidas de fluorescência. Um resultado diferente é mostrado na banda caraterística de absorção eletrônica do ODN, na qual, podemos ver um maior aumento dos valores de absorbância em relação à banda do ODN mostrado nas figuras (39.a) e (39.b).

O resultado da diminuição nos valores de Absorbância mostrado na banda do 
Laurdan, tanto na fase gel como fluida do lipídio para altas concentrações de ODN é um resultado esperado, já que na região de supercompensação de carga, a turbidez apresenta uma reversão (veja a Figura 42) e as vesículas de DODAB mudam sua estrutura para tamanhos menores (ver os resultados de DLS na seção 4.1.2.1), o qual consequentemente, é percebido com um menor espalhamento da luz incidente pelas vesículas de DODAB (fig 41. a e 41.b).

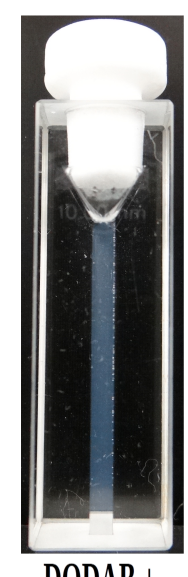

$\mathrm{DODAB}+$

Laurdan

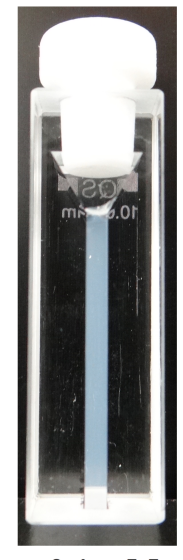

$+0.1 \mathrm{mM}$

ODN

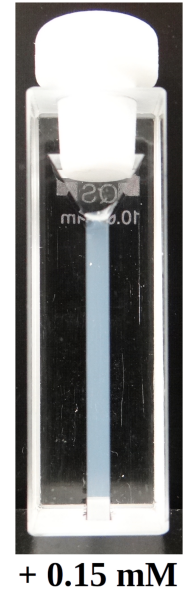

ODN

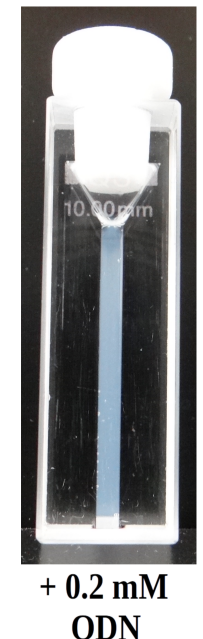

ODN

Figura 42: Avaliação da turbidez para $1 \mathrm{mM}$ de vesículas extrusadas de DODAB em presença de altas concentrações de ODN, após 4 horas de incubação a T: $30^{\circ} \mathrm{C}$.

Visto que adição de ODN no DODAB, tanto na fase gel como como na fase fluida, leva ao aumento da Absorbância na região de excitação e emissão do Laurdan, portanto ressaltamos a importância em fazer as correções dos espectros de fluorescência pelo filtro interno, conforme descrito na seção 3.4.6.

Além disso, através do espectro de absorção (Figura 39.a e 39.b) e a imagem de turbidez (Figura 40), observamos que a adição de $0.025 \mathrm{mM}$ de ODN na dispersão lipídica induz um maior espalhamento de luz e turbidez. Este alto espalhamento e turbidez inviabiliza as medidas de emissão e anisotropia de fluorescência do Laurdan. Portanto, depois que nos asseguramos que possuímos um controle das dispersões, iniciamos os experimentos com as concentrações restantes. 


\subsubsection{Espectros de emissão do Laurdan inserido em DODAB em presença de ODN}

Segundo os autores (Vequi-Suplicy, 2015) (Parasassi et al., 1991), o deslocamento de um espectro de emissão fluorescente para comprimentos de onda menores ("blue shift") representa um estado de menor relaxação com o meio, o que indica um ambiente menos polar. Por outro lado, o deslocamento para comprimentos de onda maiores ("red shift") refere-se ao estado com maior relaxação com o meio, sugerindo um ambiente mais polar. Para exemplificar, na Tabela 6 são mostrados alguns valores de máximos comprimentos de onda de emissão e polaridade obtidos da literatura ( Vequi-Suplicy et al, 2015).

Tabela 6: Valores máximos de emissão, $\lambda_{m}(\mathrm{~nm})$, em diferentes solventes, para o Laurdan. Dados extraídos da literatura (Vequi-Suplicy et al., 2015).

\begin{tabular}{lcc}
\hline Disperção & Polaridade $\epsilon$ & Laurdan $\lambda_{m}(\mathrm{~nm})$ \\
\hline Água & 78.9 & - \\
Metanol & 33.0 & 503 \\
Acetonitrila & 36.6 & 472 \\
Diclorometano & 8.9 & 442 \\
Clorofórmio & 4.8 & 441 \\
\hline
\end{tabular}

Os dados da Tabela 6 servirão como referência para a polaridade do Laurdan, para quando este encontrar-se inserido nas vesículas de DODAB em ausência e presença de ODN.

O espectro de florescência do Laurdan em bicamadas de fosfolipídios é assimétrico, e foi constatado fenomenologicamente que a forma do espectro pode mudar com a fase da bicamada lipídica de fosfolipídios (Vequi-Suplicy, 2015). A Figura 43 mostra um exemplo dos espectros de emissão do Laurdan inserido em DODAB, corrigidos e normalizados conforme descrito na seção 3.4 .6 , em $\mathrm{T}=30{ }^{\circ} \mathrm{C}$ e $60^{\circ} \mathrm{C}$. Da figura podemos ver que na fase gel do DODAB o espectro de emissão do Laurdan apresenta um pico de intensidade máxima para o comprimento de onda em $480 \mathrm{~nm}$ (veja a linha vertical tracejada de cor azul). Entretanto, na fase fluida do lipídio, a intensidade máxima encontra-se em 487 $n m$ (veja a linha vertical tracejada de cor vermelha). Este resultado nos mostra que a mudança do ambiente de gel para fluido do DODAB não afeta significativamente o 
comprimento de onda máximo de emissão do Laurdan. Baseados nos dados da Tabela 6, o Laurdan poderia encontrar-se num ambiente de polaridade relativamente alta como a acetonitrila.

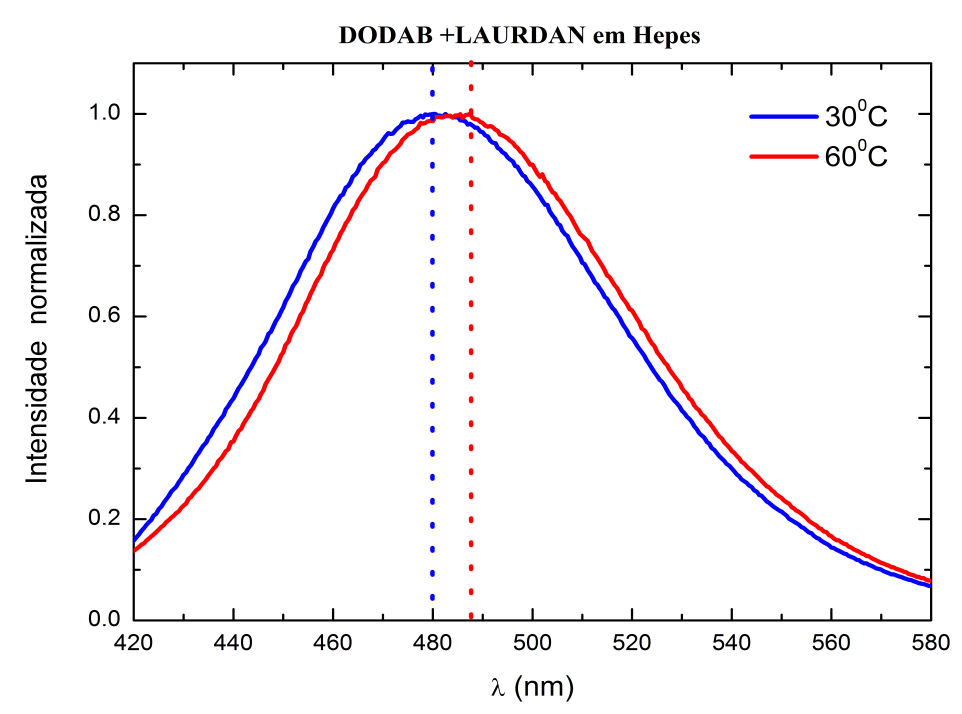

Figura 43: Espectros de emissão da sonda Laurdan inserido em $1 \mathrm{mM}$ de vesículas extrusadas de DODAB em Hepes. As linhas tracejadas marcam os máximos das intensidades para as duas fases dos lipídios, em $30^{\circ} \mathrm{C}$ e $60^{\circ} \mathrm{C}$.

Este resultado já foi discutido (Musukawa et al, 2016, em preparação), já que isto levou o DODAB a ser o primeiro lipídio em que o Laurdan mostra-se pouco sensível à transição de fase, com a proposta de que a sonda encontra-se entre a superfície da vesícula e a parte aquosa do meio (veja a seção 1.3). Novamente, como descrito no início desta seção, a localização da sonda Laurdan será usada para monitorar a polaridade na superfície da bicamada de DODAB em presença tanto para baixas como altas concentrações de ODN.

Espectros de emissão fluorescente corrigidos (usando o método de filtro interno, seção 3.4.6) do Laurdan em DODAB, em presença de baixas concentrações de ODN, para $\mathrm{T}=30{ }^{\circ} \mathrm{C}$ (a) e $60{ }^{\circ} \mathrm{C}(\mathrm{b})$, de três amostras diferentes são mostrados nas Figuras 44, 45 e 46. Como mencionado na seção anterior, dada a alta turbidez observada em presença de $[\mathrm{ODN}]=0.025 \mathrm{mM}$, somente foram analizados espectros obtidos nas duas mais baixas concentrações.

Os espectros da esquerda não normalizados, tanto para fase gel (figura 44.a, 45.a e 46.a) como para fluida do DODAB (figura 44.b, 45.b e 46.b), mostram que com a adição de ODN na dispersão lipídica a intensidade da emissão fluorescente do Laurdan aumenta em 


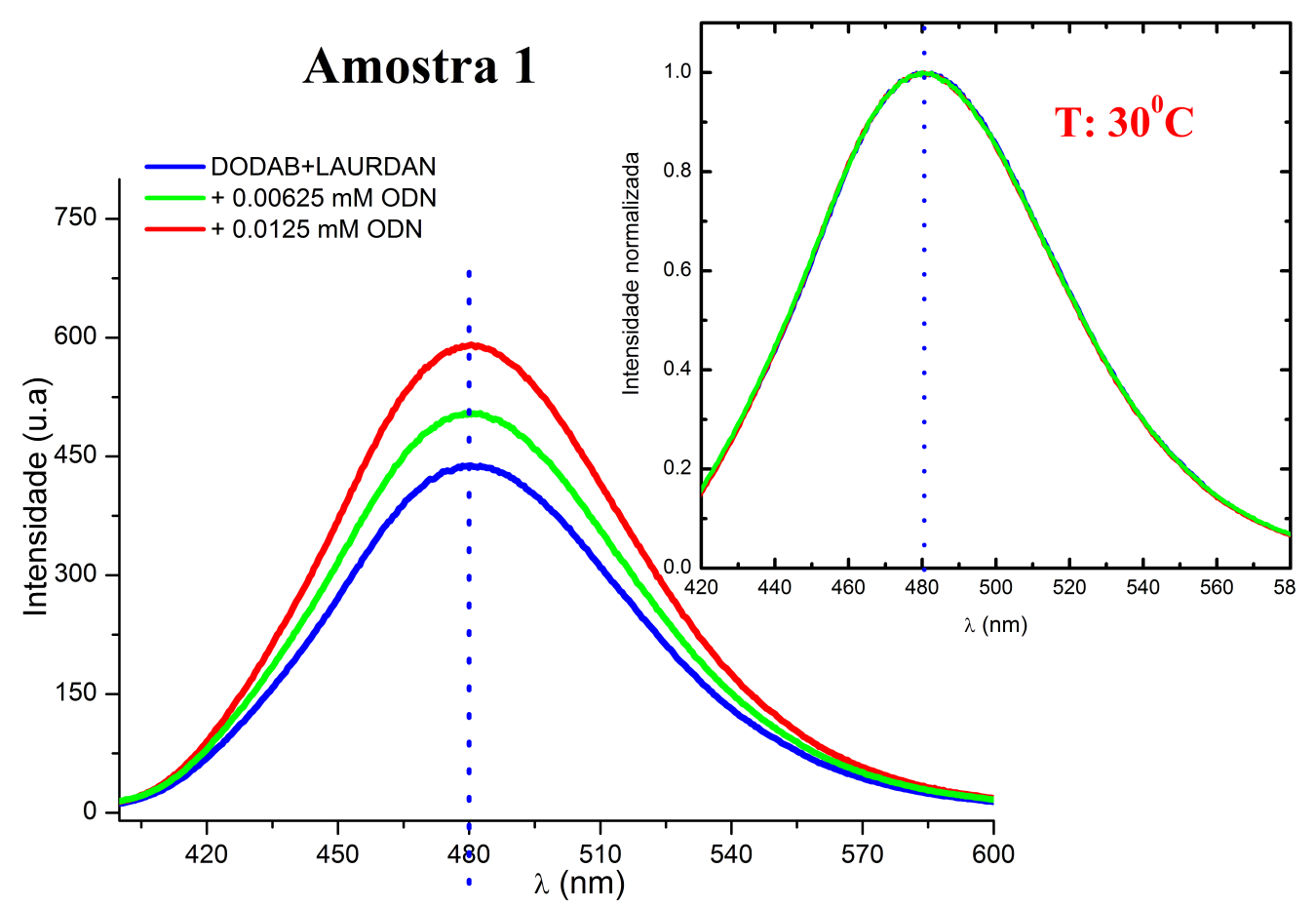

(a)

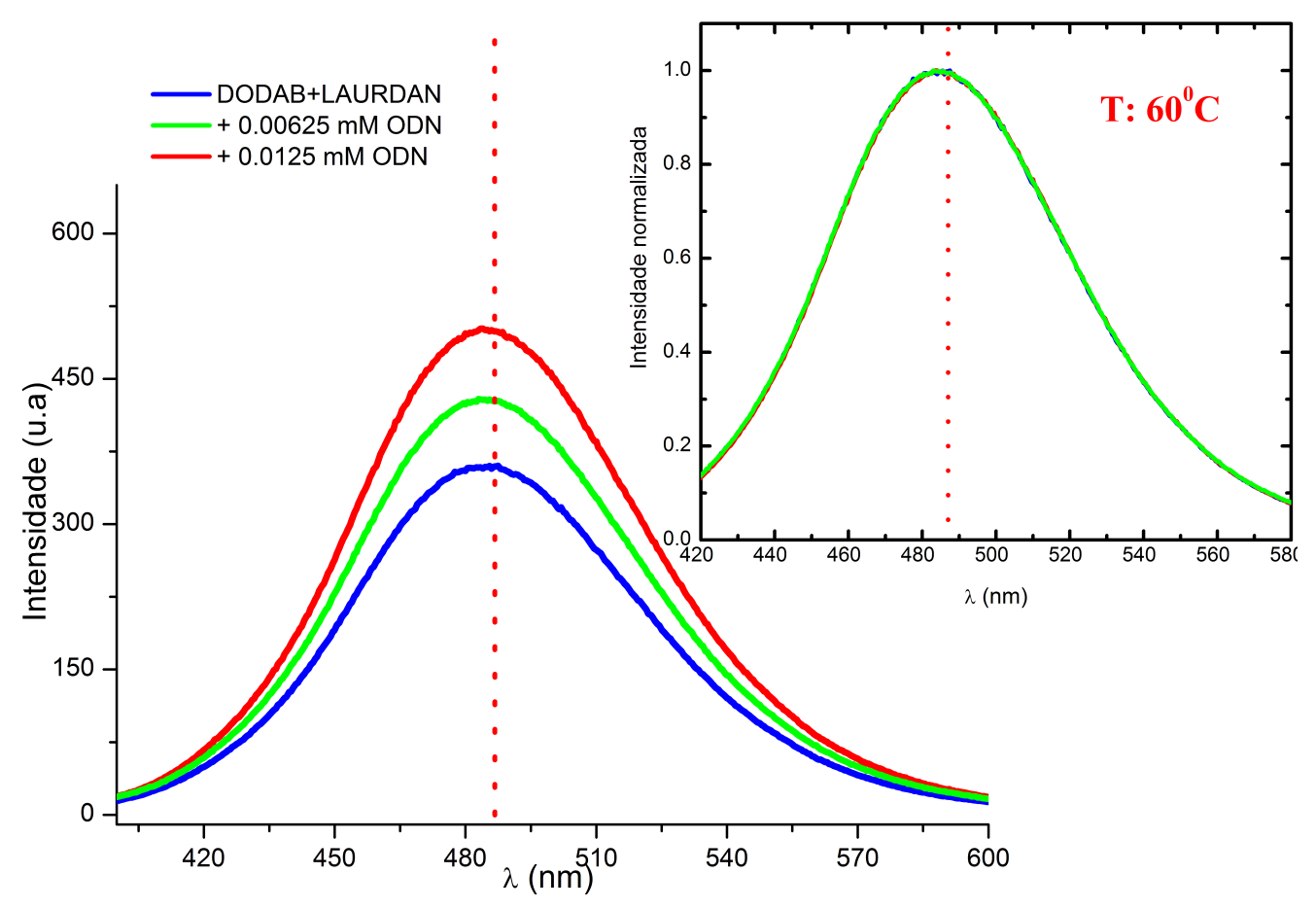

(b)

Figura 44: Espectros de emissão do Laurdan inserido em $1 \mathrm{mM}$ de vesículas extrusadas de DODAB, em presença de baixas concentrações de $O D N$, para $30^{\circ} \mathrm{C}$ (a) e $60^{\circ} \mathrm{C}$ (b). Os gráficos inseridos nos paneis à direita mostram os espectros do Laurdan normalizados. As linhas tracejadas são as mesmas mostradas na Figura 43, para comparação.

relação à intensidade fluorescente do Laurdan em ausência de ODN (espectro azul). No entanto, este aumento das intensidades de fluorescência com o aumento da concentração 


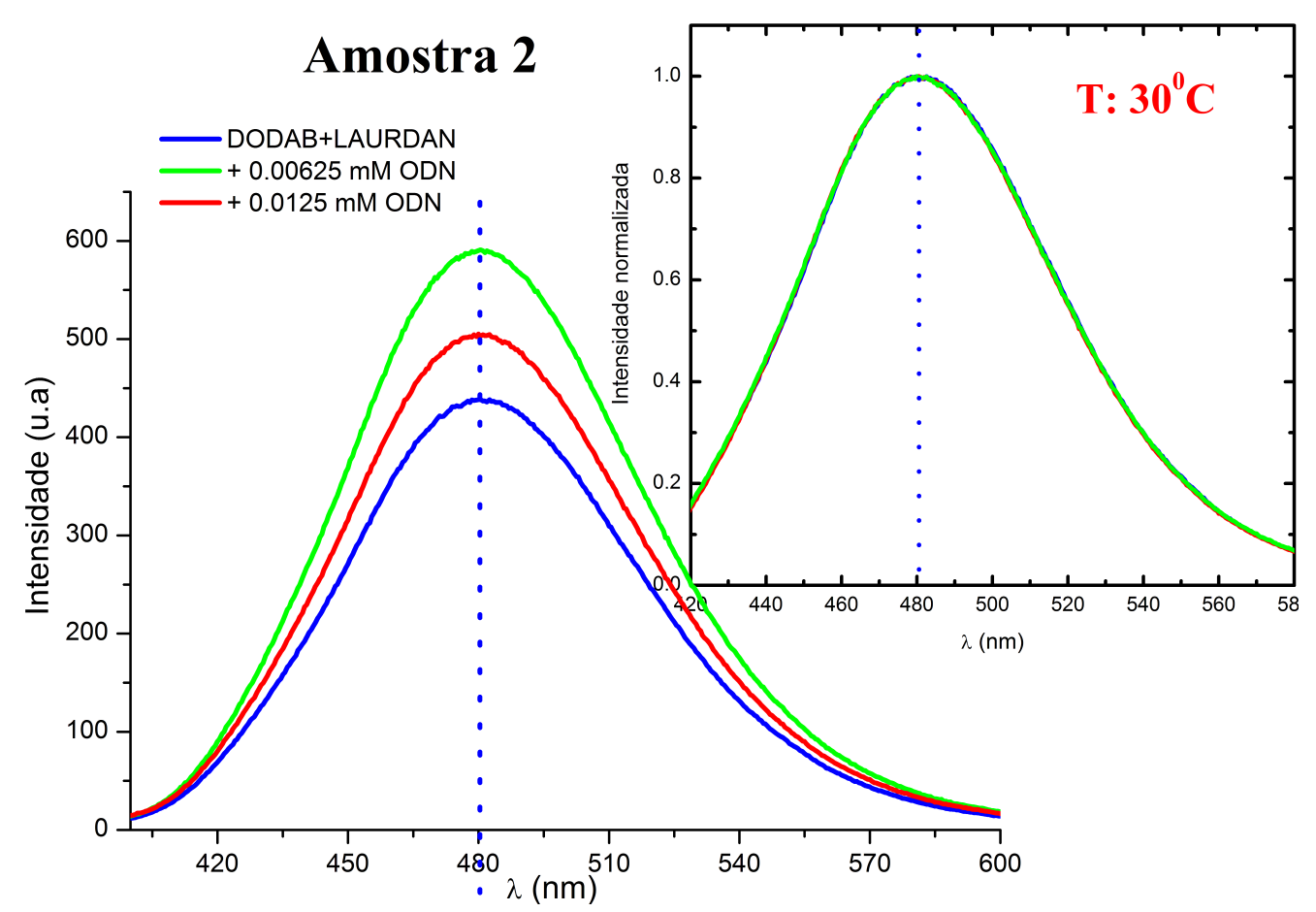

(a)

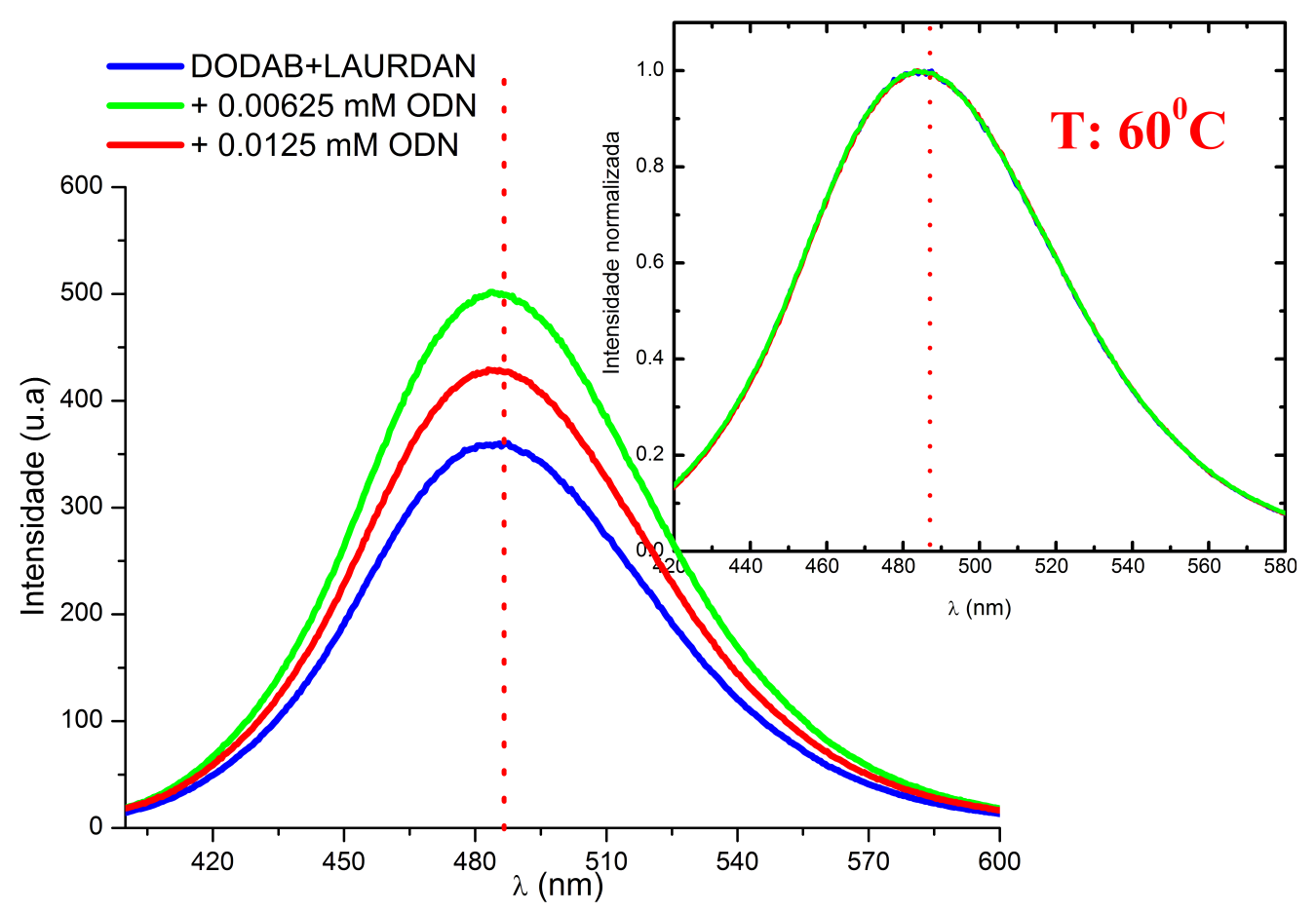

(b)

Figura 45: Espectros de emissão do Laurdan inserido em $1 \mathrm{mM}$ de vesículas extrusadas de DODAB, em presença de baixas concentrações de $O D N$, para $30^{\circ} \mathrm{C}$ (a) e $60{ }^{\circ} \mathrm{C}$ (b). Os gráficos inseridos nos paneis à direita mostram os espectros do Laurdan normalizados. As linhas tracejadas são as mesmas mostradas na Figura 43, para comparação.

(0.00625 mM e $0.0125 m M)$ não pode fornecer uma informação sobre microambiente do Laurdan, já que não são completamente reprodutíveis quando comparadas as três 


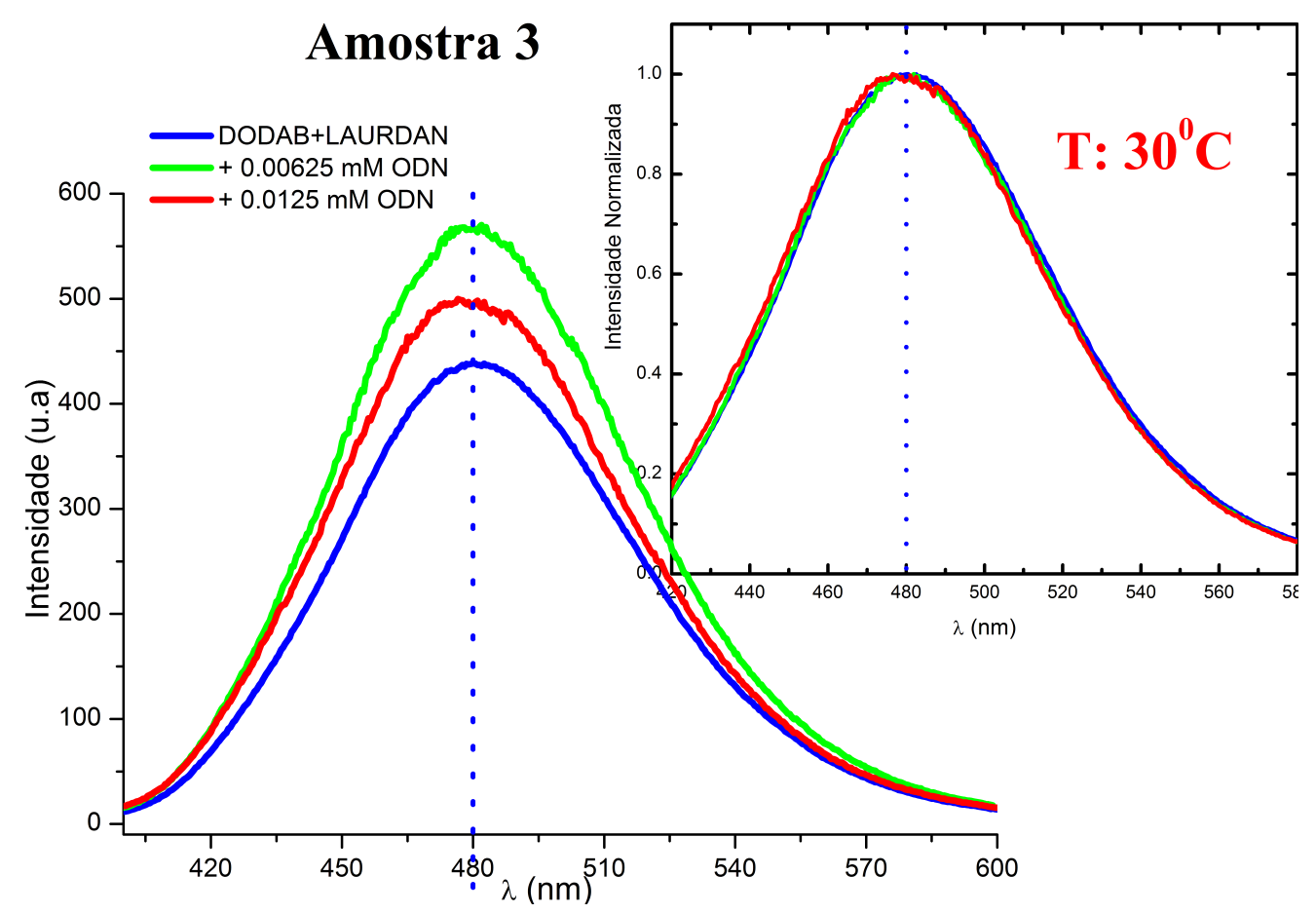

(a)

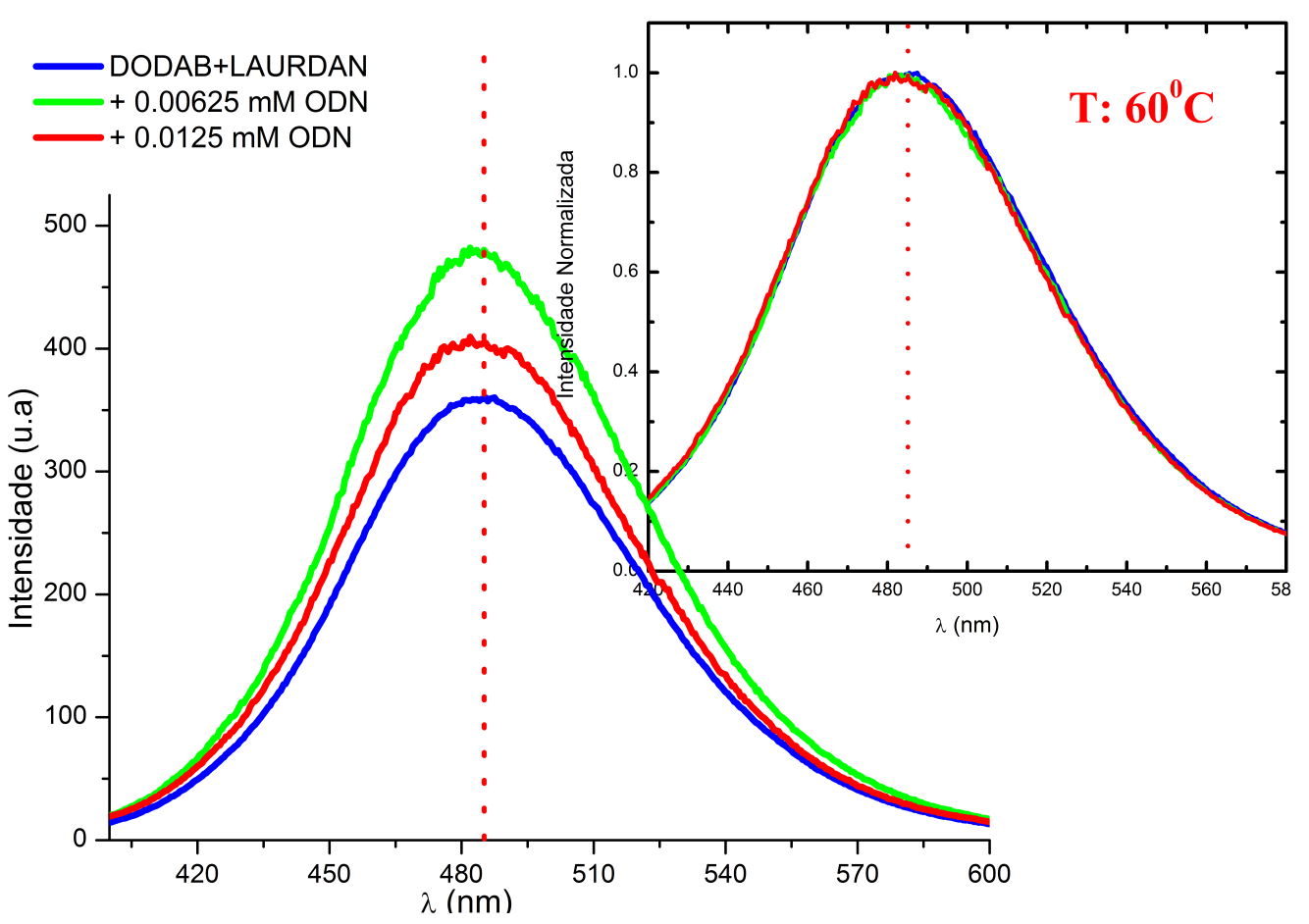

(b)

Figura 46: Espectros de emissão do Laurdan inserido em $1 \mathrm{mM}$ de vesículas extrusadas de DODAB, em presença de baixas concentrações de $O D N$, para $30^{\circ} \mathrm{C}$ (a) e $60{ }^{\circ} \mathrm{C}$ (b). Os gráficos inseridos nos paneis à direita mostram os espectros do Laurdan normalizados. As linhas tracejadas são as mesmas mostradas na Figura 43, para comparação.

amostras diferentes, tanto na fase gel como fluida do DODAB ( ver a figura 44, 45 e 46).

Os espectros de fluorescência normalizados inseridos à direita da figura (figura 44.a, 
45.a e 46.a) e (figura 44.b, 45.b e 46.b) mostram uma reproduzibilidade para trés amostras diferentes, indicando assim que não há mudanças com relação à forma do espectro, e ilustram que não existe deslocamento espectral em relação ao espectro em ausência de ODN (espectro azul) com a adição de concentrações baixas de oligonucleotídeo no arranjo de DODAB. Este resultado é uma indicação de que a adição de baixas concentrações de ODN na dispersão lipídica de DODAB não afeta de maneira significativa a polaridade do microambiente no qual se encontra o Laurdan. O aumento da intensidade de fluorescência do Laurdan com a adição de ODN devera ser mais bem investigado.

Espectros de emissão fluorescente corrigidos (usando o método de filtro interno, seção 3.4.6) do Laurdan em DODAB, em presença de altas concentrações de material genético $(0.1,0.15$ e $0.2 \mathrm{mM} \mathrm{ODN})$, para $\mathrm{T}=30{ }^{\circ} \mathrm{C}$ (a) e $60{ }^{\circ} \mathrm{C}$ (b), de três amostras diferentes são mostrados nas figuras 47,48 e 49.

Dos espectros não normalizados mostrados no lado esquerdo das figuras (47.a, 48.a e 49.a) e figuras (47.b, 48.b e 49.b), podemos ver que a intensidade de emissão fluorescente do Laurdan com a adição de: 0.1, 0.15 e $0.2 \mathrm{mM}$ de ODN aumenta em relação à intensidade do espectro de emissão do Laurdan em DODAB puro (espectro azul). Novamente, o aumento na intensidade de fluorescência do Laurdan com o aumento na concentração de $\operatorname{ODN}(0.1,0.15$ e $0.2 \mathrm{mM})$ é pouco reprodutível, tanto na fase gel como na fase fluida quando comparada com as três amostras diferentes. Mostrando assim pouca informação sobre microambiente do Laurdan e necessita ser mais bem investigado.

Dos espectros normalizados pela amplitude, mostrados no lado direito para cada fase do DODAB (Figura 47.a, 48.a e 49.a e Figura 47.b, 48.b e 49.b), podemos ver que a posição do espectro do Laurdan é reproduzível para as três amostras diferentes, mostrando deslocamento com a adição de altas concentrações de oligonucleotídeo ( 0.1 , 0.15 e $0.2 \mathrm{mM}$ ) principalmente na fase gel da bicamada, movendo-se na direção de baixos comprimentos de onda ("blue shift"). Das figuras (47, 48 e 49), pode-se inferir que na fase gel do DODAB o deslocamento espectral é de aproximadamente $9 \mathrm{~nm}$ e na fase fluida cerca de $5 \mathrm{~nm}$, mostrando deslocamentos pequenos. Portanto, pode-se assumir que o Laurdan ainda se encontra num ambiente semelhante à acetonitrila (Tabela 6), e que a adição de altas concentrações de ODN na dispersão lipídica afeta a polaridade ou o 


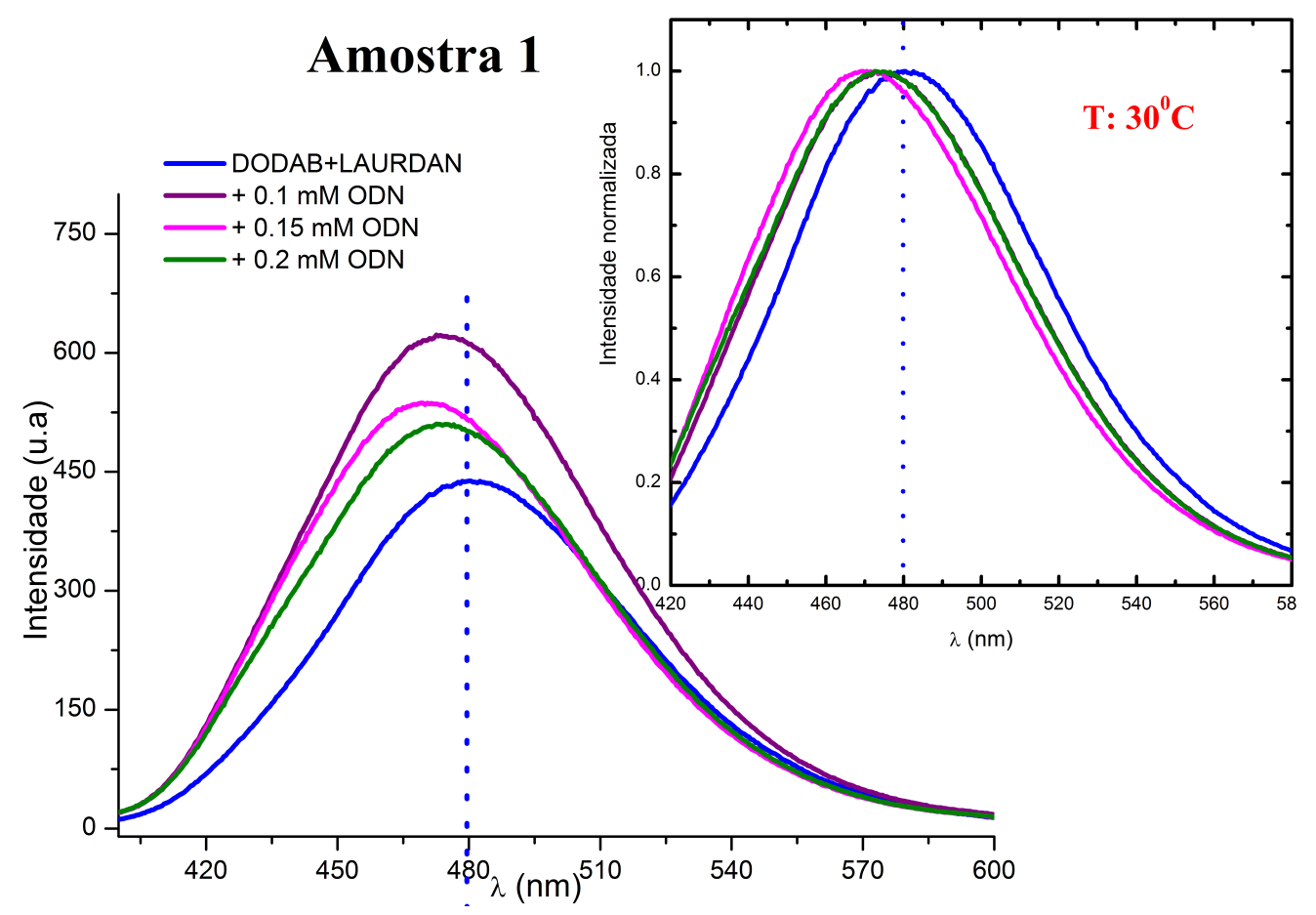

(a)

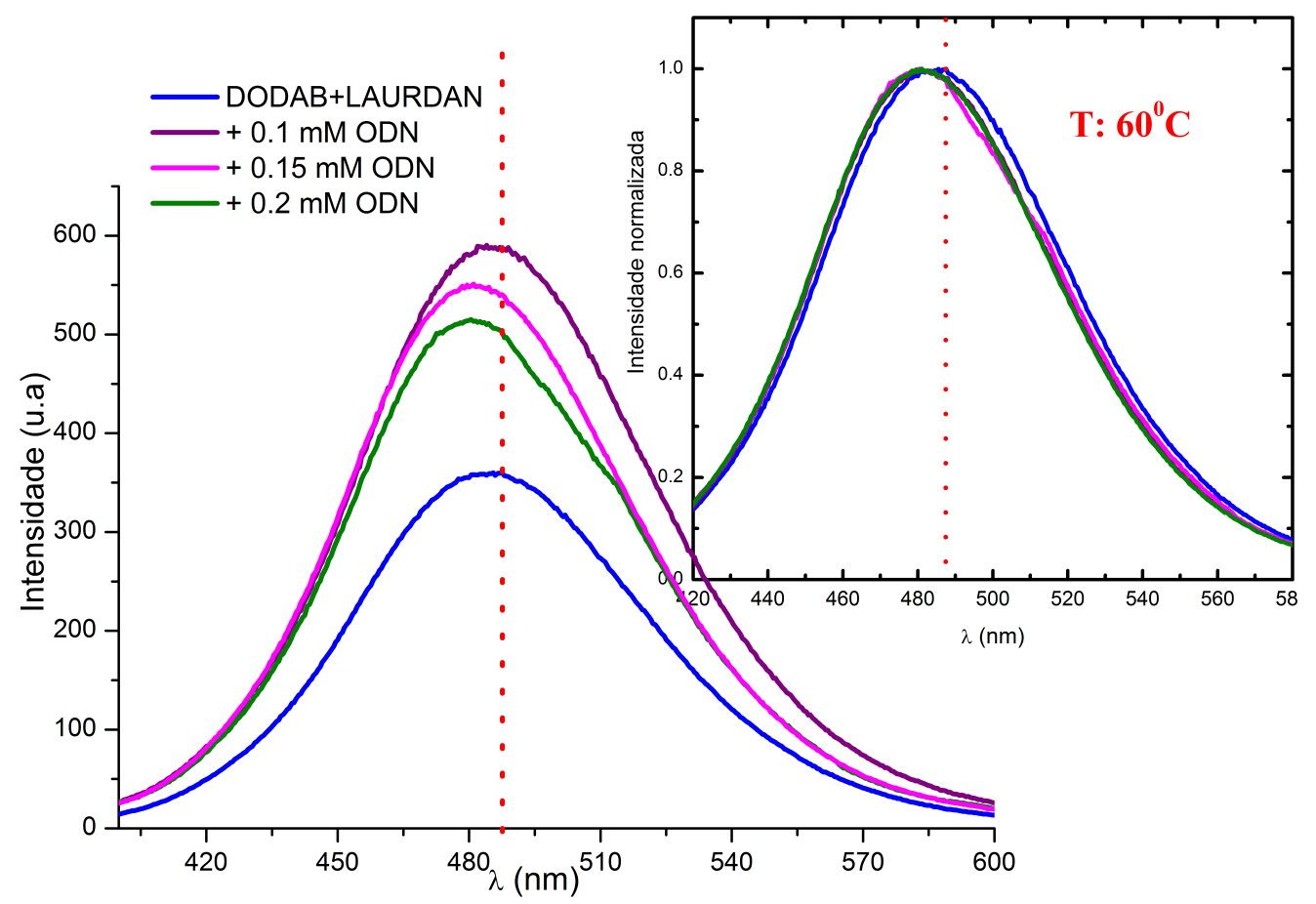

(b)

Figura 47: Espectros de emissão do Laurdan inserido em $1 \mathrm{mM}$ de vesículas extrusadas de DODAB em presença de altas concentrações de $O D N$, para $30^{\circ} \mathrm{C}$ (a) e $60^{\circ} \mathrm{C}$ (b). Os gráficos inseridos nos paneis à direita mostram os espectros do Laurdan normalizados. As linhas tracejadas são as mesmas mostradas na Figura 43, para comparação.

empacotamento do microambiente onde se encontra o Laurdan.

Pelos resultados obtidos nas seções 4.1 e 4.2, foi possível constatar que com a 


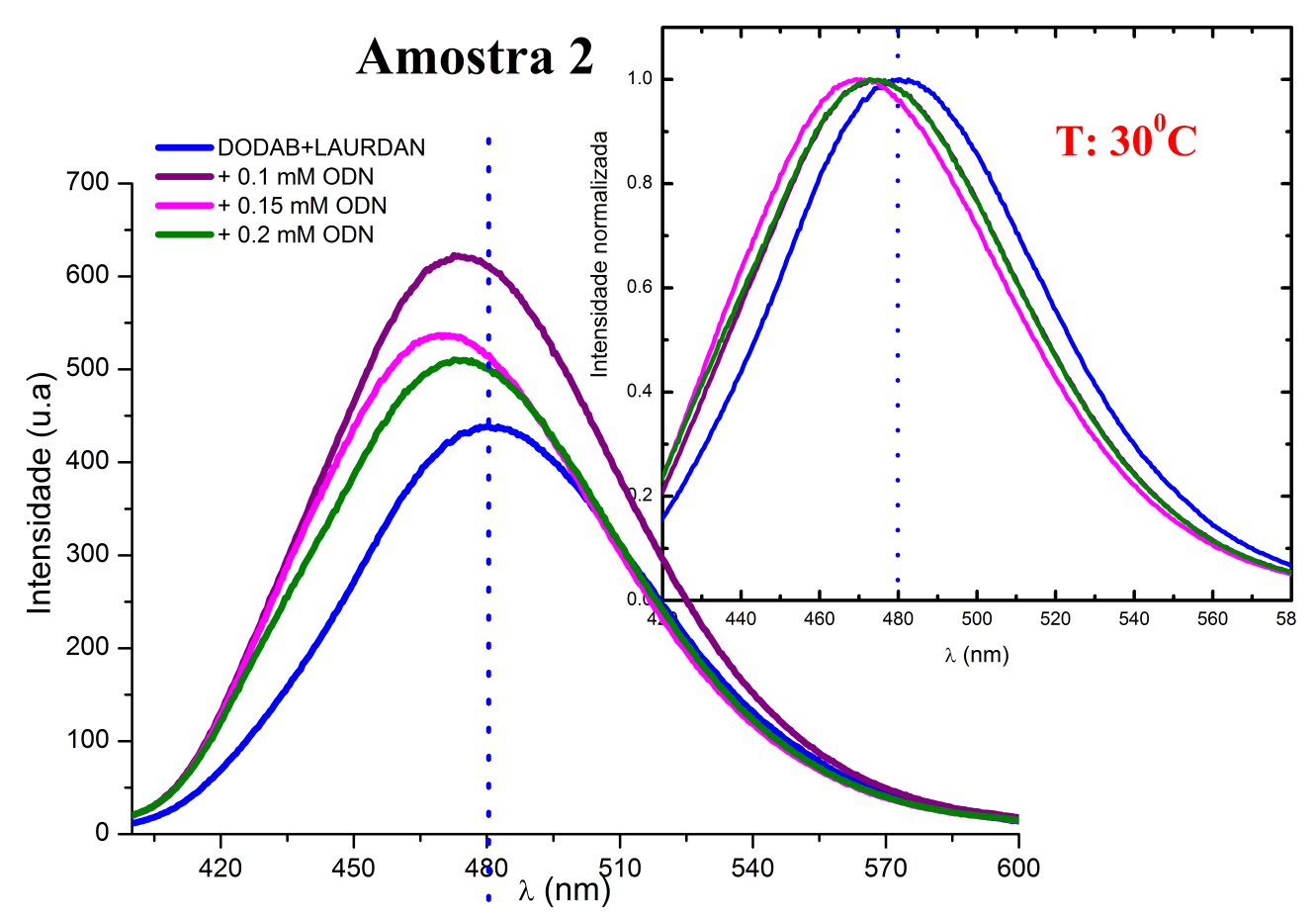

(a)

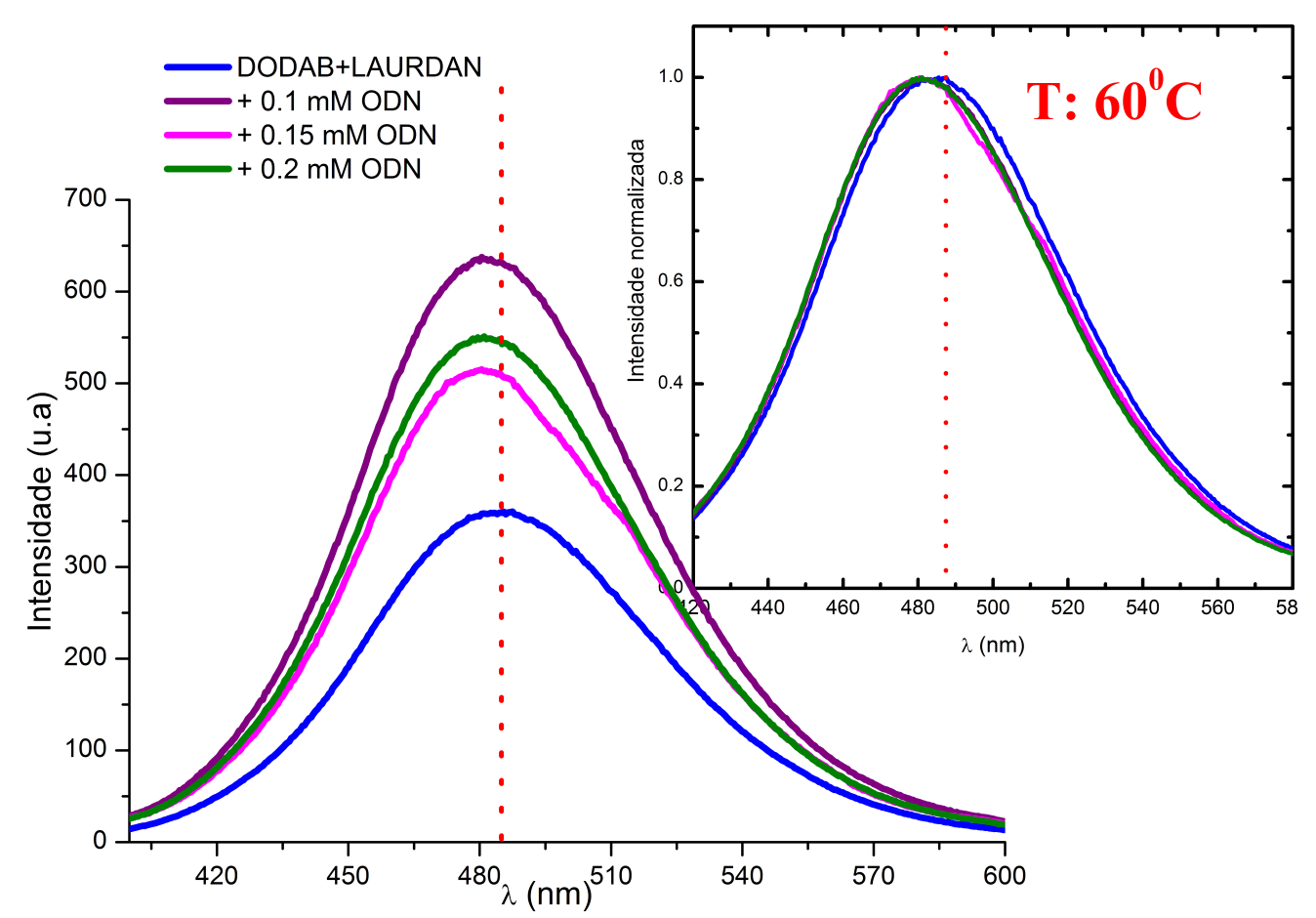

(b)

Figura 48: Espectros de emissão do Laurdan inserido em $1 \mathrm{mM}$ de vesículas extrusadas de DODAB em presença de altas concentrações de $O D N$, para $30^{\circ} \mathrm{C}$ (a) e $60^{\circ} \mathrm{C}$ (b). Os gráficos inseridos nos paneis à direita mostram os espectros do Laurdan normalizados. As linhas tracejadas são as mesmas mostradas na Figura 43, para comparação.

adição de baixas e altas concentrações de ODN na dispersão lipídica de DODAB, os oligonucleotídeos induzem uma modificação na estrutura das vesículas, mostrando assim, 


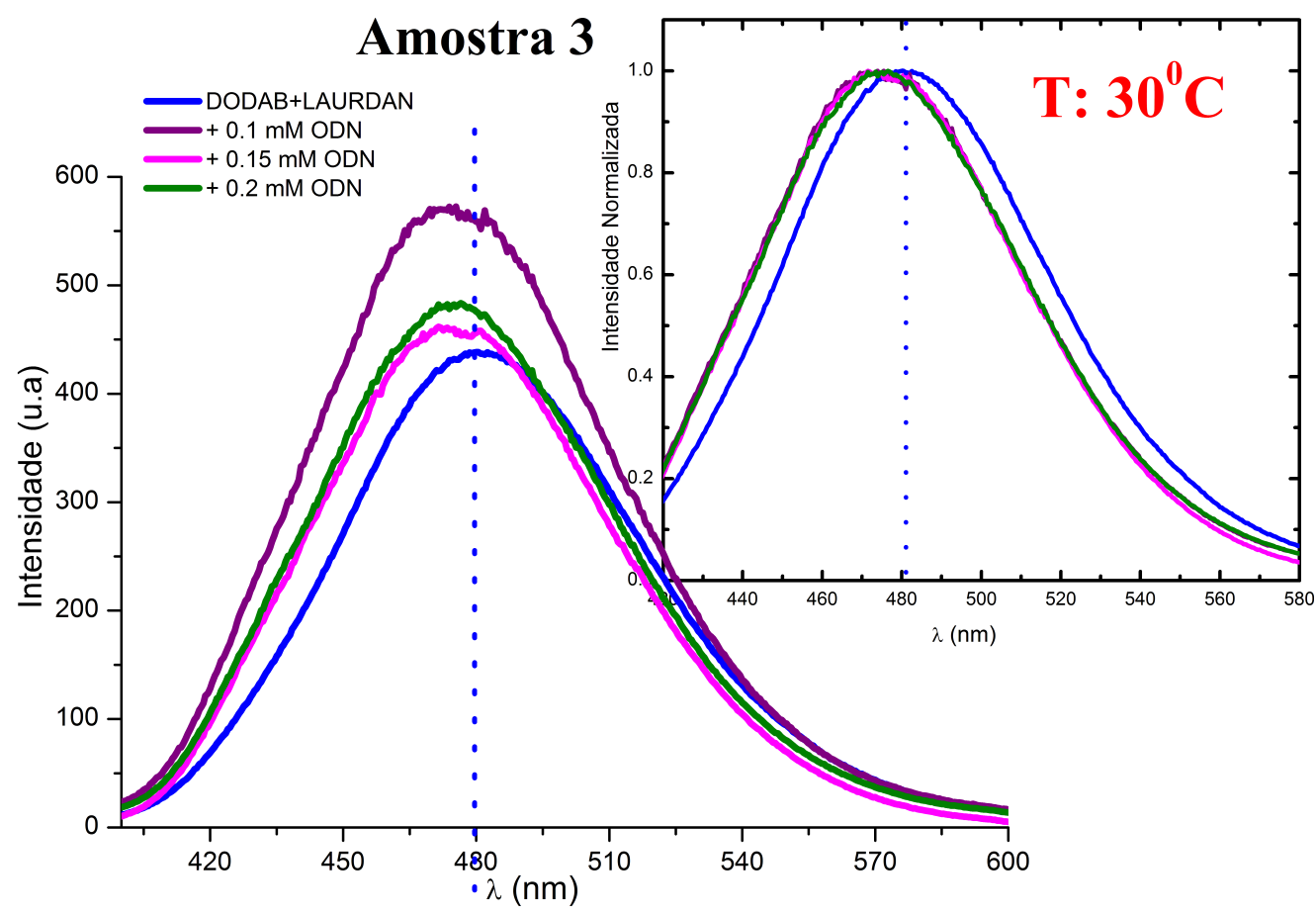

(a)

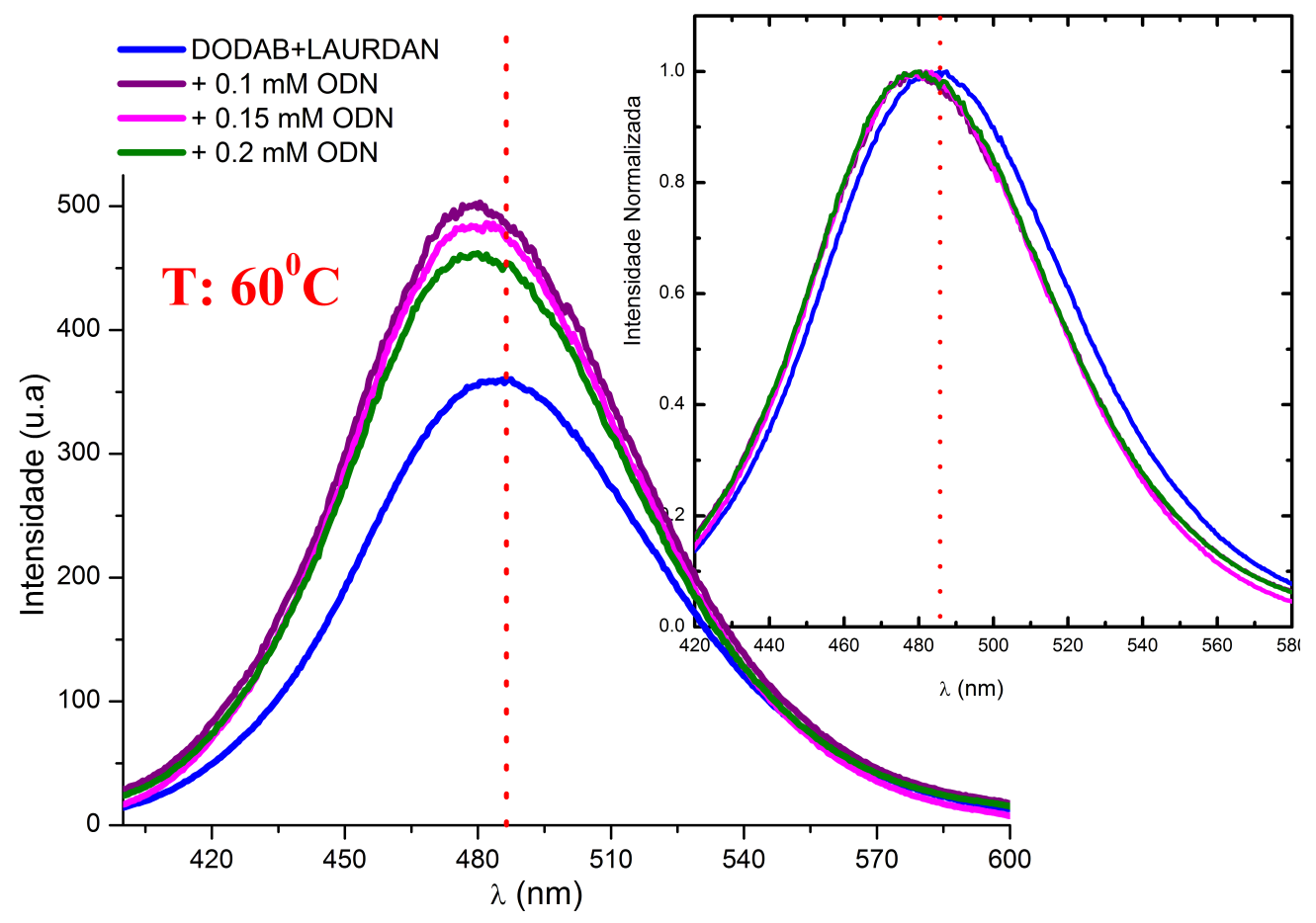

(b)

Figura 49: Espectros de emissão do Laurdan inserido em $1 \mathrm{mM}$ de vesículas extrusadas de DODAB em presença de altas concentrações de $O D N$, para $30^{\circ} \mathrm{C}$ (a) e $60^{\circ} \mathrm{C}$ (b). Os gráficos inseridos nos paneis à direita mostram os espectros do Laurdan normalizados. As linhas tracejadas são as mesmas mostradas na Figura 43, para comparação.

vesículas multilamelares estáveis de diâmetros variáveis com a [ODN], além disso, de uma possível desidratação na superfície da vesícula de DODAB. Com isto vê-se que o Laurdan 
se mostra sensível em monitorar tais modificações, principalmente em presença de altas concentrações de ODN, e na fase gel da membrana do DODAB.

\subsubsection{Anisotropia do Laurdan}

Por medidas de anisotropia estática, podemos ver a dependência do movimento rotacional do Laurdan com a mudança do meio em que ele é inserido (superfície do DODAB), para baixas e altas concentrações de ODN. A figura 50, mostra a anisotropia do Laurdan inserido nas vesículas do DODAB com o aumento da concentração de oligonucleotídeo, para as temperaturas $\mathrm{T}=30,40,50,60^{\circ} \mathrm{C}$ medida em $470 \mathrm{~nm}$.

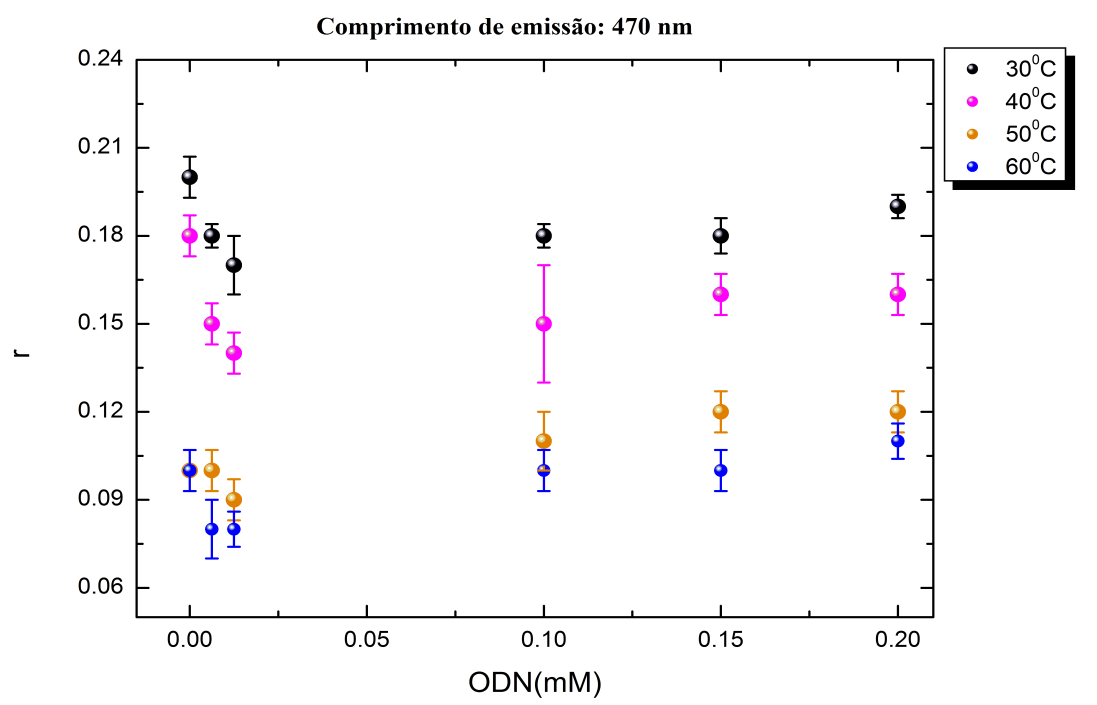

Figura 50: Anisotropia de fluorescência do Laurdan inserido em vesiculas extrusadas de $D O D A B$ com o aumento da concentração de ODN, para as temperaturas $T=30,40,50$, $60{ }^{\circ} \mathrm{C}$. As medidas da anisotropia foram realizadas utilizando $\lambda_{\text {exc }}=350 \mathrm{~nm}$ e $\lambda_{\text {em }}=$ $470 \mathrm{~nm}$.

Pela figura, verificamos uma queda nos valores de anisotropia com adição em torno de $0.0125 m M$ de ODN, indicando úma diferença no comportamento rotacional do Laurdan com a adição de baixas concentrações de ODN para a fase gel $\left(30,40{ }^{\circ} \mathrm{C}\right)$ e fluída $(50$, $60{ }^{\circ} \mathrm{C}$ ) do DODAB, com maior diminuição da anisotropia para a fase gel do DODAB. A queda dos valores é uma indicação de que estas concentrações de ODN (0.00625 e 0.0125 $m M$ ) podem gerar um microambiente mais frouxo no qual se encontra o Laurdan. No entanto, também é importante mencionar que embora os valores de anisotropia diminuam a posição dos espectros de emissão fluorescente não se altera, conforme discutido 
anteriormente e mostrado nas figuras 44, 45 e 46.

Com adição de altas concentrações de ODN na dispersão lipídica de DODAB, podemos ver uma reversão nos valores de anisotropia, a qual é praticamente constante para estas três concentrações $(0.1,0.15$ e $0.2 \mathrm{mM})$ tanto na fase gel $\left(30,40^{\circ} \mathrm{C}\right)$ como na fluída $\left(50,60{ }^{\circ} \mathrm{C}\right)$ do DODAB. Na fase gel do lipídio, $30^{\circ} \mathrm{C}$ e $40^{\circ} \mathrm{C}$, os valores medidos de anisotropia são ainda um pouco menores do que as medidas para bicamadas de DODAB puro. Além disso, também é importante observar que nesta região de altas concentrações de ODN, a posição do espectro de emissão fluorescente sofre uma pequena alteração deslocando-se para comprimentos de onda menores, conforme discutido anteriormente e mostrado na Figura 47, 48 e 49, uma indicação de menor polaridade e/ou mais rigidez do ambiente à volta do Laurdan. 


\section{CAPITULO 5}

"A man should look for what is, and not for what he thinks should be" A. Einstein 


\section{CONCLUSÕES E PERSPECTIVAS}

Neste trabalho são descritas pela primeira vez as interações entre oligonucleotídeos e vesículas extrusadas do lipídio catiônico DODAB.

Considerando os perfis de DSC, ao variarmos as concentrações de ODN em presença de $1 m M$ de DODAB observamos três regimes diferentes (Figuras 34 e 36).

Chamamos o primeiro regime de " regime em presença de baixas concentrações de ODN", observado para $[\mathrm{ODN}] \leq 0.025 \mathrm{mM}$. Nele, tanto ao aquecermos ou resfriarmos a dispersão, observamos a coexistência de dois picos de absorção de calor, um deles semelhantes ao observado para dispersões de puro DODAB, e outro, a temperaturas maiores, $\mathrm{T} \approx 47^{\circ} \mathrm{C}$. Esse resultado evidencia a coexistência de duas regiões distintas na membrana de DODAB, uma correspondente a puro anfifílico, e a outra ao complexo DODAB/ODN. Esta última, mais estável termicamente do que bicamadas de puro DODAB, dado que apresenta a transição gel-fluido a temperaturas maiores.

Chamaremos de segundo regime àquele onde $[\mathrm{ODN}] \approx 0.05 \mathrm{mM}$, no qual já não observamos o pico de absorção de calor de bicamadas de puro DODAB, mas somente o pico relativo ao complexo DODAB/ODN em $\mathrm{T} \approx 47^{\circ} \mathrm{C}$.

Por fim, o terceiro regime observado por DSC, que chamamos de "regime em presença de alta concentração de ODN", é aquele com [ODN] $\geq 0.075$ (Fig. 36), no qual é observada somente a presença de um pico duplo, largo, centrado em $\mathrm{T} \approx 53^{\circ} \mathrm{C}$, portanto, indicando grande estabilidade da fase gel do DODAB nesta configuração da vesícula. O perfil de DSC não é alterado com o aumento da [ODN], o que pode ser uma indicação de que o oligonucleotídeo não esteja se incorporando mais à vesícula, mas esteja acumulando-se no meio aquoso.

Quanto às imagens da turbidez das amostras nas celas de ensaio (Figs 24.B e 40 ), ou às medidas de turbidez através do registro do espectro de absorção (Fig 39 ), fica claro que as amostras com $[\mathrm{ODN}]=0.025$ e $0.05 \mathrm{mM}$ espalham muita luz desde o início de seu preparo. A amostra com $[\mathrm{ODN}]=0.075 \mathrm{mM}$ é pouco turva na primeira hora após seu preparo, mas a intensidade de luz espalhada aumenta com o tempo de preparo (ver Figs 24.B e 25.B..), evidenciando a instabilidade da amostra. 
Para as amostras muito turvas, o espalhamento de luz está, de fato, associado ao aumento do tamanho da partícula, como indicado pelas medidas de DLS (Fig 26). Também de acordo com o espalhamento de luz, para $[\mathrm{ODN}]=0.075 \mathrm{mM}$, observa-se, por medidas de DLS, o crescimento da vesícula com o passar do tempo (ver Fig 27).

O esquema abaixo resume a discussão feita acima:

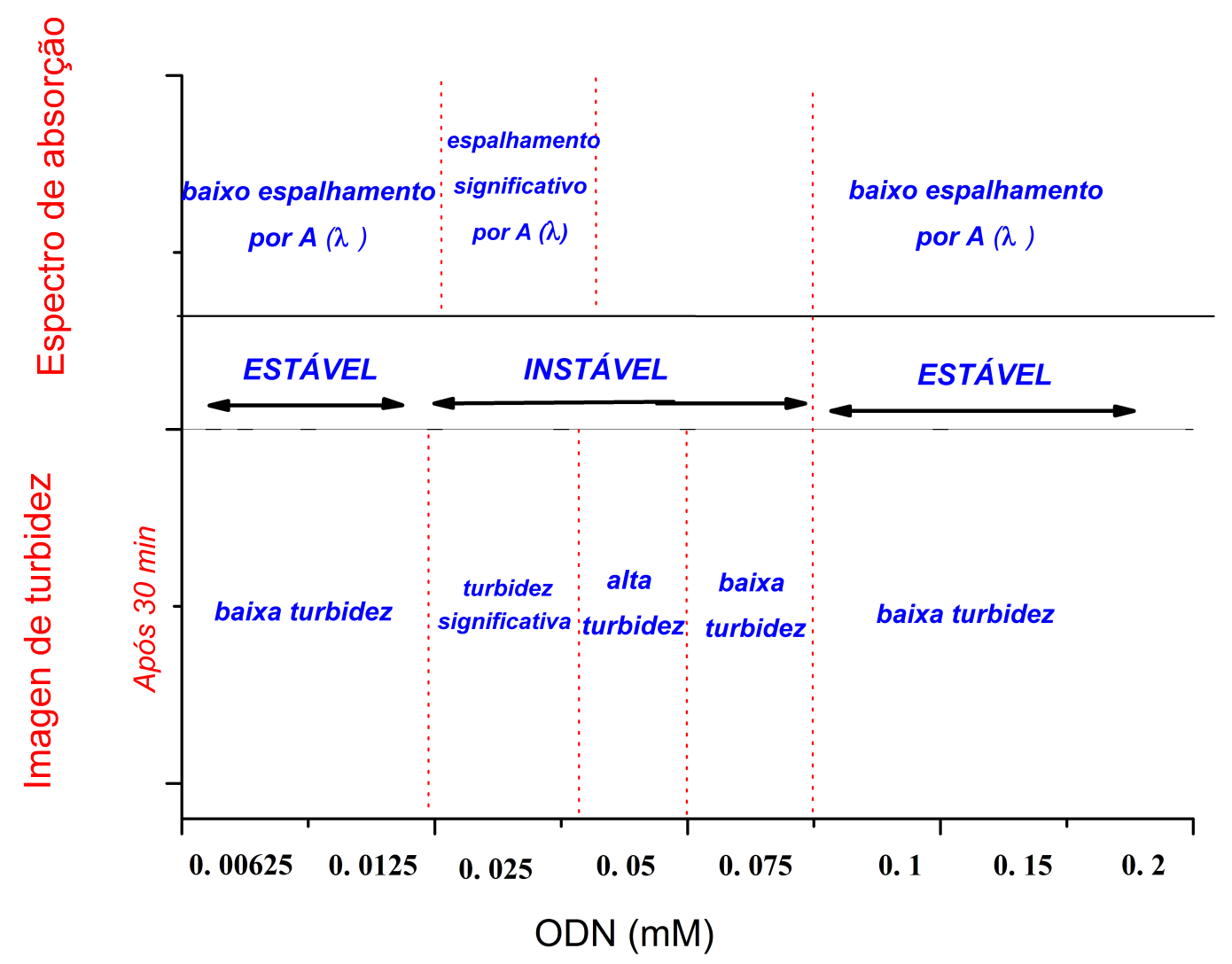

Figura 51: Caracterização dos três regimes observados em dispersões aquosas DODAB$O D N$.

Interessante observar que as medidas de SAXS já acusam a presença de algumas multilamelas na vesícula de DODAB/ODN a baixa concentração do oligonucleotídeo, $0.0125 \mathrm{mM}$. Este resultado está de acordo com os dados de DLS, que mostram um aumento do diâmetro hidrodinâmico médio $\left(D_{z}\right)$ para esta concentração de ODN. No regime de altas concentrações de ODN, por SAXS vemos a clara presença de multilamelas (Fig 30), também resultando em somente um pequeno aumento no valor de $D_{z}$ da vesícula mista DODAB/ODN. Esta é uma indicação de que se formam vesículas multilamelares, porém relativamente pequenas, com poucas multilamelas. Dados de SAXS para este 
regime, em presença de ODN e vesículas não extrusadas, foram discutidos em nosso grupo de Biomembranas (Rozenfeld et al., 2015).

Se consideramos que o oligonucleotídeo está totalmente carregado (Devlin, 2004), ele terá carga -10 . Assim, a Tabela 7 lista a carga total do ODN presente na amostra para cada uma das concentrações usadas, juntamente com os valores dos potenciais zeta medidos (Fig 26). Já vimos que as amostras com 0.025 e $0.05 \mathrm{mM}$ apresentam uma alta turbidez e espalhamento (instabilidade), certamente devido ao início da neutralização das cargas dos agregados DODAB/ODN. Caso medida após curto tempo de preparo, a amostra com $[\mathrm{ODN}]=0.075 \mathrm{mM}$ ainda está razoavelmente límpida, com baixo diâmetro hidrodinâmico médio (Fig 26.a), e já apresenta potencial zeta negativo (Fig 26.b).

Tabela 7: Magnitude da carga relativa total ODN/DODAB na dispersão, considerando que tanto ODN como o DODAB estão totalmente ionizados, e potencial zeta medido para as vesículas.

\begin{tabular}{lcc}
\hline Disperção & carga total & $\zeta(m V)$ \\
\hline DODAB: Hepes & & $+47 \pm 4$ \\
DODAB + 0.00625 mM ODN & 0.0625 & $+50.2 \pm 0.1$ \\
DODAB + 0.0125 mM ODN & 0.125 & $+49 \pm 2$ \\
DODAB + 0.025 mM ODN & 0.25 & instável \\
DODAB + 0.05 mM ODN & 0.5 & instável \\
DODAB + 0.075 mM ODN & 0.75 & $-44.2 \pm 0.4$ \\
DODAB + 0.1 $m M$ ODN & 1.0 & $-43 \pm 2$ \\
DODAB + 0.15 $m M$ ODN & 1.5 & $-41 \pm 2$ \\
DODAB + 0.2 $m M$ ODN & 2.0 & $-44 \pm 3$ \\
\hline
\end{tabular}

Considerando-se que o trabalho foi feito com $1 m M$ de vesículas extrusadas de DODAB, e que várias moléculas de DODAB não estarão ionizadas, podemos inferir que, apesar de detectarmos a presença de vesículas multilamelares (Figs 29 e 30), portanto o rompimento das vesículas em presença de ODN, e o rearranjo lipídico da dispersão, muitas vesículas devem continuar intactas e unilamelares. Isto porque, em vesículas unilamelares intactas, a neutralização de cargas aconteceria somente com os lipídios expostos na camada externa da vesícula, portanto a concentrações menores do que $0.1 \mathrm{mM}$ de ODN, como o observado. Neste raciocínio, considera-se a dificuldade de uma molécula grande e carregada como o ODN penetrar em uma bicamada lipídica, e também considera-se que a maioria das cabeças polares lipídicas estariam ionizadas. 
A observação de que a carga da superfície da vesícula se torna negativa com o aumento da concentração de ODN, pode ser compreendida com o esquema mostrado na Figura 51, já proposto anteriormente (Rosenfeld et al., 2013).

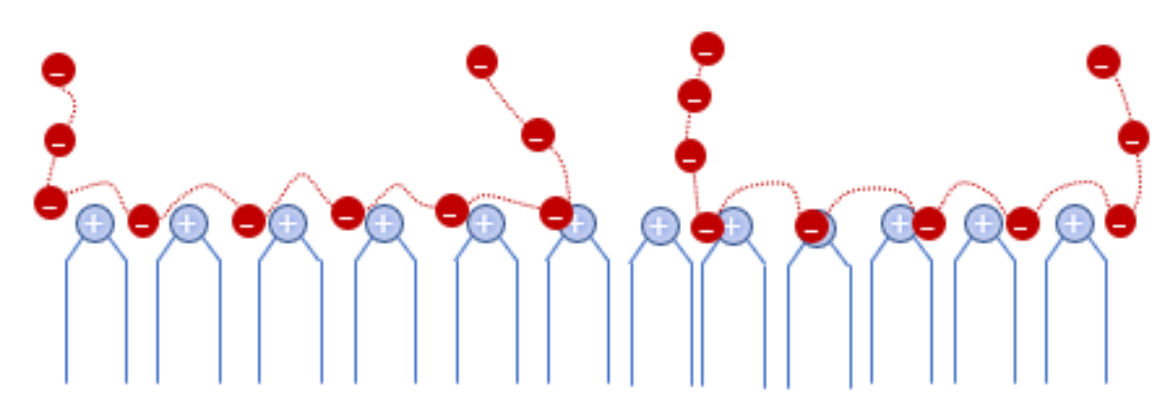

Figura 52: Esquema subtraído de (Rosenfeld et al., 2013).

Foi interessante observar que apesar do Laurdan estar situado na interface membrana/água em bicamadas de DODAB, ele não se mostrou muito sensível à presença de oligonucleotídeos na superfície da membrana. Como mencionado acima, para altas concentrações de ODN no complexo DODAB/ODN, dados de SAXS mostram claramente a transformação de vesículas unilamelares de puro DODAB para multilamelares, na presença de ODN. Com essa transformação, observamos uma variação da posição do máximo de intensidade da banda fluorescente do Laurdan de $9 \mathrm{~nm}$, no sentido de maiores energias (menores comprimentos de onda), mas somente para a fase gel da membrana. Variação muito pequena foi observada para a fase fluida. Esse deslocamento deve estar relacionado com menor relaxamento do fluoróforo com moléculas de água na superfície da bicamada e/ou maior enrijecimento no microambiente a volta do Laurdan (Vequi-Suplicy et al., JF 2013). Na mesma região de alta concentração de ODN em DODAB, também para a fase gel da membrana, dados de Ressonância Paramagnética Eletrônica (RPE) com marcadores de spin incorporados à bicamada lipídica, nas posições dos carbonos 5 e 16, mostraram um maior "empacotamento" da bicamada na presença de ODN (Rosenfeld et al., PCCP 2015).

Por outro lado, na fase gel da membrana, tanto para baixas como para altas concentrações de ODN, temos uma diminuição da anisotropia de fluorescência do Laurdan (Fig. 50). Esta pode ser uma indicação de que o fluoróforo enxerga uma região de maior fluidez na superfície da membrana, quando em presença de ODN. Entretanto, este resultado deve ser avaliado com cuidado, pois pode estar relacionado ao aumento do tempo 
de vida dos estados excitados do Laurdan (Lakowicz, 2006). Portanto, medidas de fluorescência com resolução temporal serão extremamente interessantes, e estão programadas para serem feitas em breve.

Sobre a sensibilidade do Laurdan em detectar variações de estrutura e polaridade na superfície de membranas de DODAB, será interessante o uso futuro do Laurdan, comparativamente, em diferentes estruturas de DODAB, que sabidamente possuam características diferentes. Por exemplo, provenientes de diferentes métodos de preparo, ou em presença diferentes moléculas.

Os estudos aqui apresentados fazem parte de um amplo esforço para entender as características estruturais de agregados "lipídio-material genético", com o objetivo de seu uso futuro em terapias gênicas. 


\section{REFERÊNCIAS}

1. Adamson, A.W. Electrical aspects of surface chemistry. In: Physical Chemistry of Surfaces, 4th Edition. John Wiley and Sons, New York, pp. 185-229, (1982).

2. Alberts, B. B., Lewis, D., Raff, J., Roberts, M e Waston, J. D. Biologia Molecular da Célula. 3 ed. , Porto Alegre, (1997).

3. Alves, F.R. P. D. Estruturas vesiculares em msituras de surfactantes. (Tese de doutorado). Universidade Estadual Paulista, São Jose do Rio Preto, SP, (2008).

4. Alves, Amorin, E., Souza e Santos, D. Biologia Molecular. Rio de Janeiro: EPSJV,p.141$142,(2013)$.

5. Araujo, F.P., Petri, D.F.S e Carmona-Ribeiro, A.M. Colloid stability sodium dihexadecyl phosphate / poly (diallyldimethylammonium chloride) decorated latex. Langmuir, 21: 9495-9501, (2005).

6. Barroso, P. R, P. D. Dispersções lipídicas de dimeristoil fosfatidilglicerol: um estudo termo-estrutural. (Tese de doutorado). Universidade de São Paulo, São Paulo, SP, (2010).

7. Beer. Determination of the absorption of red light in colored liquids. In J. C. Poggendorff (Ed.), Annalen der physik und chemie (pp. 78-88). J.A. Barth, (1852).

8. Behar-Cohen, F. Systèmes de délivrance des médicaments pour le segment antérieur: bases fondamentales et applications cliniques. J Fr Ophtalmol.25(5):537-44, (2002).

9. Benatti, C.R., Feitosa, R.M, Fernandez, Lamy -Freund, M.T. Chem. Phys. Lipids 111- 93, (2001).

10. Bennett, C.F., Chiang, M.Y., Chan, H., Shoemaker, J.E.E., Mirabelli, C.K. Cationic lipids enhance cellular uptake and activity of phosphorothioate antisense oligonucleotides.Mol. Pharmacol., 41: 1023-1033, (1992).

11. Bracewell, R.N. The Hartley Transform. New York: Oxford University Press, (1986). 
12. Cantor, C.R. e Schimmel, P.R. Part II: Techniques for study of biological structure and function. New York: W.H. Freeman and Company, (1980).

13. Carmona-Ribeiro, A.M e Chaimovich, H. Salt-induced aggregation and fusion of dioctadecyldimethylammonium chloride and sodium dihexadecylphosphate vesicles. Biophys. J., 50: 621-628, (1986).

14. Carter, A.H. Classical and Statistical Thermodynamics Prentice-Hall, Inc. New Jersey. ISBN 0-13-779208-5, (2001).

15. Condon, E.U. Nuclear motions associated whit electron transitions in diatomic molecules. Physical Review, 32, 0858-0872, (1998).

16. Correia, F.M., Petri, D.F.S e Carmona-Ribeiro, A.M. Colloid stability of lipid/polyelectrolyte decorated latex. Langmuir, 20: 9535-9540, (2004).

17. Crooke, S.T. Progress in antisense techonolgy. Annu. Rev. Med. 55:61-91, (2004).

18. Cuccovia, I.M., Kawamuro, M.K., Krutman, M.A.K e Chaimovich, H. Control of reaction rates in vesicular systems. J. Am Chem. Soc., 111: 365-366, (1989) .

19. Dautzenberg, H., Jaegra, W e J,K. Polyelectrolytes: formation characterization and application. Munich, Hanser, (1994).

20. Debye, P. Ann. Phys, 46, 809, (1915).

21. Devlin, T. Bioquímica: libro de texto con aplicaciones clínicas. Reverte. p.31. ISBN8429172084. (2004).

22. Donsker, M. D. Justification and extension of Doob's heuristic approach to the Kolmogorov-Smirnov theorems». Annals of Mathematical Statistics. 23: 277-281, (1952).

23. Eisberg, R. M e Resnick, R. Física Quântica: Átomos, Moléculas, Sólidos e Partículas, Editora Campus, (1979).

24. Enoki, T. A. P. D. Estudos da Interação do peptídeo antimicrobiano KHya1 com membranas modelos. (Tese de doutorado). Universidade de São Paulo, São Paulo, SP, (2016). 
25. Evans, D.F e Wennerstrom, H. The colloidal domain - Where physics, chemistry, biology and technology meet (1). New York: VHC Publishers Inc, (1994).

26. Feigin, L.A e Svergun, D. I. Structure analysis by small-angle X-ray and neutron scattering, Plenum Press, New York, pp. 335, (1987).

27. Feitosa, E., Barreleiro, P.C.A e Olofsson, G. Phase transition in dioctadecyldimethylammonium bromide and chloride vesicle prepared by different methods. Chem. Phys. Lipids, 105, 201-213, (2000).

28. Feitosa, E., Bonassi, N.M e Loh, W. Langmuir 22 4512, (2006).

29. Fichou, Y e Férec, C. The potential of oligonucleotides for therapeutic applications. Trends Biotechnol., 24: 563-570, (2006).

30. Franck, J. Elementary processes of photochemical reactions. Transactions of the Faraday Society, 21 0536-0542, (1996).

31. Gennis, R.B. Biomembranes: molecular structure and function. New York: Springer Verlag,Inc. (1989).

32. Glatter, O e Kratky, O. Editors. Small Angle X-ray Scattering. London: Academic Press, (1982).

33. Gleave, M.E e Monia, B.P. Antisense therapy for cancer. Nat . Rev. Cancer. 5: 468-79, (2005).

34. Goodchild, J., Letsinger, R. L., Sarin, P. S., Zamecnick, M e Zamecnick, P. C. In Human Retrovíruses, Cancer and AIDS, Approaches to Prevention and Therapy; Alan, R. L., Ed.; New York, p 423, (1988).

35. Heerklotz, H. The microcalorimetry of lipid membranes. J. Phys.: Condens. Matter, 16, R441-R467, (2004).

36. Hiemenz, P. C. Principles of colloid and surface chemistry , New York: Marcel Dekker. 815 p, (1986).

37. Hotza, D. Artigo revisão: colagem de folhas ceramicas. Ceramica.v.43, n. 7, p.157164, (1997). 
38. Ilarduya, C.T., Sun, Y e Düzgünes, N. Gene delivery by lipoplexes and polyplexes. Eur. J. Pharm. Sci., 40: 159-170, (2010).

39. Israelachvili, J.N. Intermolecular and surface forces, 2nd Ed., Academic Press, London, (1992).

40. Jafelicci, M.J e Laudemir, C.V. Articulo: O Mundo dos Coloides. Quimica Nova na Escola. n. 9, (1999).

41. Juliano, R., Alam, M.R., Dixit, V e Kang H. Mechanisms and strategies for effective delivery of antisense and siRNA oligonucleotides. Nucleic Acids Res., 36: 4158-4171, (2008).

42. Kikuchi, I.S., Carmona-Ribeiro, A.M. Interaction between DNA and synthetic cationic liposomoes. J. Phys. Chem. A, 104:2829-2835, (2000).

43. Kirby, B.J. Micro- and Nanoscale Fluid Mechanics: Transport in Microfluidic Devices. Cambridge University Press. ISBN 987-0-521-11903-0, (2010).

44. Koppel, D. E. Analysis of Macromolecular Polydispersity in Intensity Correlation Spectroscopy: The Method of Cumulants. The Journal of Chemical Physics, 57(11), 4814, (1972).

45. Koolman, J. e Rohn, K.H. Bioquímica. 3 ed. Porto Alegre: Editora Artmed, (2005).

46. Kubo, R. The fluctuation-dissipation theorem. Rep. Prog. Phys. 29, 255-284, (1966).

47. Lakowicz, J. R. Topics in Fluorescence Spectroscopy. Biochemical applications.: Plenum Press, Vol. 3, (1991).

48. Lakowicz, J. R. Principles of Fluorescence Spectroscopy Principles of Fluorescence Spectroscopy, (2006).

49. Larsson, T., Wedborg, .M e Tuner, D. CorrectIion of iner-filter in fluorescence excitation -emission matris spectrosmetry using Raman scatter. Elseiver. 583: 357-363, (2006). 
50. Laue, M. von: Ro. intgenstrahl-Interferenzen. Frankfurt am Main: Akademische Verlagsgesellschaft (1960).

51. Lehninger, A.L. "Princípios de bioquímica", Ed. Sarvier, (1984).

52. Lippert, E. Dipolmoment Und Elektronenstruktur Von Angeregten Molekulen. Zeitschrift Fur Naturforschung Part a -Astrophysik Physik Und Physikalische Chemie, 10, 541-545, (1955).

53. Lonez, C., Vandenbranden,M e Ruysschaert, J. M. Cationic liposomal lipids: from gene carriers to cell signalling . Prog Lipid Res, 47 , 340 - 347, (2008).

54. Luciani, X., Monuier, S., Redon, R e Bois, A. A simple correction method of inner filter affects affecting FEEM and ist aplication to the PARAFAC descoposition. Elseiver, (2009).

55. Lúcio, D.A., Vequi-Suplicity, C.C., Fernandez, R.M e Lamy,. M.T. Laurdan Spectrum Decomposition as a Tool for the analysis of Surface Bilayers Structure and Polarity: a study whit DMPG, Peptides and Cholesterol. Springer Science New York.20: 473-482, (2009) .

56. Lytle, D.A., Rice, E.W., Johnson, C.H e Fox, K.R. Electrophoretic mobilities of Escherichia coli 0157:H7 and wild-type Escherichiacolistrains. Appl. Environ. Microbiol. 65, 3222-3225, (1999).

57. Mastrobattista, E., VAN DER, A.A., HENNINK, M.A.E.M e CROMMELIN, D.J.A. Artificial viruses: a nanotechnological approach to gene delivery. Nature Rev. Drug Discov., v. 5, p. 115-121, (2006).

58. Masukawa, M.k., Vequi-Suplicy, C.C., Duarte, E.L e Teresa Lamy, M. Fluorescent probe Laurdan does not Sence phase transition in vesicle of the cationic lipide DODAB. Universidade de São Paulo, São Paulo, SP, (2016).

59. Marvin, R., Mirochnik, Y., Chou, P e Cuinan, K. Antisense oligonucleotide intralesional therapy for human PC-3 prostate tumors carried in athymic nude mice, Division of Cellular Biology, Hektoen For Medical Research, 627 South Wood Street, Chicago, Illinois 60612, Journal of Surical Oncoly 62:194-200, (1996). 
60. Mataga, N., Kaifu, Y. E Koizumi, M. Solvent Effects Upon Fluorescence Spectra and the Dipolemoments of Excited Molecules. Bulletin of the Chemical Society of Japan, 29, 465-470, (1956).

61. Mitrakos, P., Mcdonal, P.M. Nucleotide chain length and the morphology of complexes whit cationic amphiphiles: P-NMR observations. Biochemi. Biophys. Acta, 1463: 355-373, (2002).

62. Monkkonen, J e Urtti, A. Lipid fusion in oligonucleotide and gene delivery with cationic lipids. Adv. Drug Delivery Rev., 34: 37-49, (1998) .

63. Mörters, Peter; Peres, Yuval. Brownian Motion, (2008).

64. Nelson, D. L. e Cox, M. M. Lehninger Princípios de Bioquímica. 2. Edição, São Paulo, Sarvier, (2002).

65. New, R.R.C. Lipossomes: a practical approach (1). New York, Oxford University Press, 1990.

66. Nomura, D.A., Enoki., T.A., Goldaman, C e Teresa Lamy, M. Espalhamento de Luz Dinâmico. (Apuntes). Universidade de São Paulo, São Paulo, SP, (2016).

67. Oberle, V., Bakowsky, U., Zuhorn, I. S e Hoekstra, D. Lipoplex formation under equilibrium condition reveals a three - step mechanism . Biophys J , 79 , 1447 $1454,(2000)$.

68. Oliveira, C. L. P. D. Estudos de Espalhamento de Raios X a Baixos Ângulos por Sistemas Biológicos: Teoria e Aplicações. (Tese de doutorado). Universidade de Campinas, Campinas, SP, (2005).

69. Oliveira, C. L. P. D.; PEDERSEN, J. S. Program package for data treatment, analysis and modeling, (2009).

70. Parasassi, T., De Stanio, G., Ravagnan, G., Rusch, R.M., e Gratton, E. Quantitation of lipid phases in phospholipid vesicle by the generalized polarization of Laurdan fluorescence. Biophysical journal. 60(1), 179-89, (1991). 
71. Parasassi, T., De Stanio, G., Ravagnan, G., Rusch, R.M., E Gratton, E. Quantitation of lipid phases in phospholipid vesicle by the generalized polarization of Laurdan fluorescence. Biophysical journal. 60(1), 179-89, (1998).

72. Pearson, K. The Problem of the Random Walk. Nature. 72, 294, (1905).

73. Pecora, R. Doppler Shifts in Light Scattering from Pure Liquids and Polymer Solutions.Chem. Phys., 40, 1604 (1964).

74. Pecora, R. Dynamic Light Scattering measurement of nanometer particles in liquids. Journal of Nanoparticle Research, 2:123-131, (2000).

75. Petri, D.F.S e Carmona-Ribeiro, A.M. Biomimetic Particles, In Polymeric Nanostructures and Their Applications, H. S. Nalwa (Ed.), American Scientific Publishers, p. $485-530,(2007)$.

76. Rodwell, V.W., Bender, D. A., Botham, K. M., Kennelly, P. J e Weil, P. A. Ilustrated biochemistry, 30th. Edition. Reverte.p.342. ISBN 71825347/9780071825344, (2015).

77. Roque, A. Apuntes-Aula 2. Biofísica II - FFCLRP - USP. 5910187, (2016).

78. Romero, E. L., Morrila, M.J e Bakas, L. Vectores lipidicos, Nuevas estrategias aplicadas a la terapia genica. Medicina (Buenos Aires), 61: 205-214, (2000).

79. Rozenfeld, J.H.K., Oliveira, T.R., Tereza Lamy e Carmona-Ribeiro. Interaction of cationic bilayers fragments whit a model oligonucleotide. Elseiver, 10:1016, (2011).

80. Rozenfeld, J.H.k., Duarte, E.L., Oliveira, T.R., Lonez, C e Tereza Lamy. oligonucleotide Adsorption Affectd Phase Transition but Not Interdigitation of diC14Amidine Bilayers. Langmuir, 29:11102-11108, (2013)

81. Rozenfeld, J.H.k., Duarte, E.L., Barbosa, L.R.S e Tereza Lamy. the effect of na oligonucleotide on the structure of cationic DODAB vesicles. Chem. Chem .Phys, 17: 7498-7506, (2015).

82. Salinas, S.R.A. Introdução à Física Estatística, São Paulo: Editora da Universidade de São Paulo, ISBN 987-85-314-0386-6 , (2008). 
83. Schimidt, P. W. Modern Aspects of Small-Angle Scattering (Edited by H. Brumberger), (1995).

84. Shea, R. G., Marsters, J. C e Bischofberger, N. Nucleic Acids Res. 18, 3777,(1990).

85. Shimko, A., Povolotckaia, A e Mikhaylova, A. Center for optical and laser materials research. Supported by OITSPSU. Saint Petersburg State University, (2014).

86. Smith, L.M., Sanders, J.z., kaizer, R.J., Hughes P e Dodd, C. Fluorescence detection in automated DNA sequence analysis. Nature 321:667-679, (1986).

87. Stokes, G.G. On the Change of Regrangibility of Ligth. Philosophical Transactions of the Royal Society of London, 142, 463-562, (1852).

88. Sybachin, A.V., Efimova, A.A., Litmanovich, E.A., Menger, F.M e Yaroslavov, A.A. Complexation of polycations to anionic liposomes: composition and structure of the interfacial complexes. Langmuir, 23:10034-10039, (2007).

89. Takara, M, P.D. Propiedades Ópticas de Absorção e Emissão Flurescente de Ácido orto-Aminobenzóico e seus Derivados em meio solvente(Tese de doutorado). Universidade de São Paulo, São Paulo, SP, (2006).

90. Valeur, B. "Molecular Fluorescence". Wiley-VCH Publichers, (2000).

91. Valeur, B. Molecular Fluorescence: principles and Applications. Weinheim: WileyVCH Verlag GmbH, (2001).

92. Vequi-Suplicy, C.C., Bentti, C.R e Lamy, M. T. Laurdan in fluid bilayers: Position and structural sensivity. Journal of Fluoresene, 16 (3), 431-439, (2006).

93. Vequi-Suplicy, C.C, P.D. Estudos experimentais e teòricos dos espectros eletrônicos das sondas fluorscentes Prodan e Laurdan em solventes e bicamadas lipídicas (Tese de doutorado). Universidade de São Paulo, São Paulo, SP, (2010).

94. Vequi-Suplicy, Teresa Lamy. M e Cássia Marquezin, A. The new fluorescent membrane probe Ahba: a comparative study whit the largely used Laurdan. Journal of Fluoresense. Springer Science.23 (3), 479-486, (2013). 
95. Vequi-Suplicy, C.C., Coutinho, K e Teresa Lamy. M. New Insigths on the Fluorescent Emission Spectra of Prodan and Laurdan. Springer Science New York, (2015).

96. Wang, Y., Gao, S., Ye, W. H., Yoon, H. S e Yang, Y. Y. Co - delivery of drugs and DNA from cationic core - shell nanoparticles self - assembled from a biodegradable copolymer . Nat Mater, 5 , $791-796,(2006)$.

97. Ware, B.R e Flygare, W.H. The simultaneous measurement of the electrophoretic mobility and diffusion coefficient in bovine serum albumin solutions by light scattering. Chem. Phys. Lett. 12, 81-85, (1971).

98. Weisman, S., Hirsch-Lener, D., Barenholz, Y e Talmon, Y. Nanostructure of cationic lipid-oligonucleotide complexes. Biophys. J., 87:609-614, (2004).

99. Wilson, W. W., Wade, M.M., Holman, S.C e Champlin, F.R. Status of methods for assessing bacterial cell surface charge properties based on zeta potential measurements. Journal of Microbiological Methods 43, 153-164, (2000).

100. Wu, G.F., Wang, N.N e Yu, W. Z. Nonsynchrous Change in the Head and Tail of Dioctadecyldimethylammonium Bromude Molecules during the liquid Crystalline TO Coagel Phase Transformation Process, (2009).

101. Wu, G.F, Yu., W.Z e Ji, G. Formation and Transformation of the Subgel phase in Dioctadecyldimethylammonium Bromude Aqueous Dispersions, (2011).

102. Yang, N e Machato, R.I. Delivery and targeting of oligonucleotides and siRNA in Targeted delivery of small and macromolecular drugs, Ajit S. Narang, Ram I. Machato (Eds.), CRC Press, New York, (2010). 
